\title{
AVALIAÇÃO DE POPULAÇÕES DERIVADAS DE HÍBRIDOS DE MILHO (Zea mays L.) EM CRUZAMENTOS NOS ESQUEMAS DIALÉLICO E "TOP CROSS"
}

\author{
ARNALDO AFONSO BELLUCCI \\ Engenheiro Agrônomo
}

Orientador: Prof. Dr. JOSE BRANCO DE MIRANDA FILHO

\begin{abstract}
Dissertação apresentada à Escola Superior de Agricultura "Luiz de Queiroz", da Universidade de São Paulo, para obtenção do título de Mestre em Agronomia, Área de Concentração: Genética e Melhoramento de Plantas.
\end{abstract}

\author{
P I R A C I C A B A \\ Estado de São Paulo - Brasil \\ Novembro - 1994
}


CATALOGAÇÃ NA PUBLICAÇÃO

DIVISÃO DE BIBLIOTECA E DOCUMENTAÇÃO - CAMPUS "LUIZ de QUEIROZ"/USP

Bellucci, Arnaldo Afonso

8449a Avaliação de populações derivadas de hibridos de milho (Zea mays L.) em cruzamentos nos esquemas dialélico e "top cross". Piracicaba, 1994.

133p. ilus.

Diss.(Mestre) - ESALQ

Bibliografia.

1. Milho hibrido - Cruzamento dialélico 2. Milho hibrido - Melhoramento 1. Escola Superior de Agricultura Luiz de Queiroz, Piracicaba

$\operatorname{coD} 633.15$ 


\section{AVALIAÇÃO DE POPULAÇÕES DERIVADAS DE HİBRIDOS DE MILHO (Zea mays L.) EM CRUZAMENTOS NOS ESQUEMAS DIALÉLICO E "TOP CROSS"}

ARNALDO AFONSO BELLUCCI

Aprovada em: 07.04 .1995

Comissão julgadora:

Prof. Dr. José Branco de Miranda Filho

ESALQ/USP

Prof. Dr. Lázaro José Chaves UFG

Prof. Dr. Roberto de Rissi

CIBA SEMENTES

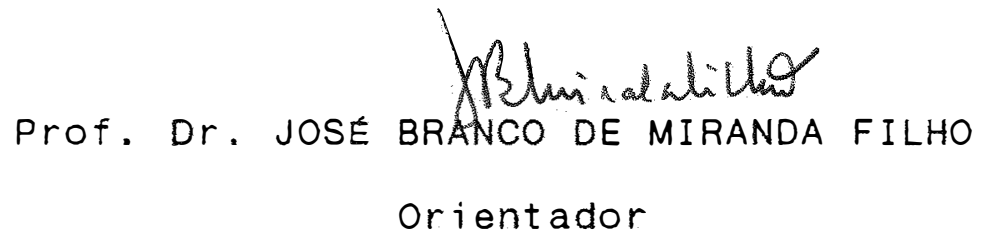


1. INTRODUÇÃO

2. REVISÃo de Literatura $\ldots \ldots \ldots \ldots \ldots \ldots \ldots \ldots \ldots \ldots \ldots \ldots$

3. Materiais e métodos $\ldots \ldots \ldots \ldots \ldots \ldots \ldots \ldots \ldots \ldots \ldots \ldots$

3.1. Materiais ....................... 13

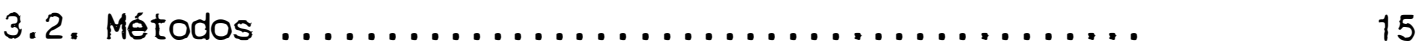

3.2.1. Preparo do Material Básico ........... 15

3.2.2. Fase Experimental ............... 16

3.2.3. Análise Preliminar dos Experimentos ...... 18

3.2.4. Análise da Variância dos Dialélicos, do "Top Cross" e Estimação de Parâmetros Componentes de Médias $\ldots \ldots \ldots \ldots \ldots \ldots \ldots$

3.2.4.1. Análise da Variância e Estimação de Parâmetros do Dialélico Completo

3.2.4.2. Análise da Variância dos Cruzamentos "Top Crosses" (Ensaio 2) e Estimação dos Parâmetros Componentes de Médias para o Modelo Reduzido 3 de GARDNER 
3.2.4.3. Análise da Variância do Dialélico Parcial (experimento 3) e Estimação dos Parâmetros Componentes de Médias para o Modelo Adaptado por MIRANDA FILHO \& GERALDI (1984) para Dialélicos

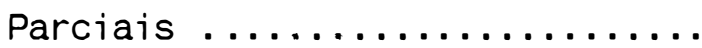

3.2.4.4. Cálculo da Soma de Quadrados das Interações dos Parâmetros com os Ambientes nas Análises Conjuntas dos Dialélicos e dos "Top Crosses"

3.2.5. Cálculo da Capacidade Geral de Combinação

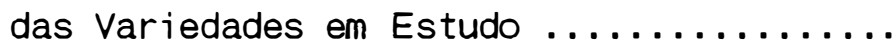

3.2.6. Determinação dos Intervalos de Confiança para as Médias Observadas .............

3.2.7. Correlação entre os Parâmetros dos Modelos e Capacidade Geral de Combinação do Dialélico Total (Experimento 1) e dos "Top

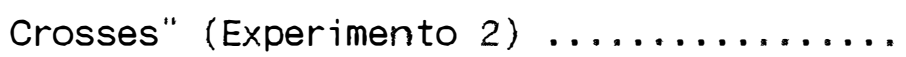

4. RESULTADOS

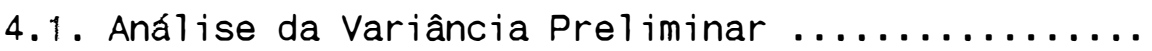

4.2. Análise do Dialélico Completo, do "Top Cross" e

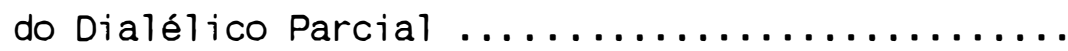


Página

4.2.1. Produção no Local $1 \ldots \ldots \ldots \ldots \ldots \ldots \ldots \ldots .42$

4.2.2. Produção no Local $2 \ldots \ldots \ldots \ldots \ldots \ldots \ldots$

4.2.3. Altura de Planta no Local $1 \ldots \ldots \ldots . . . .46$

4.2.4. Altura de Planta no Local $2 \ldots \ldots \ldots \ldots$

4.2.5. Análises Conjuntas ............... 48

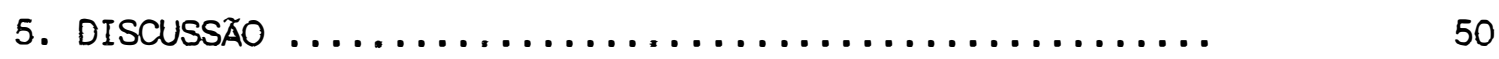

5.1. Uso de "Top Crosses" ao Invés de Dialélicos no Estudo de Variedades de Milho ............... 50

5.2. Avaliação do Uso de Gerações F2 de Híbridos Comerciais como Fonte de Germoplasma em Programas de Melhoramento $\ldots \ldots \ldots \ldots \ldots \ldots \ldots \ldots \ldots \ldots$

5.2.1. Com Base nos Parâmetros do Modelo de GARDNER \& EBERHART e Adaptações ..........

5.2.1.1. Produção de Grãos no Local 1 .... 56

5.2.1.2. Produção de Grãos no Local 2 ....

5.2.1.3. Altura de Planta no Local $1 \ldots .$.

5.2.1.4. Altura de Planta no Local $2 \ldots .$.

5.2.2. Avaliação dos Materiais Quanto ao seu

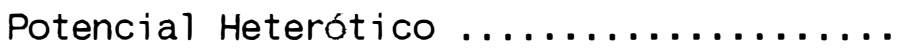

5.2.3. Avaliação do Potencial dos Materiais com Base na Comparação com as Testemunhas ....

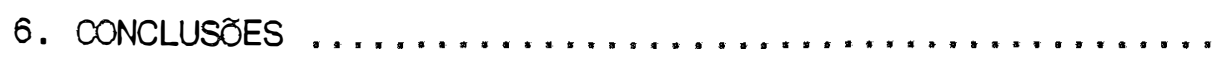

REFERENCIAS BIBLIOGRAFICAS $\ldots \ldots \ldots \ldots \ldots \ldots \ldots \ldots \ldots \ldots \ldots$

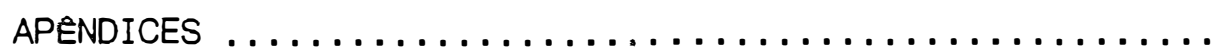




\section{LISTA DE TABELAS}

Tapela

Página

1. Valores e significância dos quadrados médios obtidos das ANAVA preliminares para produção $(\mathrm{t} / \mathrm{ha})$ e altura de planta $(\mathrm{cm})$ no experimento 1 local $1 \ldots . . \ldots \ldots \ldots \ldots \ldots \ldots \ldots . \ldots \ldots \ldots$

2. Valores e significância dos quadrados médios obtidos das ANAVA preliminares para produção ( $t / h a)$ e altura de planta $(\mathrm{cm})$ no experimento 1 local $2 \ldots \ldots \ldots \ldots \ldots \ldots \ldots \ldots \ldots . \ldots . \ldots . \ldots$

3. Valores e significância dos quadrados médios obtidos das ANAVA preliminares conjuntas para produção ( $t /$ ha) e para altura de planta $(\mathrm{cm})$ no experimento 1 - 2 locais com 3 repetições por

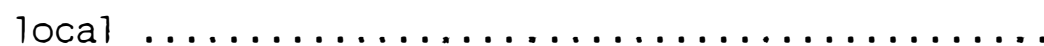

4. Valores e significância dos quadrados médios obtidos das ANAVA preliminares para produção de grãos ( $t / h a)$ e altura de planta (cm) no experimento 2 - local $1 \ldots \ldots \ldots \ldots \ldots \ldots \ldots$

5. Valores e significância dos quadrados médios obtidos da ANAVA preliminar para produção de grãos ( $t / h a)$ e altura de planta (cm) no experimento 2 - local $2 \ldots \ldots \ldots \ldots \ldots \ldots \ldots$

6. Valores e significância dos quadrados médios obtidos das ANAVA conjuntas preliminares para produção de grãos ( $t / h a)$ e altura de planta $(\mathrm{cm})$ no experimento 2 - 2 locais com 6 repetições por

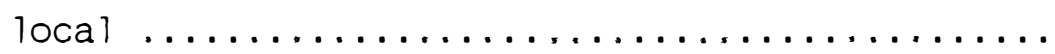


7. Valores e significância dos quadrados médios obtidos das ANAVA preliminares para produção de grãos ( $t / h a)$ e altura de planta (cm) no experimento 3 - local $1 \ldots \ldots \ldots \ldots \ldots \ldots \ldots$

8. Valores e significância dos quadrados médios obtidos das ANAVA preliminares para produção de grãos ( $t / h a)$ e altura de planta $(\mathrm{cm})$ no experimento 3 - local $2, \ldots \ldots \ldots \ldots \ldots \ldots \ldots \ldots$

9. Valores e significância dos quadrados médios obtidos das ANAVA conjuntas preliminares para produção (t/ha) e altura de planta $(\mathrm{cm})$ no experimento $3-2$ locais com 3 repetições por

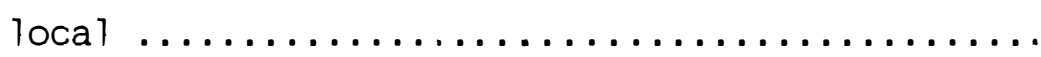

10. Médias de produção de grãos ( $t / h a$ ) das variedades (diagonal), dos híbridos intervarietais (acima da diagonal) e das testemunhas do experimento 1 local 1 - média de 3 repetições $\ldots \ldots \ldots \ldots \ldots \ldots$

11. Médias de produção de grãos ( $t / h a$ ) das variedades (diagonal), dos híbridos intervarietais (acima da diagonal) e das testemunhas do experimento 1 local 2 - média de 3 repetições ..............

12. Médias de produção de grãos ( $t / h a)$ das variedades (diagonal), dos híbridos intervarietais (acima da diagonal) e das testemunhas do experimento 1 - 2 locais - média de 6 repetições $\ldots \ldots \ldots \ldots \ldots$ 
13. Médias de produção ( $t / h a)$ das variedades, dos nibridos "top crosses" e testemunhas do experimento 2 - locais 1 e 2 (média de 6 repetições) e de 2 locais (média de 12

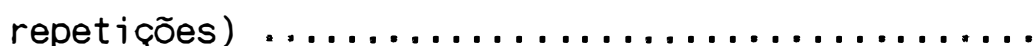

14. Médias de produção ( $t / h a$ ) das variedades, dos hibridos intervarietais e das testemunhas do experimento 3 - local 1 - média de 3 repetições.

15. Médias de produção ( $t / h a)$ das variedades, dos híbridos intervarietais e das testemunhas do experimento 3 - local 2 - média de 3 repetições.

16. Médias de produção ( $t / h a)$ das variedades, dos híbridos intervarietais e das testemunhas do experimento 3 - 2 locais - média de 6 repetições

17. Médias de altura de planta $(\mathrm{cm})$ das variedades (diagonal), dos híbridos intervarietais (acima da diagonal) e das testemunhas do experimento 1 local 1 - média de 3 repetições $\ldots \ldots \ldots \ldots \ldots \ldots$.

18. Médias de altura de planta ( $\mathrm{cm}$ ) das variedades (diagonal), dos híbridos intervarietais (acima da diagonal) e das testemunhas do experimento 1 local 2 - média de 3 repetições ..............

19. Médias de altura de planta $(\mathrm{cm})$ das variedades (diagonal), dos híbridos intervarietais (acima da diagonal) e das testemunhas do experimento 1 - 2 locais - média de 6 repetições ............. 
20. Médias de altura de planta ( $\mathrm{cm}$ ) das variedades, dos híbridos "top crosses" e testemunhas do experimento 2 - locais 1 e 2 (médias de 6 repetições por local) e de 2 locais (média de 12

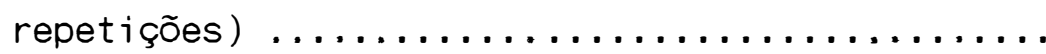

21. Médias de altura de planta $(\mathrm{cm})$ das variedades, dos híbridos intervarietais e das testemunhas do experimento 3 - local 1 - média de 3 repetições.

22. Médias de altura de planta $(\mathrm{cm})$ das variedades, dos híbridos intervarietais e das testemunhas do experimento 3 - local 2 - média de 3 repetições.

23. Médias de altura de planta $(\mathrm{cm})$ das variedades, dos híbridos intervarietais e das testemunhas do experimento 3 - 2 locais - média de 6 repetições

24. Intervalos de confiança para as médias de variedades e híbridos intervarietais para os 3 experimentos nos 2 locais e na média dos dois locais, para produção ( $t / h a$ ) e altura de planta (cm) ao nível de $95 \%$ de probabilidade $\ldots . . . .$.

25. Heteroses (\%) observadas no experimento 1 (acima da diagonal) e preditas* no experimento 2 (abaixo da diagonal) para o caráter produção de grãos no

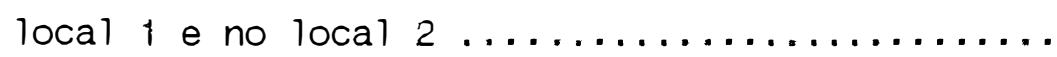

26. Heteroses (\%) observadas no experimento 3 para o caráter produção de grãos nos locais 1 e 2 ..... 
27. Heteroses (\%) observadas no experimento 1 (acima da diagonal) e preditas* no experimento 2 (abaixo da diagonal) para o caráter altura de planta nos locais 1 e $2 \ldots \ldots \ldots \ldots \ldots \ldots \ldots \ldots \ldots \ldots \ldots . . . \ldots \ldots$

23. Heteroses (\%) observadas no experimento 3 para 0 caráter altura de planta nos locais 1 e $2 \ldots . .$.

29. Valores e significância dos quadrados médios obtidos das análises da variância das tabelas dialélicas para os caracteres produção de grãos $(\mathrm{t} / \mathrm{ha})$ e altura de planta $(\mathrm{cm})$ - experimento 1 -

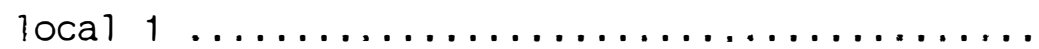

30. Valores e significância dos quadrados médios obtidos das análises da variância das tabelas dialélicas para os carecteres produção de grãos (t/ha) e altura de planta $(\mathrm{cm})$ - experimento 1 local $2 \ldots \ldots \ldots \ldots \ldots \ldots \ldots \ldots \ldots \ldots \ldots \ldots$

31. Valores e significância dos quadrados médios obtidos da análise da variância das tabelas dialélicas para os caracteres produção de grãos ( $t / h a)$ e altura de planta $(\mathrm{cm})$ no experimento 1 -

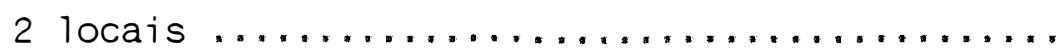

32. Valores e significância dos quadrados médios obtidos das análises da variância dos cruzamentos "top crosses" para os caracteres produção ( $t / \mathrm{ha}$ ) e altura de planta $(\mathrm{cm})$ - experimento 2 - local 1 
33. Valores e significância dos quadrados médios obtidos das análises da variância dos cruzamentos "top crosses" para os carecteres produção ( $t / h a$ ) e altura de planta $(\mathrm{cm})$ - experimento 2 - local 2

34. Valores e significância dos quadrados médios obtidos das análises da variância dos cruzamentos "top crosses" para os caracteres produção ( $t / h a$ ) e altura de planta (cm) - experimento 2 -

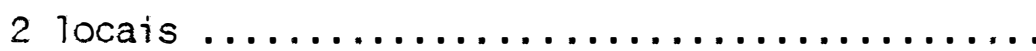

35. Valores e significância dos quadrados médios obtidos das análises da variância das tabelas dialélicas para os caracteres produção ( $t / h a)$ e altura de planta $(\mathrm{cm})$ - experimento 3 - local 1 .

36. Valores e significância dos quadrados médios obtidos das análises da variância das tabelas dialélicas para os carecteres produção ( $t / h a)$ e altura de planta $(\mathrm{cm})$ - experimento 3 - local 2 .

37. Valores e significância dos quadrados médios obtidos das análises da variância das tabelas dialélicas para os caracteres produção de grãos ( $t / h a)$ e altura de planta $(\mathrm{cm})$ no experimento 3 -

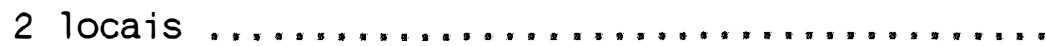

38. Parâmetros componentes de médias do modelo de GARDNER \& EBERHART (1966) aplicado ao estudo de cruzamentos dialélicos, suas respectivas variâncias $(t / h a)^{2}$, e capacidade geral de combinação $\left(\hat{g}_{j}\right)$ das variedades para o caráter produção ( $t / h a)$ no experimento 1 - local $1 \ldots .$. 
39. Parâmetros componentes de médias do modelo de GARDNER \& EBERHART (1966) aplicado ao estudo de cruzamentos dialélicos, suas respectivas variâncias $(t / h a)^{2}$, e capacidade geral de combinação $\left(\hat{g}_{j}\right)$ das variedades para o caráter produção $(t / h a)$ no experimento 1 - local $2 \ldots .$.

40. Parâmetros componentes de médias do modelo II I de GARDNER (1967) aplicado ao estudo de cruzamentos "top crosses", e capacidade geral de combinação $\left(\hat{g}_{j}\right)$ das variedades para o caráter produção ( $t / h a)$ no experimento 2 - local 1 e

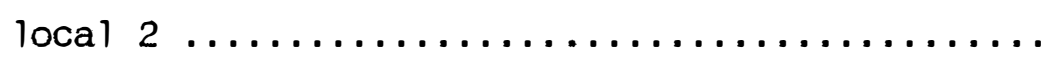

41. Parâmetros componentes de médias do modelo de GARDNER \& EBERHART (1966) adaptado por MIRANDA FILHO \& GERALDI (1984) aplicado ao estudo de cruzamentos dialélicos parciais, suas respectivas variâncias $(t / h a)^{2}$, e capacidade geral de combinação $\left(\hat{g}_{j}\right)$ das variedades para o caráter produção de grãos ( $t / h a)$ no experimento 3 -

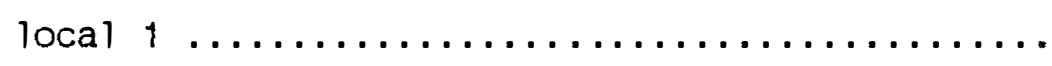

42. Parâmetros componentes de médias do modelo de GARDNER \& EBERHART (1966) adaptado por MIRANDA FILHO \& GERALDI (1984) aplicado ao estudo de cruzamentos dialélecos parciais, suas respectivas variâncias $(t / h a)^{2}$, e capacidade geral de combinação $\left(\hat{g}_{j}\right)$ das variedades para o caráter produção de grãos ( $t / h a$ ) no experimento 3 local $2 \ldots \ldots \ldots \ldots \ldots \ldots \ldots \ldots \ldots \ldots$ 
43. Parâmetros componentes de médias do modelo de GARDNER \& EBERHART (1966) aplicado ao estudo de cruzamentos dialélicos, suas respectivas variâncias $(\mathrm{cm})^{2}$, e capacidade geral de combinação $\left(\hat{g}_{\mathrm{j}}\right)$ das variedades para 0 caráter altura de planta $(\mathrm{cm})$ no experimento 1 - local 1

44. Parâmetros componentes de médias do modelo de GARDNER \& EBERHART (1966) aplicado ao estudo de cruzamentos dialélicos, suas respectivas variâncias $(\mathrm{cm})^{2}$, e capacidade geral de combinação $\left(\hat{g}_{j}\right)$ das variedades para o caráter altura de planta $(\mathrm{cm})$ no experimento 1 - local 2

45. Parâmetros componentes de médias do modelo III de GARDNER (1967) aplicado ao estudo de cruzamentos "top crosses", e capacidade geral de combinação $\left(\hat{g}_{j}\right)$ das variedades para o caráter altura de planta $(\mathrm{cm})$ no experimento 2 - local 1 e local $2 \ldots \ldots \ldots \ldots \ldots \ldots \ldots \ldots \ldots \ldots \ldots \ldots \ldots$

46. Parâmetros componentes de médias do modelo de GARDNER \& EBERHART (1966) adaptado por MIRANDA FILHO \& GERALDI (1984) aplicado ao estudo de cruzamentos dialélecos parciais, suas respectivas variâncias $(\mathrm{cm})^{2}$, e capacidade geral de combinação das variedades $\left(\hat{g}_{j}\right)$ para o caráter altura de planta $(\mathrm{cm})$ no experimento 3 - local 1 
47. Parâmetros componentes de médias do modelo de GARDNER \& EBERHART (1966) adaptado por MIRANDA FILHO \& GERALDI (1984) aplicado ao estudo de cruzamentos dialélecos parciais, suas respectivas variâncias $(\mathrm{cm})^{2}$, e capacidade geral de combinação $\left(\hat{g}_{j}\right)$ para o caráter altura de planta (cm) no experimento 3 - local $2 \ldots \ldots \ldots \ldots \ldots$

48. Correlação de Spearman entre os parâmetros dos modelos e capacidade geral de combinação no experimento 1 (dialélico) e do experimento 2 ("top cross") nos dois locais para produção e

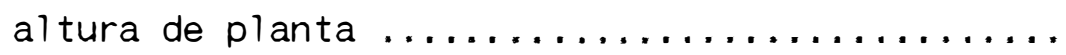




\section{AVALIAÇÃO DE POPULAÇÕES DERIVADAS DE HÍBRIDOS DE MILHO (Zea mays L.) EM CRUZAMENTOS NOS ESQUEMAS DIALÉLICO E "TOP CROSS"}

Autor: ARNALDO AFONSO BELLUCCI

Orientador: Prof. Dr. JOSE BRANCO DE MIRANDA FILHO

RESUMO

o objetivo do presente trabalho foi o de estudar a possibilidade do uso de cruzamentos "top crosses" ao invés de dialélicos na avaliação de variedades de milho (Zea mays, L.) e do uso de híbridos comerciais como fonte de germoplasma em programas de melhoramento. Para o primeiro objetivo foram instalados dois experimentos sendo um com o dialélico completo sem recíprocos, e um com os cruzamentos "top crosses". Para o segundo objetivo incorporou-se mais um experimento que se constituiu de um dialélico parcial onde foi incluído mais um grupo de variedades. As variedades estudadas constituiram-se de gerações F2 de hibridos comerciais de milho e se tratavam portanto de materiais adequados aos dois objetivos. 
As conclusões foram que cruzamentos "top crosses" podem ser usados na avaliação de variedades desde que não se tenha como objetivo a identificação de cruzamentos especificos mais heteróticos para os caracteres estudados (principalmente produção de grãos) onde o componente heterose especifica se mostrou importante, e que os hibridos comerciais são uma fonte muito boa de germoplasma para programas de melhoramento que busquem materiais com bom potencial de produtividade. 


\section{DIALLEL CROSSES AND TOP-CROSS FOR THE EVALUATION OF POPULATIONS DERIVED FROM MAIZE (Zea mays L.) HYBRIDS}

Author: ARNALDO AFONSO BELLUCCI

Adviser: Prof. Dr. JOSE BRANCO DE MIRANDA FILHO

SUMMARY

The objective of the present work was to study the possibility of using the top cross procedure instead of diallel cross for evaluating corn (Zea mays L.) varieties. The experimental material comprized $10 \mathrm{~F} 2$ populations from commercial hybrids and their genetics potential as useful germplasm was investigated.

For the first objective two trials were carried out: i) a $10 \times 10$ complete diallel cross; and i i) a 20 entries experiment comprising $10 \mathrm{~F} 2$ populations and the 10 respective topcross, using a mixture of the $1 \mathrm{~F} 2$ populations as tester. Both diallel and topcross experiments were used for evaluating the potential of populations as useful germplasm; for that purpose, a third trial ( $8 \times 10$ partial diallel cross) was also used. The latter comprised eight F2 populations of experimental hybrids besides the ten 
populations already mentioned.

The overall results led to the conclusions that the top cross procedure may be used for the evaluation of maize varieties when specific heterosis is not significant or when there is no interest in heterosis in specific cross. Otherwise, the diallel procedure is preferable. It was also concluded that the F2 generations of commercial hybrids showed to be promising germplasm sources for using in hybrid maize breeding programs. 


\section{INTRODUÇÃO}

A avaliação do germoplasma disponivel para aproveitamento em programas de melhoramento de milho é um ponto importante e que deve merecer atenção dos melhoristas, uma vez que é uma fase critica e dela pode depender o sucesso do programa. A variabilidade existente dentro da espécie é muito grande e deve-se antes de qualquer coisa identificar os materiais mais adequados aos objetivos dos programas de melhoramento. De fato existem limitações de recursos e, quando canalizados para objetivos de curto prazo como nos programas comerciais privados, a utilização de populações sabidamente mais promissoras parece ser uma estratégia naturalmente racional.

Dentre os métodos de avaliação de germoplasma em cruzamentos, os mais relatados são sem dúvida os que se baseiam em dialélicos, que se prestam à avaliação de materiais de qualquer natureza genética, desde linhagens endogâmicas até variedades de polinização aberta. Dentre os métodos para avaliação de cruzamentos dialélicos, o mais usada em milho é o desenvolvido por GARDNER \& EBERHART 
(1966). Este se baseia num dialélico completo entre as variedades a serem avaliadas. A aplicação de cruzamentos dialélicos na avaliação de materiais é um processo bastante trabalhoso tanto na fase de cruzamentos quanto na fase de avaliação em ensaios, consumindo um volume grande de recursos, principalmente quando precisa-se avaliar um grande número de materiais. Assim surgiram modificações na metodologia original visando diminuir o número de tratamentos avaliados em ensaios ou alternativamente viabilizar a avaliação de um número maior de materiais. Uma das proposições do presente trabalho é avaliar na prática o método sugerido por CHAVES \& MIRANDA FILHO (1993, 1994) na avaliação de variedades de milho. Com os resultados disponiveis, também procurou-se estudar a viabilidade do uso de hibridos comerciais como fonte de germoplasma em programas de melhoramento. 


\section{REVISÃO DE LITERATURA}

A literatura sobre melhoramento de milho revela que, em geral, a utilização dos diversos métodos de melhoramento que valorizam a geração e manutenção da variabilidade dentro de populações, como acontece com os diferentes métodos de seleção recorrente, são os mais comumente encontrados. No entanto, na prática, o melhoramento de populações não tem sido extensivamente utilizado, principalmente em programas de empresas privadas, tanto no Brasil como no exterior. As empresas privadas dão muito maior importância aos métodos de reciclagem de linhagens pelos métodos de Pedigri (HALLAUER, 1989) e que se constituem do aproveitamento da variabilidade gerada quando da autofecundação da geração $F 1$ do cruzamento entre duas linhagens ou de um ou dois retrocruzamentos do $F 1$ para um dos pais. Como era de se esperar, a reciclagem constante de linhagens levou à um estreitamento da base genética disponivel como destacado por SPRAGUE (1971), RUSSEL (1975), SMITH (1988) entre outros. BROWN (1975) estimou que somente dois ou três entre 130 complexos raciais disponiveis estavam 
sendo utilizados nos EUA. A conscientização do perigo representado por esse estreitamento da base genética levou os melhoristas americanos a começarem à introduzir novos germoplasmas em seus programas de melhoramento como destacam GOODMAN (1975) e GERRISH (1983). HALLAUER (1985) destaca que $70 \%$ dos melhoristas americanos reconhecem a necessidade de se dar maior importância aos programas de seleção recorrente de populações base para que uma maior variabilidade possa ser gerada, mantida e explorada, necessidade essa também destacada por HALLAUER \& MIRANDA FILHO (1988) e HALLAUER $(1989)$.

No caso dos ambientes tropicais, o grande número de populações presentes em um grande número de programas de melhoramento, tem proporcionado uma base genética bem maior (PATERNIANI, 1990) sendo que neste caso, - problema de estreitamento da base genética tende a ser menos grave. Nesta circunstância, torna-se relevante a tarefa de escolher dentro de um vasto número de populações disponiveis as mais adequadas aos objetivos dos programas de melhoramento. Surge então a necessidade de se ter uma metodologia adequada à avaliação de materiais à serem introduzidos nos programas.

Os cruzamentos dialélicos têm sido os instrumentos mais utilizados na avaliação de genótipos ( linhagens, sintéticos, variedades, populações, complexos raciais, etc), existindo várias metodologias que envolvem 
dialélicos e que servem tanto para avaliação do potencial do material em cruzamentos, como para predição de compostos que podem ser sintetizados a partir desses materiais.

Cruzamentos dialélicos compreendem todos os cruzamentos possiveis entre um grupo de materiais dois a dois, e a análise é feita a partir da construção de uma tabela dialélica que contém todos os $n(n-1) / 2$ híbridos possiveis, podendo ou não conter os materiais parentais e os híbridos recíprocos. As bases para o estudo de materiais com base em dialélicos foram estabelecidas por SMITH (1919) ${ }^{1}$ e os cruzamentos dialélicos parciais, onde nem todos os cruzamentos possiveis são feitos tiveram sua utilização relatada por KUDRJAWZEW (1934) ${ }^{1}$.

O trabalho de SPRAGUE \& TATUM (1942) propiciou um maior desenvolvimento dos trabalhos com cruzamentos dialélicos; esses autores, trabalhando com linhagens endogâmicas de milho, estabeleceram os conceitos de capacidade geral e de capacidade específica de combinação, relacionando a primeira a efeitos genéticos aditivos e a segunda a efeitos genéticos não aditivos (dominantes ou epistáticos). YATES (1947) apresentou uma análise de variância de dados obtidos de todos os cruzamentos possiveis entre um grupo de linhagens homozigóticas duas a duas. GREEN (1948) através de um estudo semelhante concluiu que a capacidade de combinação de um material é um caráter

\footnotetext{
${ }^{1}$ citados por MIRANDA FILHO (1974).
} 
herdáve1. HULL (1945) e GRIFFING (1950) analizaram dados de cruzamentos dialélicos usando técnicas de regressão, sendo que o primeiro usou linhagens puras e seus híbridos simples para estimar a magnitude da dominância para genes responsáveis pela produtividade em milho.

JINKS \& HAYMAN (1953), JINKS $(1954,1955)$ e HAYMAN (1954a e 1954b) desenvolveram métodos para análise e interpretação de cruzamentos dialélicos. GRIFFING (1956a e 1956b) desenvolveu metodologia para análise de quatro tipos de tabelas dialélicas; completa (incluindo híbridos, reciprocos e variedades parentais); só de hibridos e recíprocos; de híbridos e parentais; e só com híbridos.

Os trabalhos até aqui citados, se referem a dialélicos a partir de linhagens endogâmicas, já que visavam avaliar e discutir as qualidades das linhagens em combinações hibridas, acompanhando a tendência da época em que foram executados, na qual se dava pouca importância às populações e ao seu melhoramento. Com a tendência de se usar cada vez mais variedades de polinização livre em programas de melhoramento de milho (MIRANDA FILHO, 1974 e CARVALHO, 1980) começaram a surgir trabalhos com dialélicos de populações. Assim GARDNER (1965) e GARDNER \& EBERHART (1966) apresentaram uma metodologia para a análise de dialélicos de variedades cujo modelo permite a decomposição da média de um determinado caráter em seus diversos componentes; efeito de variedades $\left(v_{i}\right)$, efeito de heterose $\left(h_{i j}\right)$; prevê também a decomposição da 
heterose total nos efeitos de heterose média $(\bar{h})$, heterose de variedade $\left(h_{i}\right)$ e heterose especifica $\left(s_{i i}\right)$. O modelo é apropriado para a análise de dialélicos entre um conjunto fixo de variedades. GARDNER (1967) forneceu fórmulas simplificadas para a estimação dos componentes de médias e para a análise da variancia para um modelo completo.

Uma limitação prática do uso de dialélicos é - grande número de cruzamentos a serem feitos e avaliados em ensaios quando o número de materiais envolvidos é grande. Assim, surgiu o conceito de dialélicos parciais que geram um número menor de cruzamentos permitindo a avaliação de um número maior de materiais com os mesmos recursos. Os sistemas de dialélicos parciais se adaptam perfeitamente aos programas de melhoramento que $v i s a m$ a obtenção de híbridos já que esses programas envolvem grande número de linhagens. MIRANDA FILHO \& GERALDI (1984) adaptaram o modelo de GARDNER \& EBERHART (1966) para dialélicos parciais envolvendo dois grupos de variedades, fornecendo as formulas para a análise de variância e estimação dos componentes de médias. GERALDI \& MIRANDA FILHO (1988) discutem outros modelos de dialélico parcial para avaliação de genótipos em cruzamentos quando estes são divididos em dois grupos distintos.

o esquema de dialélico parcial circulante foi primeiramente sujerido por KEMPTHORNE \& CURNOW (1961), para um conjunto aleatório de linhagens (genotipos) de uma 
população, neste esquema, somente uma parte dos cruzamentos são avaliados experimentalmente.

Alguns trabalhos discutem o número ideal de cruzamentos que devem ser feitos com cada material no esquema circulante, como os de MURTHY et al (1967), ANAND \& MURPHY (1969) e BRAY (1971). O esquema de dialélico circulante adaptado para o nivel interpopulacional foi apresentado por MIRANDA FILHO \& VENCOVSKY (1995); este esquema foi utilizado por GONÇALVES (1987) e DANTAS (1988) para a avaliação de linhagens de milho e em seus trabalhos apresentaram amplas revisões sobre cruzamentos dialélicos em geral e sobre o esquema circulante em particular.

os esquemas dialélicos completos ou incompletos (parciais) diminuem bastante o trabalho envolvido nos cruzamentos entre as variedades e na avaliação dos hibridos, permitindo que se avalie um maior número de materiais, ou que se tenham estimativas de parâmetros mais confiáveis através do uso de um maior número de repetições durante a fase de experimentação. CHAVES \& MIRANDA FILHO (1993, 1994) sugerem o uso de cruzamentos "top crosses" ao invés dos dialélicos para a avaliação do potencial dos materiais envolvidos e o aproveitamento das informações obtidas para a sintese de compostos. O modelo utilizado por esses autores é o modelo reduzido número 3 de GARDNER (1967) que não leva em consideração o efeito de heterose específica, presente no modelo de GARDNER \& EBERHART (1966). Uma 
simulação feita pelos autores mostrou a validade do procedimento quando usado na predição de médias de compostos que possam ser sintetizadas a partir dos materiais envolvidos, havendo neste caso quase uma equivalência entre os resultados obtidos pelos dois processos. Esse esquema de "top crosses" permite a avaliação de um número bem maior de materiais que o dialélico ou uma maior precisão nos dados com - mesmo volume de recursos.

Sem dúvida, a quase totalidade dos trabalhos envolvendo dialélicos de variedades encontrados na literatura usa os modelos de GARDNER \& EBERHART (1966), que se adaptam também à linhagens puras, linhagens com qualquer nivel de endogamia, sintéticos e populações. Segundo HAMMOND \& GARDNER (1974) e PARTERNIANI (1990) esses modelos auxiliam o melhorista na escolha dos materiais para melhoramento, sendo de grande importância tanto em programas cujo objetivo seja a obtenção de linhagens para a obtenção de híbridos, quanto em programas de obtenção de variedades melhoradas para uso direto. Segundo VENCOVSKY (1970) uma das principais vantagens desses modelos é a sua flexibilidade, pois a partir de um número básico de materiais e seus cruzamentos, qualquer número e tipo de populações derivadas podem ser estudadas sem complicações; o autor faz também uma ampla revisão sobre cruzamentos dialélicos de variedades, sua utilização, análise e interpretação de resultados, fornecendo também fórmulas para a estimação de médias de compostos de variedades. 
MIRANDA FILHO \& RISSI (1975) e MORAES et al (1991) forneceram metodologias para estimação da interação dos parâmetros dos modelos de GARDNER \& EBERHART (1966) com - ambiente. MIRANDA FILHO \& VENCOVSKY (1994) apresentaram uma extensão da metodologia de MIRANDA FILHO \& RISSI (1975) aplicável a modelos com três fatores e não restrita à sruzamentos dialélicos.

Quanto à significância dos componentes do modelo de GARDNER \& EBERHART (1966) e suas derivações esse mesmo trabalho além de SILVA (1969) e MIRANDA FILHO $(1974)^{2}$ encontraram significância para efeito de variedades $\left(v_{j}\right)$ e de heterose média $(\bar{h})$ na análise de variância do dialélico. HALLAUER \& EBERHART (1966), VENCOVSKY (1970), BENZANILLA (1971), BARRIGA \& VENKOVSKY (1973), MIRANDA FILHO $(1974)^{2}$, SOUZA JUNIOR (1981), MIRANDA FILHO \& VENCOVSKY (1984), MISEYIC et al (1989) e DELBONI et al (1989) encontraram significância para efeito de variedades $\left(v_{j}\right)$, heterose média $(\bar{h})$ e para heterose de variedades $\left(h_{j}\right)$. TROYER \& HALLAUER (1968), HALLAUER \& SEARS (1968), EBERHART (1971) e CARVALHO (1980) encontraram significância para todos os componentes do mode 0 completo.

\footnotetext{
${ }^{2}$ Grupo I de materiais.
} 
Esses resultados de significância dos componentes citados até aqui se referem somente ao caráter produtividade. No entanto alguns outros autores incluiram em seus trabalhos análises de outras características; assim BARRIGA \& VENCOVSKY (1973) detectaram significância para efeitos de variedades $\left(v_{j}\right)$ e heterose de variedades $\left(h_{j}\right)$ para - caráter altura de planta, para altura de espiga detectaram significância somente para efeito de variedades $\left(v_{j}\right)$. MIRANDA FILHO (1974) verificou significância para efeito de variedades $\left(v_{j}\right)$, e de heterose média $(\bar{h})$ em um dos grupos de variedades estudados, e também efeito de heterose de variedades $\left(h_{j}\right)$ quando um segundo grupo formado pela inclusão de duas outras variedades de porte alto foi analisado, isto tanto para altura de planta e altura de espigas.

SOUZA JUNIOR (1981) para o caráter altura de planta encontrou significância para todos os componentes do modelo. Esse mesmo trabalho e mais o de MUNGONA \& POLLACK (1988), para o caráter altura de espigas, detectaram significância para efeito de variedades $\left(v_{j}\right)$, heterose média $(\bar{h})$ e para heterose especifica $\left(s_{j j}\right)$.

Alguns outros autores estudaram também caracteres como teor de oleo no grão (DUDLEY et a 1, 1977; MISEVIC et al, 1989), umidade do grão (MISEVIC et al, 1989) dias para florescimento, acamamento por tombamento, acamamento por quebramento (MUNGONA \& POLLACK, 1988). 
Os modelos de análise de dialélicos desenvolvidos por GRIFFING (1956a e 1956b) também são hoje bastante empregados, principalmente para estudo de herança, e normalmente se contituem em dialélicos de linhagens, ROOD \& MAYOR (1981) usaram o método I I de Griffing para estudar a herança da sensibilidade ao fotoperiodo e BARRIGA \& BURRIS (1988) usaram o mesmo método para estudar a herança da resistência à danos de secagem artificial em linhagens de mitho. NEVADO \& CROSS (1990) usando o método IV de Griffing, estudaram a herança da taxa relativa de crescimento (vigor inicial de plântulas) e sua relação com produtividade. Grande parte dos autores que usaram os métodos de análise desenvolvidos por Griffing se dedicaram ao estudo da herança de resistência à doenças, como por exemplo os trabalhos de BORGES (1987), THOMPSON et a 1 (1987), CALLAWAY et al (1990), ULRICH et al (1990) entre outros. 


\title{
3. MATERIAIS E MÉTODOS
}

\author{
3.1. Materiais
}

Para a realização deste trabalho foram utilizadas as gerações F2 de dois grupos de híbridos de milho, sendo que o grupo I se constituiu de 10 híbridos comerciais e o grupo I I de 8 híbridos experimentais, um dos híbridos (BR-201), teve sua geração F2 participando dos dois grupos.

- grupo I constituiu-se da geração F2 dos seguintes hibridos comerciais:

\begin{tabular}{|c|c|c|c|c|}
\hline \multicolumn{2}{|l|}{ MATER I AL } & \multirow{2}{*}{$\frac{C O D \cdot F 2}{V_{1}}$} & \multirow{2}{*}{$\frac{\text { IDENT. }}{G-551}$} & \multirow{2}{*}{$\frac{\text { EMPRESA }}{\text { CIBA SEMENTES }}$} \\
\hline HI BRIDO & 1 & & & \\
\hline HIBRIDO & 2 & $\vee 2$ & $G-85$ & CIBA SEMENTES \\
\hline HI BR I DO & 3 & V3 & $G-500$ & CIBA SEMENTES \\
\hline HI BR I DO & 4 & V4 & $X L-678$ & BRASKALB \\
\hline HIBR I DO & 5 & V5 & $X L-605$ & BRASKALB \\
\hline HIBR I DO & 6 & V6 & $D K-8701$ & BRASKALB \\
\hline HI BR I DO & 7 & $\vee 7$ & $c-133$ & ICI SEMENTES \\
\hline HIBRIDO & 8 & V8 & $B R-201$ & EMBRAPA (SEM. FARTURA) \\
\hline HI BR I DO & 9 & V9 & $c-125$ & CARG ILL \\
\hline HIBRIDO & 10 & V10 & $C-511 \mathrm{~A}$ & CARGILL \\
\hline
\end{tabular}


o grupo II constitui-se das gerações F2 dos seguintes híbridos experimentais, todos da EMBRAPA:

\begin{tabular}{lll}
\hline MATERIAL & COD. F2 & IDENT. \\
\hline HIBRIDO 11 & E1 & BR-111 \\
HIBRIDO 12 & E2 & BR-107 \\
HIBRIDO 13 & E3 & BR-136 \\
HIBRIDO 14 & E4 & BR-606 \\
HIBRIDO 15 & E5 & BR-106 \\
HIBRIDO 16 & E6 & BR-302 \\
HIBRIDO 17 & E7 & BR-300 \\
HIBRIDO 18 & E8 & BR-201 \\
\hline
\end{tabular}

As gerações $F 2$ de cada um desses híbridos foi obtida por polinização aberta em lotes isolados e cada uma delas constitui-se portanto um sintético de base genética bastante estreita, já que estes híbridos são duplos e triplos. Para tornar mais fácil a descrição dos procedimentos, de agora em diante cada um desses materiais vai ser chamado de variedade, assim, a geração $F 2$ do híbrido 1 vai ser chamada de variedade 1 ou $V 1$, a do híbrido 2 de variedade 2 ou $V 2$ e assim por diante, as do grupo II serão chamadas de E1 a E8.

Como testemunhas foram incluidos nos ensaios 3 híbridos comerciais da Ciba sementes de lançamento 
relativamente recente no mercado, esses mesmos hibridos também tiveram sua geração F2 incluida no trabalho, são eles:

\begin{tabular}{llllc}
\hline TEST. & COD. & CICLO & TIPO & LANÇ. MERC. \\
\hline G-551 & T1 & normal & duplo & 1990 \\
G-85 & T2 & precoce & triplo & 1990 \\
G-500 & T3 & normal & triplo & 1987
\end{tabular}

\subsection{Métodos}

\subsubsection{Preparo do Material Básico}

No ano agrícola de $1988 / 89$ foram obtidas as gerações $F 2$ de todos os híbridos em lotes isolados de polinização aberta. No ano seguinte, foram plantados em Cascavel-PR, 4 lotes de polinização manual:

Lote $\mathrm{n}^{1}$ : uma linha de cada uma das variedades parentais para multiplicação das sementes.

Lote n2 : plantio pareado ( 2 a 2 ) de todas as $[n(n-1) / 2]=45$ combinações possiveis entre as variedades do grupo I (dialélico completo dentro do grupo I).

Lote $n^{\circ} 3$ : plantio de cada uma das variedades do grupo I ao lado de uma mistura de todas essas mesmas variedades para a obtenção dos cruzamentos "top crosses". 
16.

Lote $n^{\circ} 4$ : plantio pareado de cada variedade do grupo I ao lado de cada variedade do grupo I I (dialélico parcial) para obtenção dos nibridos intervarietais intergrupos.

As linhas dos campos de polinização possuiam 10 metros de comprimento com um estande ideal de 51 plantas por linha. No lote número 1 as variedades foram polinizadas por cruzamentos fraternais e nos outros para os cruzamentos que foram feitos nos dois sentidos foi misturado o pólen de pelo menos cinco plantas do macho para cada espiga da fêmea correspondente.

\subsubsection{Fase Experimental}

Para o ciclo $1990 / 91$ foram preparados 3 experimentos em blocos casualizados:

Experimento № 1 : incluiu as 10 variedades parentais do grupo I, os 45 hibridos intervarietais (reciprocos não foram incluidos), e as 3 testemunhas num total de 58 entradas com 3 repetições em cada local.

Experimento № 2 : incluiu as 10 variedades parentais do grupo I, os 10 hibridos "top crosses" e as 3 testemunhas num total de 23 entradas com 6 repetições em cada local.

Experimento № 3 : incluiu as 10 variedades parentais do grupo I, as 8 variedades parentais do grupo II, 
os 30 hibridos intervarietais intergrupos e 2 testemunhas num total de 100 entradas com 3 repetições por local.

Cada parcela constituiu-se de duas linhas de 6 metros de comprimento com 0.9 m entre 1 inhas perfazendo uma area de $10.8 \mathrm{~m}^{2}$ com um estande ideal de 62 plantas por parcela (55000 plantas por hectare).

Os experimentos foram instalados em dois 1ocais: Cascavel-PR (local 1) e em Uberlândia-MG (local 2), sendo portanto dois ambientes muito distintos em todos os aspéctos (clima, tipo de solo, fertilidade natural e fotoperíodo). o plantio dos experimentos foi mecanizado (plantadeira de parcelas) e executado na mesma época sendo os niveis de adubação e os tratos culturais os mesmos nos dois locais.

No campo foram tomados os dados de estande e altura de planta e na colheita (mecanizada) foram tomados dados de produção por parcela (kg) e umidade (\%).

o peso de grãos foi corrigido para 13,0\% de umidade e transformado para toneladas por hectare para uma melhor visualização do nivel de produtividade dos materiais. Não foi feita a correção de produtividade em relação ao estande final, pois além do plantio mecânico em condições ideais ter propiciado uma variação bastante pequena entre as parcelas, considerou-se a capacidade de germinação como uma caracteristica componente da produtividade final, uma vez que toda a semente utilizada nos experimentos foi produzida no 
mesmo campo e submetida ao mesmo processamento, devendo portanto ter a mesma qualidade fisiológica.

\subsubsection{Análise Preliminar dos Experimentos}

$$
\text { Foram feitas análises de variância }
$$

preliminares dos três experimentos nos dois locais para as duas caracteristicas estudadas, isto é, produção e a ltura de planta, foram considerados fixos os efeitos de tratamentos e aleatórios os efeitos de repetições e o erro experimental.

O modelo estatistico para análise da variância para cada local no delineamento de blocos casualizados é o seguinte:

$$
Y_{i k}=\mu+t_{i}+b_{k}+e_{i k}
$$

onde:

$$
\begin{aligned}
& Y_{i k}=\text { observação do tratamento } i \text { na repetição } k \\
& \mu=\text { média das observações } \\
& t_{i}=\text { efeito fixo do tratamento } i \\
& b_{k}=\text { efeito aleatório de bloco } k \\
& e_{i k}=\text { erro experimental associado ao tratamento i na } \\
& \quad \text { repetição } k
\end{aligned}
$$


o quadro para análise da variância preliminar para cada local é o seguinte:

G.L.

\begin{tabular}{lrrrrrr}
\cline { 2 - 3 } F.V. & EXP & EXP 2 & EXP 3 & & Q.M. & $F$ \\
\hline Repetições & 2 & 5 & 2 & & Q1 & Q1/Q7 \\
Tratamentos & 57 & 22 & 99 & & Q2 & Q2/Q7 \\
$\quad$ Variedades & 9 & 9 & 17 & & Q3 & Q3/Q7 \\
$\quad$ Hibridos & 44 & 9 & 79 & & Q4 & Q4/Q7 \\
$\quad$ Testemunhas & 2 & 2 & 1 & & Q5 & Q5/Q7 \\
$\quad$ Grupos & 2 & 2 & 2 & & Q6 & Q6/Q7 \\
Erro & 114 & 110 & 198 & & Q7 &
\end{tabular}

Na análise de variancia preliminar conjunta (dois locais), foram considerados fixos os efeitos de locais e tratamentos e aleatórios o efeito de repetições dentro de locais e o erro experimental. O modelo estatistico para a análise conjunta preliminar é o seguinte:

$$
Y_{i j k}=\mu+t_{i}+I_{j}+b_{k(j)}+(t I)_{i j}+e_{i j k}
$$

onde:

$$
\begin{aligned}
& Y_{i j k}=\text { observação do trat. } i \text { na rep. } k \text { no local j } \\
& \mu=\text { média geral das observações } \\
& t_{i}=\text { efeito fixo do tratamento } i \\
& l_{j}=\text { efeito fixo do local } j
\end{aligned}
$$


$b_{k(j)}=$ efeito aleatório da rep. $k$ dentro do local j

$(t 1)_{i j}=$ efeito fixo da interação do tratamento $i$ com o local j

$e_{i j k}=$ erro experimental associado ao tratamento $i$ na repetição $k$ do local j

o quadro para a análise conjunta preliminar é

o seguinte:

\begin{tabular}{|c|c|c|c|c|c|c|}
\hline \multirow[b]{2}{*}{$F . V$. } & \multicolumn{4}{|c|}{ G.L. } & \multirow[b]{2}{*}{ Q.M. } & \multirow[b]{2}{*}{$F$} \\
\hline & EXP & 1 & EXP 2 & EXP 3 & & \\
\hline Locais & 1 & & 1 & 1 & Q1 & Q1/Q13 \\
\hline Repet ições/Locais & 4 & & 10 & 4 & Q2 & Q2/Q13 \\
\hline Trat amentos & 57 & & 22 & 99 & Q3 & Q3/Q13 \\
\hline Variedades & 9 & & 9 & 17 & Q4 & Q4/Q13 \\
\hline Hibridos & 44 & & 9 & 79 & Q5 & Q5/Q13 \\
\hline Test emunhas & 2 & & 2 & 1 & Q6 & Q6/Q13 \\
\hline Grupos & 2 & & 2 & 2 & Q7 & Q7/Q13 \\
\hline Tratam. $\times$ Locais & 57 & & 22 & 99 & Q8 & Q8/Q13 \\
\hline Varied.x Locais & 10 & & 9 & 17 & Q9 & Q9/Q13 \\
\hline Hibr.x Locais & 44 & & 9 & 79 & Q10 & Q10/Q13 \\
\hline Test. $x$ Locais & 2 & & 2 & 1 & Q11 & Q11/Q13 \\
\hline Grupos $x$ Locais & 2 & & 2 & 2 & Q12 & Q12/Q13 \\
\hline Erro Médio & 228 & & 220 & 396 & Q13 & \\
\hline
\end{tabular}


3.2.4. Análise da Variância dos Dialélicos, do "Top Cross" e Estimação de Parâmet ros Componentes de Médias

3.2.4.1. Análise da Variância e Estimação de Paråmetros do Dialélico Completo

A análise do dialélico completo foi feita de acordo com o modelo de GARDNER \& EBERHART (1966):

$$
Y_{j j^{*}}=\mu+\frac{1}{2}\left(v_{j}+v_{j^{\prime}}\right)+\theta h_{j j^{\prime}}
$$

onde:

$Y_{j j^{\prime}}=$ média da variedade $\left(j=j^{\prime}\right)$ ou do híbrido $\left(j \neq j^{\prime}\right)$

$\mu=$ média das variedades

$V_{j}$ ou $V_{j}=$ efeito das variedades $j e j^{\prime}$ respectivamente

$h_{j^{\prime}}=$ efeito de heterose

$\theta=$ coeficiente condicional $\left(\theta=0\right.$ se $j=j^{\prime} ; \theta=1$ se $\left.j \neq j^{\prime}\right)$

O efeito da heterose $\left(h_{j j^{\prime}}\right)$ pode ser assim

decomposto:

$$
h_{j f^{\prime}}=\bar{h}+h_{f}+h_{j}+s_{j f^{\prime}}
$$

onde:

$$
\begin{aligned}
& \bar{h}=\text { heterose média } \\
& h_{j} \text { ou } h_{j^{\prime}}=\text { heterose de variedades (contribuição de j ou } j^{\prime}
\end{aligned}
$$




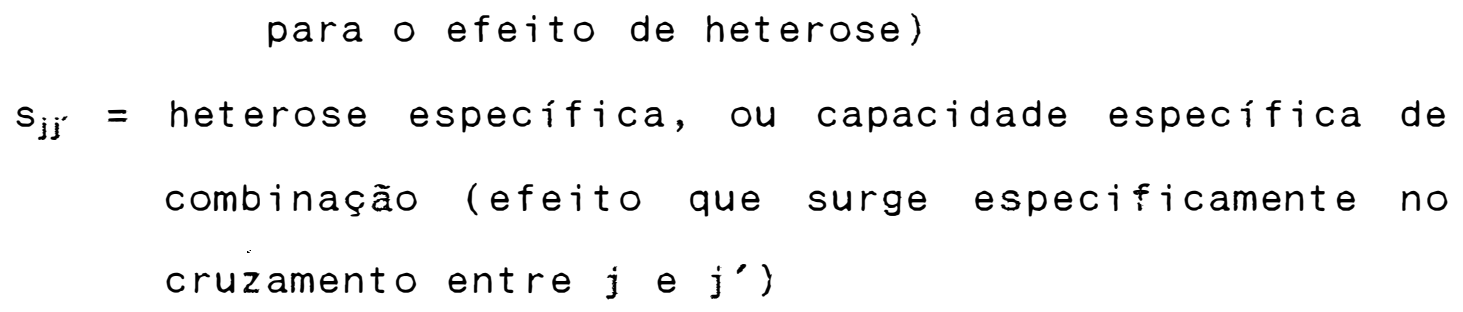

onde:

$\bar{e}_{j j^{\prime}}=$ erro experimental médio associado às médias $Y_{j j}$

Nesse caso, o quadro da ANAVA para um local é

o seguinte :

\begin{tabular}{lccc}
\hline FV & GL & QM & F \\
\hline Tratamentos* & 54 & Q1 & Q1/Q6 \\
Variedades & 9 & Q2 & Q2/Q6 \\
Heterose Média & 1 & Q3 & Q3/Q6 \\
Heterose de Variedades & 9 & Q4 & Q4/Q6 \\
Heterose Especifica & 35 & Q5 & Q5/Q6 \\
Erro Médio** & 114 & Q6 & \\
\hline
\end{tabular}

* Tratamentos = Variedades + hibrido intervarietais

* Obtido da análise preliminar da variância para o local ao nível de médias ( $Q M$ do erro/nº de repetições) 
O modelo utilizado para a análise conjunta da variância do dialélico foi o seguinte (MORAES et al, 1991):

$$
\begin{gathered}
Y_{i j j^{\prime}}=\mu+\frac{1}{2}\left(v_{j}+v_{j^{\prime}}+I v_{i j}+I v_{i j^{\prime}}\right)+I_{i}+ \\
+\theta\left(\bar{h}+h_{j}+h_{j}+s_{j j^{\prime}}+1 \bar{h}_{i}+1 h_{i j}+1 h_{i j^{\prime}}+1 s_{i j j^{\prime}}\right)+e_{j j^{\prime}}
\end{gathered}
$$

onde:

$1_{i}$ é o efeito do local i

o quadro da ANAVA conjunta da variância é o

\begin{tabular}{|c|c|c|c|}
\hline FV & GL & QM & $F$ \\
\hline Trat amentos & 54 & Q1 & Q1/Q12 \\
\hline Variedades & 9 & Q2 & $Q 2 / Q 12$ \\
\hline Heterose Média & 1 & Q3 & Q3/Q12 \\
\hline Heterose variedade & 9 & Q4 & Q4/Q12 \\
\hline Heterose Especifica & 35 & Q5 & Q5/Q12 \\
\hline Locais & 1 & Q6 & Q6/Q12 \\
\hline Trat amentos $\times$ Locais & 54 & Q7 & Q7/Q12 \\
\hline Variedades $\times$ Locais & 9 & Q8 & Q8/Q12 \\
\hline Heterose Média x Locais & 1 & Q9 & Q9/Q12 \\
\hline Heterose de Variedades $\times$ Loc. & 9 & Q10 & Q10/Q12 \\
\hline Heterose Especifica $x$ Locais & 35 & Q11 & Q11/Q12 \\
\hline Erro Médio* & 228 & Q12 & \\
\hline
\end{tabular}
seguinte:

* Erro Médio da Análise de Variância conjunta preliminar ao nivel de médias (QM do resíduo/n de repetições por local $x$ no de locais). 
As fómulas para o cálculo da soma de quadrados na análise de variância do dialélico são as seguintes:

$$
\begin{aligned}
& \text { SQtrat }=\sum_{j=1}^{n} V_{j}^{2}+\sum_{j<j^{\prime}}^{n} H_{j j^{\prime}}^{2}-\frac{2 P^{2}}{n(n+1)} \\
& \text { SQvar }=\frac{1}{n+2}\left[\sum_{j=1}^{n}\left(2 V_{j}+H_{j} .\right)^{2}-\frac{4 P^{2}}{n}\right] \\
& \text { SQhet }=\sum_{j=1}^{n} V_{j}+\sum_{j<j} H_{j j}^{2}+\frac{1}{n+2}\left[\frac{2 P^{2}}{n+1}-\sum_{j=1}^{n}\left(2 V_{j}+H_{j}\right)^{2}\right] \\
& \text { sQhet média }=\frac{1}{n}\left[\frac{2 H_{.}^{2}}{n-1}+V^{2}-\frac{2 P^{2}}{n+1}\right] \\
& \text { sQhet. var. }=\frac{1}{(n-2)(n+2)} \sum_{j=1}^{n}\left[(n-2) v_{j}-2 H_{j}\right]^{2}-\frac{4}{n}\left[\frac{H_{\cdot}^{2}}{n-2}-\frac{P^{2}}{n+2}-\frac{V_{\cdot}^{2}}{n}\right] \\
& \text { sqhet. esp. }=\sum_{j<j} H_{j,}^{2}-\frac{1}{n-2}\left[\sum_{j=1}^{n} H_{j}^{2}-\frac{2 H_{.}^{2}}{n-1}\right]
\end{aligned}
$$

onde:

$$
\begin{aligned}
& v_{j}=\text { valor observado para a variedade } j \\
& H_{j j}=\text { valor observado para o hibrido } j \times j^{\prime} \\
& H_{j .}=\text { soma dos híbridos com a variedade } j \\
& \bar{H}_{j .}=\text { média dos híbridos com a variedade } j \\
& V_{.}=\text {soma de todas as variedades do dialélico } \\
& H_{.}=\text {soma total dos híbridos } \\
& P=V \text {. + H. }=\text { soma total da tabela dialélica } \\
& n=\text { número total de variedades parentais }
\end{aligned}
$$


As fórmulas para a estimação dos parâmetros componentes de médias para o modelo de GARDNER \& EBERHART (1966) utilizadas no presente caso e suas respectivas variâncias (vâr) são as seguintes:

$$
\begin{aligned}
& \boldsymbol{\beta}=\overline{\mathrm{V}}=\frac{\mathrm{V}}{\mathrm{n}} \\
& \operatorname{vâr}(\boldsymbol{\beta})=\frac{\sigma^{2}}{n} \\
& \theta_{j}=V_{j}-\bar{V} \\
& \operatorname{vâr}\left(\hat{\vartheta}_{j}\right)=\frac{n-1}{n} \hat{\sigma}^{2} \\
& \hat{\overline{\mathrm{h}}}=\overline{\mathrm{H}}-\overline{\mathrm{V}} \\
& \operatorname{vâr}(\hat{\hat{h}})=\frac{n+1}{n(n-1)} \hat{\partial}^{2} \\
& \hat{h}_{j}=\frac{n-1}{n-2}\left(\bar{H}_{j}-\bar{H}\right)-\frac{1}{2}\left(V_{j}-\bar{V}\right) \\
& \operatorname{vâr}\left(\hat{h}_{j}\right)=\frac{(n-1)(n+2)}{4 n(n-2)} \cdot \hat{\sigma}^{2} \\
& s_{j j^{\prime}}=H_{j j^{+}}+\frac{n}{n-2} \bar{H}-\frac{n-1}{n-2}\left(\bar{H}_{j \cdot}+H_{. j}\right) \\
& \operatorname{vâr}\left(\hat{s}_{j j^{\prime}}\right)=\frac{n-3}{n-1} \cdot \hat{\partial}^{2}
\end{aligned}
$$

onde:

$$
\begin{aligned}
& A=\bar{v}=\bar{V}_{.}=\text {média estimada das variedades; } \\
& \hat{\nabla}=\text { efeito estimado da variedade } j ; \\
& \bar{H}=\bar{H}_{. .}=\text {média dos híbridos } \\
& \hat{\sigma}^{2}=\text { estimativa do erro residual ao nível de médias ou } \\
& \text { seja; } \\
& \hat{\sigma}^{2}=\frac{Q}{I}
\end{aligned}
$$

onde:

$$
\begin{aligned}
Q= & \text { erro residual da análise preliminar (nivel de } \\
& \text { totais) } \\
r= & \text { número de repetições }
\end{aligned}
$$


3.2.4.2. Análise da Variância dos Cruzamentos "Top Crosses" (Ensaio 2) e Estimação dos Parâmetros Componentes de Médias para o Modelo Reduzido 3 de GARDNER (1967)

Para a análise da variância dos cruzamentos "top crosses" do experimento 2 usou-se o modelo reduzido número 3 de GARDNER (1967) como sugerido por CHAVES \& MIRANDA FILHO (1993, 1995), que difere do modelo completo de GARDNER \& EBERHART por negligenciar o efeito do componente Heterose Especifica $\left(s_{j j^{\circ}}\right)$, assim;

$$
Y_{j j^{\prime}}=\mu+\frac{1}{2}\left(v_{j}+v_{j \cdot}+\bar{h}+h_{j}+h_{j \cdot}+e_{j j^{\circ}}\right)
$$

sendo o significado dos componentes equivalentes aos do modelo completo.

O quadro da ANAVA dos "top crosses" para esse modelo em um único local segundo CHAVES \& MIRANDA FILHO (1995) é o seguinte:

\begin{tabular}{crrl}
\hline FV & GL & QM & F \\
\hline Tratamentos & 19 & Q1 & Q1/Q5 \\
Variedades & 9 & Q2 & Q2/Q5 \\
Het. Média & 1 & Q3 & Q3/Q5 \\
Het. Varied. & 9 & Q4 & Q4/Q5 \\
Erro* & 110 & Q5 & \\
\hline
\end{tabular}

*obtido da ANAVA preliminar para o local ao nivel de médias ( $Q M$ do resíduo/número de repetições) 
Modelo para a ANAVA conjunta:

$$
\begin{aligned}
& Y_{i j j^{*}}=\mu+\frac{1}{2}\left(v_{j}+v_{j^{\prime}}+1 v_{i j^{\prime}}+1 v_{i j^{\prime}}\right)+I_{i}+ \\
& +\theta\left(\bar{h}+h_{j}+h_{j^{\prime}}+1 \bar{h}_{i}+1 h_{i j}+1 h_{i j^{\prime}}\right)+e_{i j j^{\prime}}
\end{aligned}
$$

Quadro da ANAVA conjunta:

\begin{tabular}{crcc}
\hline FV & GL & QM & $F$ \\
\hline Tratamentos & 19 & Q1 & Q1/Q9 \\
Variedades & 9 & $Q 2$ & Q2/Q9 \\
Het. Média & 1 & $Q 3$ & Q3/Q9 \\
Het. de Var. & 9 & Q4 & Q4/Q9 \\
Tratam. x Locais & 19 & Q5 & Q5/Q9 \\
Varied. x Loc & 9 & Q6 & Q6/Q9 \\
Het. Média x Loc & 1 & Q7 & Q7/Q9 \\
Erro Médio* & 220 & Q9 & \\
\hline
\end{tabular}

* erro médio da ANAVA preliminar ao nível de médias

As fórmulas para os cálcuios das somas de quadrados da análise de variância dos parâmetros do modelo reduzido número 3 de GARDNER (1967) adaptado para cruzamentos "top crosses" como sugerido por CHAVES \& MIRANDA FILHO (1993, 1995) são as seguintes:

$$
\text { SQtrat }=\sum_{j=1}^{n} v_{j}^{2}+\sum_{j=1}^{n} T_{j}^{2}-\frac{\left(V_{.}+T_{0}\right)^{2}}{2 n}
$$

$$
\text { sqvaried }=\frac{1}{5} \sum_{j}\left[2\left(\mathrm{~V}_{j}-\overline{\mathrm{V}}\right)+\left(\mathrm{T}_{j}-\overline{\mathrm{T}}\right)\right]^{2}
$$




$$
\text { SQhet média }=\frac{1}{2 n}(V .-T .)^{2}
$$

$$
\text { sohet. varied }=\frac{1}{5} \sum_{j}\left[\left(V_{j}-\bar{V}\right)-2\left(T_{j}-\bar{T}\right)\right]^{2}
$$

onde:

$$
\begin{aligned}
& T_{j}=\text { "top crosses" da variedade } j ; \\
& \bar{T}=\text { média dos "top crosses"; } \\
& T_{.}=\text {total dos "top crosses" }
\end{aligned}
$$

As fómulas para cálculos dos parâmetros do modelo reduzido número 3 de GARDNER (1967) e suas respectivas variâncias (var) são as seguintes:

$$
\begin{array}{lr}
\hat{\beta}=\bar{V}=\frac{V}{n} & \operatorname{vâr}(\hat{\beta})=\frac{\partial^{2}}{n} \\
\hat{v}_{j}=V_{j}-\bar{V} & \operatorname{vâr}\left(\hat{v}_{j}\right)=\frac{n-1}{n} \hat{\partial}^{2} \\
\hat{\bar{h}}=\frac{n}{n-2}(\bar{T}-\bar{v}) & \operatorname{vâr}(\hat{\bar{h}})=\frac{2 n}{(n-1)^{2}} \partial^{2} \\
\hat{h}_{j}=\frac{n}{n-2}\left[\left(T_{j}-\bar{T}\right)-\frac{1}{2}\left(V_{j}-\bar{V}\right)\right] & \operatorname{vâr}\left(\hat{h}_{j}\right)=\frac{5 n(n-1)}{4(n-2)^{2}} \partial^{2}
\end{array}
$$

onde:

$$
\hat{\sigma}^{2}=\text { quadrado médio do residuo ao nível de médias }
$$


As heteroses preditas foram calculadas pela

fórmula:

$$
h_{j j^{\prime}}^{*}=\bar{h}+h_{j}+h_{j}
$$

onde:

$$
h_{j i}^{*}=\text { heterose predita no cruzamento } j \times j^{\prime}
$$

3.2.4.3. Análise da Variancia do Dialélico Parcial (experimento 3 ) e Estimação dos Parâmetros Componentes de Médias para o Modelo Adaptado por MIRANDA FILHO \& GERALDI (1984) para Dialélicos Parciais

Para a Análise da Variância do dialélico parcial foi usado 0 modelo de GARDNER \& EBERHART (1966) adaptado para dialélicos parciais por MIRANDA FILHO \& GERALDI $(1984):$

$$
Y_{i j}=\mu+\alpha d+\frac{1}{2}\left(v_{i}+v_{j}\right)+\theta\left(\bar{h}+h_{i}+h_{j}+s_{i j}\right)+e_{i j}
$$

sendo que:

$d=$ medida da diferença entre os 2 grupos de materiais

$\alpha=0$ para os hibridos $\left(Y_{i j}\right)$

$\alpha=-1$ para o grupo de materiais de menor média

$\alpha=1$ para o grupo de materiais de maior média 
o quadro da Análise da Variância para um local é o seguinte:

\begin{tabular}{lrrc}
\hline FV & GL & QM & $F$ \\
\hline Tratamentos & 97 & Q1 & Q1/Q9 \\
Variedades (1) & 9 & Q2 & Q2/Q9 \\
Variedades (2) & 7 & Q3 & Q3/Q9 \\
Grupos & 1 & $Q 4$ & Q4/Q9 \\
Heterose Média & 1 & Q5 & Q5/Q9 \\
Heterose de Varied. (1) & 9 & Q6 & Q6/Q9 \\
Heterose de Varied. (2) & 7 & $Q 7$ & Q7/Q9 \\
Heterose Especifica & 63 & $Q 8$ & Q8/Q9 \\
Erro* & 198 & Q9 & \\
\hline
\end{tabular}

* anava preliminar ao nível de médias

$$
\begin{aligned}
& Y_{i j k}=\mu+\alpha\left(d+l_{k} d\right)+\frac{1}{2}\left(v_{i}+v_{j}+l v_{i k}+l v_{j k}\right)+l_{k}+ \\
& +\theta\left(\bar{h}+h_{i}+h_{j}+s_{i j}+l_{k} \bar{h}+l h_{i k}+l h_{j k}+s_{i j k}\right)+e_{i j k}
\end{aligned}
$$

sendo que l é o efeito do local k 
O quadro da ANAVA conjunta é o seguinte:

\begin{tabular}{|c|c|c|c|}
\hline FV & GL & QM & $F$ \\
\hline Tratamentos & 97 & Q1 & Q1/Q17 \\
\hline Variedades (1) & 9 & Q2 & Q2/Q17 \\
\hline Variedades ( 2 ) & 7 & Q3 & Q3/Q17 \\
\hline Grupos & 1 & Q4 & Q4/Q17 \\
\hline Heterose Média & 1 & Q5 & $Q 5 / Q 17$ \\
\hline Het. de Variedades (1) & 9 & Q6 & Q6/Q17 \\
\hline Het. de Variedades (2) & 7 & Q7 & Q7/Q17 \\
\hline Het. Específica & 63 & Q8 & Q8/Q17 \\
\hline Trat amentos $x$ Locais & 97 & Q9 & Q9/Q17 \\
\hline Varied (1) x Locais & 9 & Q10 & Q10/Q17 \\
\hline Varied (2)x Locais & 7 & Q11 & Q11/Q17 \\
\hline Grupos $x$ Locais & 1 & Q12 & Q12/Q17 \\
\hline Heterose Média $x$ Locais & 1 & Q13 & Q13/Q17 \\
\hline Het. de Varied.(1) x Locais & 9 & Q14 & Q14/Q17 \\
\hline Het. de Varied.(2) x Locais & 7 & Q15 & Q15/Q17 \\
\hline Heterose Especifica & 63 & Q16 & Q16/Q17 \\
\hline Erro Médio* & 396 & Q17 & \\
\hline
\end{tabular}

* Erro médio da análise preliminar ao nível de médias ( $Q M$ do residuo/n de reps $x \mathrm{n}$ de locais)

As fórmulas para cálculo das somas de quadrados na ANAVA do dialélico parcial são as seguintes:

$$
\begin{gathered}
\text { SQtrat }=\sum_{i} V_{i}^{2}+\sum_{j} V_{j}^{2}+\sum H_{i j}^{2}-\frac{P^{2}}{n} \\
\text { SQvar }(1)=\frac{4}{4+I} \sum\left[V_{j}-\bar{V}_{(2)}+\frac{1}{2}\left(H_{. j}-I \bar{H}\right)\right]^{2}
\end{gathered}
$$




$$
\begin{aligned}
& S Q \operatorname{var}(2)=\frac{4}{4+I} \sum\left[\mathrm{V}_{j}-\bar{V}_{(1)}+\frac{1}{2}\left(\mathrm{H}_{1},-\overline{\mathrm{H}}\right)\right]^{2} \\
& \text { sogrupos }=\frac{I J}{n(4+I+J)}\left[(I+2) \bar{V}_{(1)}-(J+2) \bar{V}_{(2)}+(J-I) \bar{H}\right]^{2} \\
& \text { sQhet média }=\frac{I J}{4+I+J}\left[\bar{V}_{(1)}+\bar{V}_{(2)}-2 \bar{H}\right]^{2} \\
& \text { sohet. } \operatorname{var}(1)=\frac{I}{4+I} \sum_{J}\left[V_{j}-\bar{V}_{(2)}-2\left(\bar{H}_{j}-\bar{H}\right)\right]^{2} \\
& \text { sqhet. } \operatorname{var}(2)=\frac{J}{4+J} \sum_{I}\left[V_{i}-\bar{V}_{(1)}-2\left(\bar{H}_{i}-\bar{H}\right)\right]^{2} \\
& \text { sqhet.esp }=\sum \mathrm{H}^{2}-\frac{1}{\mathrm{~J}} \sum \mathrm{H}_{\mathrm{i} .}^{2}-\frac{1}{\mathrm{I}} \sum \mathrm{H}_{. \mathrm{j}}^{2}+\frac{1}{\mathrm{IJ}} \mathrm{H}_{. .}^{2}
\end{aligned}
$$

onde:

$$
\begin{aligned}
& n=\text { número total de variedades } \\
& J=\text { número de variedades do grupo } 1 \\
& I=\text { número de variedades do grupo } 2 \\
& P=\text { soma total da tabela dialélica } \\
& H_{.}=\text {soma total dos hibridos } \\
& \bar{H}=\text { média dos híbridos } \\
& V_{j}=\text { variedades do grupo } 1 \\
& \bar{V}(1)=\text { Média do grupo } 1 \\
& V_{i}=\text { variedades do grupo } 2 \\
& \bar{V}(2) \text { Média do grupo } 2 \\
& H=\text { hibridos } \\
& H_{j}=\text { hibridos com a variedade } j \text { do grupo } 1 \\
& H_{i}=\text { híbridos com a variedade } i \text { do grupo } 2 \\
& H_{. j}=\text { soma dos híbridos com a variedade } j \\
& H_{i}=\text { soma dos hibridos com a variedade } i
\end{aligned}
$$


As fórmulas para cálculo dos parâmetros componentes do modelo e suas respectivas variâncias são as seguintes:

$$
\begin{aligned}
& \hat{\mu}=\frac{1}{2}\left(\bar{V}_{(1)}+\bar{V}_{(2)}\right) \\
& \operatorname{vâr}(\hat{\beta})=\frac{I+J}{4 I J} \partial^{2} \\
& a=\frac{1}{2}\left(\bar{v}_{(1)}-\bar{v}_{(2)}\right) \\
& \operatorname{vâr}(\hat{d})=\frac{I+J}{4 I J} \partial^{2} \\
& \theta_{i}=V_{i}-\bar{V}_{(1)} \\
& \operatorname{vâr}\left(\hat{\theta}_{i}\right)=\frac{I-1}{I} \hat{\partial}^{2} \\
& \theta_{j}=V_{j}-\bar{V}_{(2)} \\
& \operatorname{vâr}\left(\hat{v}_{j}\right)=\frac{J-1}{J} \hat{\sigma}^{2} \\
& \hat{\bar{h}}=H-\beta \\
& \operatorname{vâr}(\hat{\bar{h}})=\frac{4+I+J}{4 I J} \partial^{2} \\
& \hat{h}_{i}=\bar{H}_{i}-\bar{H}+\frac{1}{2}\left(\bar{V}_{(1)}-V_{i}\right) \\
& \operatorname{vâr}\left(\hat{h}_{i}\right)=\frac{(I-1)(4+J)}{4 I J} \partial^{2} \\
& \hat{h}_{j}=\bar{H}_{. j}-\bar{H}+\frac{1}{2}\left(\bar{V}_{(2)}-V_{j}\right) \\
& \operatorname{vâr}\left(\hat{h}_{j}\right)=\frac{(J-1)(4+I)}{4 I J} \partial^{2} \\
& \mathrm{~S}_{i j}=\mathrm{H}_{i j}+\overline{\mathrm{H}}-\overline{\mathrm{H}}_{\dot{j}}-\overline{\mathrm{H}}_{j} \text {. } \\
& \operatorname{vâr}\left(\hat{S}_{i j}\right)=\frac{(I-1)(J-1)}{I J} \hat{\sigma}^{2}
\end{aligned}
$$

3.2.4.4. Cálculo da Soma de Quadrados das Interações dos Parâmetros com os Ambientes nas Análises Conjuntas dos Dialélicos e dos "Top Crosses"

Nos 3 experimentos, as somas de quadrados das interações dos parâmetros com os ambientes foram calculadas pela metodologia proposta por MIRANDA FILHO \& RISSI (1975) 
que se baseia na seguinte expressão:

$$
S_{p y}=I_{1} S_{p 1}+r_{2} S_{p 2}-\left(I_{1}+r_{2}\right) S_{p 12}
$$

onde:

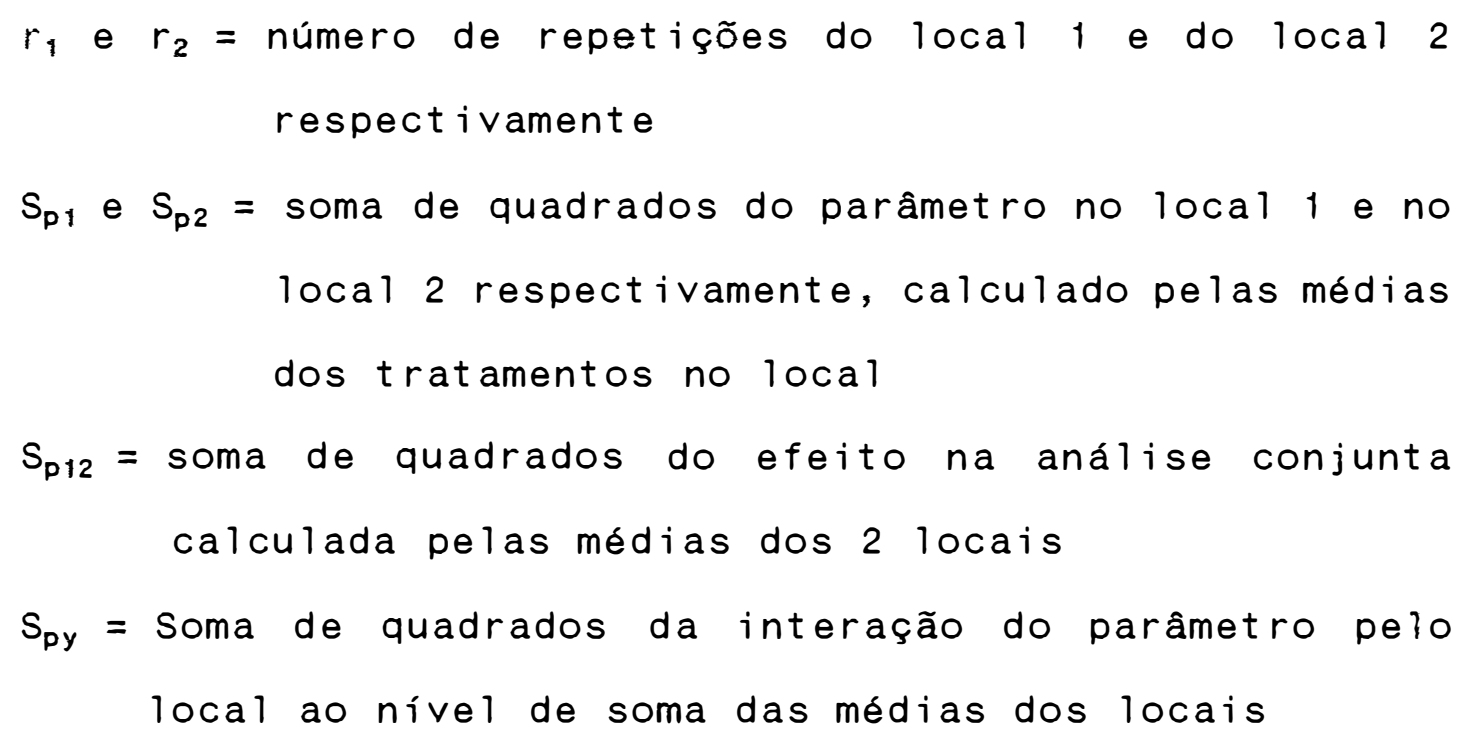

Para compatibilização com o erro residual da análise conjunta, Spy deve ser dividido pelo número de locais, já que na fórmula apresentada a soma de quadrados é obtida ao nivel da soma das médias dos locais. Assim no nosso caso, como $r_{1}=r_{2}$, a formula pode ser simplificada da seguinte maneira:

$$
S_{p y}=\frac{S_{p 1}+S_{p 2}-2 S_{p 12}}{L}
$$

onde $L$ é o número de locais e $S_{p y}$ já é diretamente compativel com o resíduo da análise conjunta. 
3.2.5. Cálculo da Capacidade Geral de Combinação das Variedades em Estudo

A capacidade geral de combinação $\left(\hat{g}_{i}\right)$ para todas as variedades foi calculada baseando-se nos parâmetros efeito de variedades $\left(\hat{V}_{i}\right)$ e heterose de variedades $\left(\hat{h}_{i}\right)$ como proposto por GARDNER \& EBERHART (1966), assim:

$$
\hat{g}=\frac{1}{2} \theta_{i}+\hat{h}_{i}
$$

Do mesmo modo, os efeitos de capacidade geral de combinação do dialélico parcial foram estimadas por (GERALDI \& MIRANDA FILHO, 1988):

$$
\begin{array}{ll}
\hat{g}_{i}=\frac{1}{2} v_{i}+\hat{h}_{i} & \text { para o grupo I } \\
\hat{g}_{j}=\frac{1}{2} v_{j}+\hat{h}_{j} & \text { para o grupo II }
\end{array}
$$

3.2.6. Determinação dos Intervalos de Confiança para as Médias Observadas

Foram determinados intervalos de confiança para as médias observadas para cada local e para os 2 locais em conjunto para os 2 caracteres estudados ao nivel de $95 \%$ de probabilidade da seguinte forma:

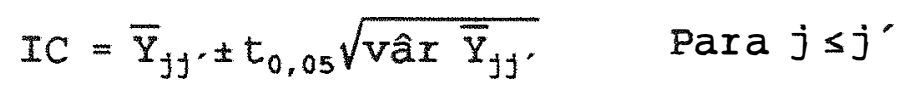


Sendo que var $\bar{Y}_{j j}$ é o erro da análise de variância preliminar dividido pelo número de repetições (variância residual ao nível de médias).

3.2.7. Correlação entre os Paråmetros dos Modelos e Capacidade Geral de Combinação do Dialélico Total (Experimento 1) e dos "Top Crosses" (Experimento 2)

As correlações entre os parâmetros estimados pelo modelo completo de GARDNER \& EBERHART (1967) usado no experimento 1 (dialélico total) e os parâmetros estimados pelo modelo reduzido de GARDNER (1967) usado no experimento 2 ("top crosses"), assim como entre as estimativas das capacidades gerais de combinação nos dois modelos foram feitas pelo coeficiente de correlação de spearman (não paramétrico) que se aplica a dados dispostos em "ranking", isto é, não é o valor dado que é considerado, mas sim o seu "ranking" em relação aos outros valores. Considerou-se esse procedimento válido pois normalmente a seleção é feita estabelecendo-se "rankings" para os dados (ou parâmetros) e escolhendo-se os maiores ou menores valores. 
A correlação de Spearman ( $r s$ ) tem a seguinte

expressão:

$$
r S=1-\frac{6 \sum\left(R_{1}-R_{2}\right)^{2}}{n\left(n^{2}-1\right)}
$$

onde:

$$
\begin{aligned}
\mathrm{n}= & \text { número de variedades } \\
\mathrm{R}_{1}= & \text { posição do valor ou parâmetro ("rank") no } \\
& \text { procedimento } 1 \text { (dialélico) } \\
\mathrm{R}_{2}= & \text { posição do valor ou parâmetro ("rank") no } \\
& \text { procedimento } 2 \text { ("top crosses") }
\end{aligned}
$$

De acordo com STEEL \& TORRIE (1960). 


\section{RESULTADOS}

\subsection{Análise da Variância Preliminar}

Foram feitas análises de variância preliminares dos três experimentos para cada um dos dois locais e também para os dois locais em conjunto para os dois caracteres estudados, isto é, produção e altura de planta. os resultados dessas análises encontram-se nas Tabelas 1, 2 e 3 para o experimento $1 ; 4,5$ e 6 para o experimento 2; 7, 8 e 9 para o experimento 3. Nessas tabelas encontram-se também os coeficientes de variação (cV\%) dos experimentos.

Os coeficientes de variação foram maiores no local 1 (Cascavel) para os dois caracteres estudados, embora as médias de produtividade (Tabelas 10 à 16) desse local tenham sido superiores, isso deveu-se à uma maior desuniformidade de solo desse local em relação ao local 2 (uberlândia), que embora menos fértil, sem dúvida é mais uniforme. Apesar disso, os coeficientes de variação obtidos no local 1 ainda são aceitaveis, variando de $15,03 \%$ à $19,38 \%$ 
para o caráter produção de grãos e de $4,88 \%$ à $7,66 \%$ para o caráter altura de planta.

A maior desun iformidade no local 1 também pode ser verificada pelo efeito de repetições nas análises individuais dos 3 experimentos, isto é, para o local 1 houve efeito significativo de repetições nos 3 experimentos para o caráter produção de grãos e nos experimentos 2 e 3 para o caráter altura de planta. Já no local só houve significância para efeito de repetições no experimento para - caráter produção e no experimento 2 para o caráter altura de planta.

Foram significativos os efeitos de tratamentos nos três experimentos nos dois locais, evidenciando-se assim a diversidade entre eles, o que era de se esperar, já que existem diferenças de origem e de depressão endogâmica pois as variedades são gerações F2 de híbridos de linhagens, o que torna suas médias bastante menores que a dos híbridos intervarietais. o efeito de tratamentos na análise preliminar foi decomposto em seus quatro efeitos constituintes, como fontes de variação: efeito de variedades, híbridos, testemunhas e grupos.

No local 1, o efeito de variedades não foi significativo nos 3 experimentos para o caráter produção de grãos, evidenciando uma uniformidade das variedades quanto ao seu comportamento "per se". Para o caráter altura de planta, não se detectou significância somente no experimento 1 que 
40.

pode ser explicada pelo maior erro experimental. No experimento 3, a significância do efeito de variedade pode ser explicada pelo aumento do número delas pela inclusão de um novo grupo (grupo 2), aumentando assim a diversididade entre elas para o caráter.

o efeito de híbridos só não foi significativo para o caráter produção no experimento 1 do local 1 , sendo nesse caso significativo para o caráter altura de planta, e para o caráter produção no experimento 2 do local 1 . No local 2 houve alta significância para efeito de híbridos nos 3 experimentos nos 2 locais, indicando diferenças entre eles, e como em alguns casos não houve significância para efeito de variedades, pode-se já na análise preliminar supor-se que a heterose deve ser importante para esses carateres.

Não houve detecção de significância para efeito de testemunhas para o caráter produção de grãos nos três experimentos e nos dois locais, o que é uma indicação de comportamento semelhante entre elas, embora o pequeno número de testemunhas ( 2 ou 3 ) dificulte a detecção de significância pelo baixo número de graus de liberdade no teste $F$. Para o caráter altura de planta, houve uma maior diferença no comportamento das testemunhas, com significância em todos os experimentos nos 2 locais à $5 \%$ ou à $1 \%$ de probabilidade à excessão do experimento 3 no local 2.

Como esperado, houve efeito altamente significativo de grupos nos dois locais e nos três 
experimentos, devido principalmente à grande diferença nos valores de médias para os dois caracteres estudados, diferença essa causada pela depressão endogâmica presente nas variedades e que não se apresenta nos híbridos, sendo que nestes a heterose presente está superestimada pela endogamia das variedades.

As análises conjuntas dos experimentos mostraram efeitos significativos de locais nos três experimentos para os dois caráteres estudados, o que já era de se esperar pois os dois locais onde os experimentos foram conduzidos diferem muito quanto às condições de clima e de solo, e, devido à distância geográfica $(1000 \mathrm{~km}$ no sentido da latitude), existem diferenças também de fotoperiodo.

Na análise conjunta os efeitos de tratamentos foram significativos para os três experimentos nos dois caracteres, para isso contribuindo os efeitos significativos de seus componentes: efeitos de variedades (que só não foi significativo para o caráter produtividade no experimento 1), hibridos e grupos (altamente significativos para os 2 caracteres nos três experimentos), sendo que o componente testemunhas só mostrou significância para altura de planta no experimento 1 .

A interação tratamentos $x$ locais não mostrou significância para os 2 caracteres no experimento 1 , sendo que nesse experimento, a decomposição desse efeito só mostrou significância ao nivel de $5 \%$ de probabilidade para a 
interação testemunhas $x$ locais para produção de grãos e de hibridos $x$ locais para altura de planta. No experimento 2 houve significância para efeito de tratamentos $x$ locais, principalmente em função da interação de grupos $x$ locais, para o caráter produção de grãos. Para altura de planta, não houve significância para efeito de tratamentos $x$ locais $e$ para nenhum de seus componentes. No experimento 3 houve significância de tratamentos $x$ locais para os dois carateres estudados, sendo que no caso da produção de grãos, a significância ao nível de $1 \%$ deveu-se principalmente ao componente hibridos $x$ locais que foi o único significativo. Para o caráter altura de planta só houve significância para o efeito de variedades x locais.

\subsection{Análise do Dialélico Completo, do "Top Cross" e do Dialélico Parcial}

\subsubsection{Produção no Local 1}

As médias de produtividade para os experimentos 1,2 e 3 encontram-se nas Tabelas 10,13 e 14, as respectivas ANAVA estão nas Tabelas 29,32 e 35 .

As ANAVA do dialélico completo (experimento 1) como mostrada na Tabela 29 mostrou significância para efeito de tratamentos e de heterose média $(\bar{h})$ para esse caráter, não 
havendo significância para efeito da variedades $\left(v_{j}\right)$, heterose de variedades $\left(h_{j}\right)$ e de heterose especifica $\left(s_{j^{j}}\right)$.

Já para os componentes do modelo de GARDNER \& EBERHART (1966), a não significância para efeito de variedades pode significar pouca diferença genética entre elas. Pode-se considerar que a diferença entre elas pode existir mas não foi grande o suficiente para ser detectada, devido ao alto erro associado à esse local. A significância para heterose média indica efeito de heterose, a não significancia para heterose de variedades indica que a heterose não varia muito entre os cruzamentos, distribuindose entre eles. Não se detectou efeito significativo de heterose especifica.

No experimento 2 , o modelo que despreza a heterose especifica chega aos mesmos resultados (Tabela 32 ), mostrando que a análise dos "top crosses" no lugar do dialélico não leva à perda de nenhuma informação relevante. No experimento 3 , baseado no modelo adaptado por MIRANDA FILHO \& GERALDI (1984), os resultados da ANAVA não podem ser comparados aos dos experimentos 1 e 2 pois trata-se de um novo grupo de variedades e hibridos entre elas. Na ANAVA do experimento 3 foi detectada significância para efeito de variedades (1) ao nivel de 5\% de probabilidade e para efeito de variedades (2) ao nivel de 1\% de probabilidade, indicando que houve diferenças entre variedades dentro de cada um dos grupos, embora a não significância para o componente "grupos" 
nos mostre que os dois grupos de variedades não são muito contrastantes para o caráter. Quanto aos componentes da heterose, só houve significância para efeito de heterose média, novamente indicando que houve uma distribuição dessa heterose entre os cruzamentos e pouca variação entre eles com relação à esse componente.

Os valores dos componentes de médias dos modelos utilizados estão representados nas Tabelas de 38 à 42 para os 3 experimentos. No caso do experimento 2 , o modelo não possui o componente Capacidade Especifica de Combinação $\left(s_{i j}\right)$, e nos outros dois modelos esse componente não tem significância, sugerindo que o modelo do experimento 2 é eficiente no presente caso, explicando toda a variação entre médias.

Os valores da heterose encontram-se nas Tabelas 25 (experimentos 1 e 2) e 26 (experimento 3 ). As heteroses médias foram de $27,4 \%, 35,7 \%$ e $23,7 \%$ para os experimentos 1,2 e 3 respectivamente com variação entre $-10,7 \%\left(H_{1.3}\right)$ à $64 \%\left(H_{1.6}\right)$ no experimento $1 ; 3,6 \%\left(H_{2.3}\right)$ à $74 \%$ $\left(H_{4,6}\right)$ no experimento 2 e de $-6,8 \% \quad\left(H_{10.1}\right)$ à $55 \%\left(H_{4.3}\right)$ no experimento 3 .

\subsubsection{Produção no Loca] 2}

As respectivas médias de produtividade ( $\mathrm{kg} / \mathrm{ha}$ ) para os experimentos 1,2 e 3 neste local estão nas Tabelas 
11,13 e 15. Os quadros das ANAVA para esses experimentos se encontram nas Tabelas 30,33 e 36 para os mesmos ensaios. Foi detectada significância para todos os componentes dos dois modelos empregados nos experimentos 1 e 2 , evidenciando que, nesse local, as variedades não constituem um grupo homogêneo, existe heterose ( $\bar{h}$ significativa) mas esta é variável entre os diversos cruzamentos ( $h_{j}$ significativa) e em pelo menos alguns cruzamentos existe heterose especifica importante ( $s_{j j}$ significativa) indicando que o uso do modelo reduzido do experimento 2 , resulta em perda de informação em alguns cruzamentos especificos.

No experimento 3 , não houve significância somente para heterose de variedades $\left(h_{j}\right)$ para nenhum dos 2 grupos de variedades envolvidos, indicando que a heterose não varia muito de cruzamento para cruzamento, embora a significância para a heterose especifica $\left(s_{i j}\right)$ sugira que em pelos menos alguns cruzamentos ela seja importante.

Os parâmetros componentes de médias dos modelos utilizados, para o local 2 estão representados nas Tabelas 39,40 e 42 .

As heteroses obtidas encontram-se nas Tabelas 25 e 26 e foram de $36,4 \%, 34,1 \%$ e $28,3 \%$ em média para os experimentos 1,2 e 3 respectivamente variando de $-1,5 \%\left(H_{7.9}\right)$ à $78 \%\left(H_{2.10}\right)$ no experimento $1 ;-7,3 \%\left(H_{2.9}\right)$ à $57,5 \%\left(H_{3.10}\right)$ no experimento 2 e de $-1,5 \%\left(H_{9.1}\right)$ à $74 \%\left(H_{3.8}\right)$ no experimento 3 . 


\subsubsection{Altura de Planta no Local 1}

As médias de altura de planta para os experimentos 1, 2 e 3 encontram-se nas Tabelas 17, 20 e 21 respectivamente, com base nessas tabelas foram feitas as ANAVA cujos quadros se encontram nas Tabelas 29,30 e 35 .

Novamente houve coincidência nesse local entre os procedimentos 1 e 2 com relação à significância dos componentes dos modelos, sendo que só houve significância para efeito de variedades e de heterose média, não havendo portanto perda de informações caso seja utilizado somente o modelo reduzido ("top crosses"), os resultados indicam portanto que embora o grupo de variedades seja homogêneo, existe heterose e que ela está distribuida de maneira equilibrada entre os cruzamentos.

No experimento 3 , a situação foi semelhante já que só não foi detectada a existência de significância para efeito de variedades e de heterose especifica. Os parâmetros componentes de médias dos modelos dos ensaios 1,2 e 3 encontram-se nas Tabelas 43,45 e 46 respectivamente.

As heterose obtidas encontram-se nas Tabelas 27 e 28 e em média foram de $4,9 \%, 4,1 \%$ e $4,4 \%$ para os experimentos 1,2 e 3 respectivamente com variação de $-4,3 \%$ $\left(H_{5.10}\right)$ à $13,0 \%\left(H_{5.7}\right)$ no experimento $1 ;-2,5 \%\left(H_{2.3}\right)$ à $9,5 \%\left(H_{7.8}\right)$ no experimento 2 e de $-3,2 \% \quad\left(H_{8.2}\right)$ à $14,9 \% \quad\left(H_{10.5}\right)$ no experimento 3 . 


\subsubsection{Altura de Planta no Local 2}

As médias dessa característica nesse local encontram-se nas Tabelas 18,20 e 22 para os experimentos 1 , 2 e 3 respectivamente. Os quadros das ANAVA correspondentes encontram-se nas Tabelas 30,33 e 36 e nelas pode-se observar que no experimento 1 só não houve efeito significante para o componente heterose de variedades $\left(h_{j}\right)$, o mesmo acontecendo no experimento 2. Nota-se que houve significância para heterose especifica $\left(s_{j j^{\prime}}\right)$ no experimento 1 , indicando que em pelo menos alguns cruzamentos ela é importante, informação que não é fornecida no experimento 2 que cujo modelo não a considera.

No experimento 3 , houve significância para todos os componentes do modelo, à excessão do componente grupos de variedades, indicando similaridade entre eles para esse caractere. Os parâmetros componentes de médias dos modelos nesse local encontram-se nas Tabelas 44,45 e 47 .

As heteroses obtidas encontram-se nas Tabelas 27 e 28 sendo em média 4,9\%, 2,4\% e 5,4\% para os experimentos 1,2 e 3 respectivamente variando de $-4,0 \%\left(H_{1.3}\right)$ à $20,5 \%\left(H_{5.7}\right)$ no experimento $1 ;-3,3 \%\left(H_{2.9}\right)$ a $8,0 \%\left(H_{4.5}\right)$ no experimento 2 e de $-6,5 \%\left(H_{1.6}\right)$ à $23 \%\left(H_{2.8}\right)$ no experimento 3 . 


\subsubsection{Análises Conjuntas}

Com o intuito de se avaliar as interações dos componentes dos modelos com os ambientes nos quais foram conduzidos os experimentos, foram feitas análises conjuntas de variancia baseadas nas médias dos 2 locais para os 2 caracteres estudados.

Os quadros das análi ses conjunt as encontram-se nas Tabelas 31,34 e 37 , a parte referente às interações dos componentes do modelo com os locais serão levados em consideração, já que a avaliação dos materiais com base em médias de locais tão distintos não é apropriada. Assim, no experimento 1, a significância para a interação variedades $x$ locais só foi verificada para altura de planta, indicando portanto que para produção, houve pouca interação com o ambiente, apesar destes serem bastante distintos. No experimento 2 , so houve significância para efeito de heterose média $x$ locais indicando que esse parâmetro foi afetado pelo ambiente, mas somente para o caráter produção.

No experimento 3 que compreendia um número maior de variedades, houve significância de efeito de variedades $(1) \times$ local, variedades $(2) \times$ local e de heterose média x local para o carater produtividade, indicando grande interação desse grupo de materiais com o ambiente para esse caráter. Para altura de planta, tivemos significância somente para variedades (2) x local e para heterose de 
variedades (1) $\times$ local, indicando que embora o grupo 2 de variedades tenha sido mais afetado pelo ambiente, o comportamento heterótico do grupo de variedades 1 foi mais afetado pelo ambiente que o do grupo 2. 


\section{DISCUSSÃO}

5.1. Uso de "Top Crosses" ao Invés de Dialélicos no Estudo de Variedades de Milho

Como já salientado, o presente trabalho tem dois objetivos principais, sendo o primeiro o de estudar o uso do modelo reduzido de GARDNER (1967) aplicado à cruzamentos "top crosses" de variedades ao invés de dialélicos completos que usam o modelo completo de GARDNER \& EBERHART (1966) no estudo de variedades de milho. Aproveitando-se os dados gerados e dispondo de dados de mais um dialélico parcial envolvendo as mesmas variedades em cruzamento com um segundo grupo delas, resolveu-se avaliar também esses materiais, isto é, gerações $F 2$ de híbridos comerciais, como fonte de germoplasma em programas de melhoramento de milho. Para tornar mais clara a discussão, esses objetivos serão abordados separadamente.

A substituição dos cruzamentos dialélicos completos (GARDNER \& EBERHART, 1966) por um sistema de cruzamentos em "top cross", usando o modelo reduzido de 
GARDNER (1967) facilitaria na prática a avaliação de materiais a serem usados em programas de melhoramento. De fato, em vez dos $n(n+1) / 2$ entradas ( $n$ variedades e $n(n-1) / 2$ cruzamentos) ter-se-ia $2 n$ entradas ( $n$ variedades e $n$ "top cross") no procedimento sugerido (CHAVES \& MIRANDA FILHO, 1993 e 1995) sendo assim possivel o uso de um número maior de repetições ou a avaliação de um número maior de variedades com os mesmos recursos.

CHAVES \& MIRANDA FILHO (1993, 1995) sugeriram - uso de "top crosses" em lugar de dialélicos para a análise da variância e estimação de parâmetros do modelo reduzido, também propuseram uma metodologia para a predição de compostos. Os autores usaram dados simulados de uma tabela dialélica, utilizando médias das linhas para representar as médias de "top crosses" e chegaram à resultados satisfatórios. Neste trabalho foi utilizada essa metodologia para o estudo de dez variedades obtidas a partir de híbridos comerciais. Para esse fim foram conduzidos os experimentos 1 e 2 envolvendo exatamente os mesmos materiais só mudando a forma de cruzamento, ou seja, dialélico completo no experimento 1 e "top cross" no experimento 2.

A metodologia sugerida se baseia no fato de na maioria dos trabalhos conduzidos com dialélicos de variedades não se ter encontrado significância para o componente de heterose específica (HALLAUER \& MIRANDA FILHO, 1988; VENCOVSKY, 1970). 
Analisando os quadros da ANAVA para cada local dos experimentos 1 (Tabelas 29 e 30) e 2 (Tabelas 32 e 33 ) verifica-se que existe equivalência quanto à significância dos componentes das médias nos dois experimentos, à excessão da heterose especifica que não aparece no modelo do experimento 2. Isso demonstra certa equivalencia entre os dois procedimentos; no entanto, tem-se que ter em consideração que a significância para a heterose específica do experimento 1 no local 2 para os dois caracteres estudados implica em sua importância em pelo menos alguns cruzamentos, informação esta que não é resgatada no sistema de cruzamentos de "top cross". A perda dessas informações não é tão importante quando o interesse é apenas em conhecer o potencial das variedades, mas torna-se importante, quando além disso busca-se também os melhores cruzamentos para uso em programas de obtenção de híbridos (intervarietais ou de linhagens provenientes dessas variedades), ou em programas de seleção recorrente recíproca, onde a deteç̧ão de cruzamentos que exibam uma maior heterose é importante. Pode-se sugerir no caso de se ter que avaliar um número grande de materiais, em uma primeira fase, selecionar-se por "top crosses" os melhores materiais por sua capacidade geral de combinação ( $\left.g_{j}\right)$ e após essa seleção fazer-se o dialélico entre os materiais selecionados, quando então pode-se escolner materiais também pela capacidade especifica de combinação $\left(s_{j j^{j}}\right)$. 
As tabelas de parâmetros componentes de médias para os dois caracteres estudados (Tabelas $38,39,40,43,44$ e 45) mostram que existe uma boa correlação (Spearman) entre as duas metodologias no que se refere aos valores e "ranking" desses parâmetros $\left(\hat{v}_{j}, \hat{h}_{j}\right.$ e $\left.\hat{g}_{j}\right)$, como pode ser observado na Tabela 48, indicando que as informações tomadas com base no "top cross" não são discrepantes em relação ao dialélico completo, pelo contrário, a possibilidade do uso de um número maior de repetições proporcionariam informações mais precisas quanto à esses parâmetros em relação ao próprio dialélico. Com relação à heterose média (Tabelas 38, 39 e 40), observase também equivalência entre os dois procedimentos. Portanto, ao selecionar as melhores ou piores variedades com base nos parâmetros componentes dos modelos, as duas metodologias tem resultados semelhantes, principalmente no local 2 onde o erro experimental foi menor. Deve-se observar que se fossem incluidas as variedades, híbridos intervarietais e "top crosses" no mesmo experimento, essas correlações seriam sem dúvida maiores pois não haveria interferência do ambiente (solo) entre os experimentos.

Quanto às heteroses observadas nos dialélicos $\left(h_{j j}=\bar{h}+h_{j}+h_{j}+s_{j j}\right)$ e as heteroses preditas nos "top crosses" $\left(h_{j j}^{*}=\bar{h}+h_{j}+h_{j^{\prime}}\right)$ observa-se nas Tabelas 25 a 28 que existe pouca correspondência entre elas; isto é, quando há interesse em cruzamentos especificos, deve-se recorrer aos 
dialélicos e não ao "top cross" já que esse não permite a identificação dos híbridos mais heteróticos. Uma boa indicação da importância da heterose específica para o caráter produção surge quando comparam-se as tabelas de médias de produção com as tabelas de parâmetros dos experimentos 1 e 3 que incluem o componente heterose especifica (Tabelas 11 e 38, 19 e 39 para o ensaio 1; 14 e 41, 15 e 42 para ensaio 3), verifica-se que os híbridos mais produtivos tem heteroses especificas positivas e altas enquanto os hibridos menos produtivos tem heteroses especificas negativas e altas. Conclui-se então que, pelo menos para os materiais usados nesse estudo, a heterose especifica tem uma grande importância como componente da média dos híbridos. Para o caráter altura de planta (Tabelas 17 e 43, 18 e 44 para o experimento 1; 21 e 46, 22 e 47 para - experimento 3) a tendência é a mesma, embora a correspondência entre a heterose especifica e a média do caráter não seja tão grande, isso devendo-se ao fato do caráter não apresentar uma heterose tão alta como para a produção de grãos.

A heterose especifica não tem influência na seleção de uma variedade pela sua capacidade geral de combinação $\left(\hat{g}_{j}\right)$ pois esse parâmetro se baseia no efeito de variedades $\left(\hat{v}_{j}\right)$ e heterose de variedades $\left(\hat{h}_{j}\right)$ isto é; $\hat{g}_{j}=1 / 2$ $\hat{v}_{j}+\hat{h}_{j}$. Da mesma forma, para a sintese de compostos, na 
fórmula utilizada para a predição de médias (CHAVES \& MIRANDA FILHO, 1993, 1994):

$$
Y_{c o}=\hat{\beta}+\frac{1}{K} \sum_{J=1}^{K} \hat{v}_{J}+\frac{K-1}{K} \hat{\bar{h}}+\frac{2(K-1)}{K^{2}} \sum_{J=1}^{K} \hat{h}_{J}+\frac{2}{K^{2}} \sum_{J\langle J}^{K} s_{J J^{\prime}}
$$

- componente heterose especifica $\left(s_{j j^{\prime}}\right)$ tem muito pouca importância pois é dividido por $k^{2}$; assim, à medida que aumenta o tamanho do composto $(k)$ a somatória tende à 0 , sendo que no composto amplo (incluindo todas as variedades) e nos compostos de tamanho $n-1$, a somatória é 0 .

Conclui-se então que o uso de "top crosses" pode ser bastante út il dependendo dos objetivos dos programas de melhoramento, isto é, se o objetivo é conhecer as variedades no que diz respeito à capacidade geral de combinação e estimação de parâmetros para a predição de compostos o procedimento é válido. Por outro lado, se houver a necessidade de escolher os cruzamentos mais heteróticos entre as variedades para uso direto em hibridos intervarietais, programas de seleção recorrente recíproca, ou como fonte de linhagens usando desde o inicio informações sobre combinações especificas, deve-se recorrer aos dialélicos completos ou parciais (desde que a combinação desejada esteja presente), principarmente se os materiais forem altamente heteróticos como os utilizados neste estudo. 
5.2. Avaliação do Uso de Gerações F2 de Híbridos Comerciais como Fonte de Germoplasma em Programas de Melhoramento

\subsubsection{Com Base nos Parâmetros do Modelo de GARDNER \& EBERHART e Adaptações}

5.2.1.1. Produção de Grãos no Local 1

Com relação aos parâmetros dos modelos, para - caráter produção no local 1, a ANAVA do dialélico do experimento 1 (Tabela 29) acusou significância somente para - componente heterose média $(\bar{h})$, isso significa que as variedades não diferem muito quanto ao seu valor "per se". Existem duas explicações possiveis para a não significância do componente variedades $\left(v_{\mathbf{j}}\right)$ nesse local: ou a precisão experimental não permitiu uma discriminação das variedades, já que o erro experimental associado à esse local foi relativamente alto, ou as variedades realmente se equivalem nesse ambiente, implicando nesse caso que cada uma delas possua uma quantidade equivalente de alelos favoráveis, alelos esses que devem estar em locos diferentes em cada uma delas, pois a não significância da heterose de variedades e da heterose especifica mostra que a heterose se distribui uniformemente entre os cruzamentos. No experimento 2 (Tabela 32) que usa um modelo que não inclui a heterose 
especifica, os outros componentes se comportam da mesma maneira, valendo aqui as mesmas observações.

Não se encontrou na literatura consultada nenhum trabalho usando o modelo de GARDNER \& EBERHART (1966) em que o componente variedades não tivesse acusado significância. No presente caso, nesses dois experimentos no local 1, a falta de precisão experimental pode ter influenciado bastante, mas deve-se considerar também que as médias dessas variedades foram relativamente baixas pelo efeito de depressão endogâmica, o que dificultou a detecção de diferenças entre elas. Isso pode ser verificado quando se decompõe a soma de quadrados da ANAVA e onde $10 \%$ da soma de quadrados ( $S Q$ de tratamentos) foi devida à efeitos de variedades e 90\% foi devida a efeito de heterose. No experimento 2, essa proporção é de 11 e $89 \%$ respectivamente, esses dados estão em completo desacordo com a literatura onde a maioria dos trabalhos mostra uma proporção de aproximadamente 1:1 (GARDNER, 1967 e MIRANDA F.ILHO, 1974), ou efeitos maiores de variedades como nos trabalhos de GARDNER \& PATERNIANI (1967) e CARVALHO (1980), devendo-se isso sem dúvida à diferença de base genética entre os materiais usados,

Para o experimento 3 usou-se um modelo adaptado por MIRANDA FILHO \& GERALDI (1984) para dialélicos parciais. Esse modelo é apropriado quando não há interesse no cruzamento de todas as variedades entre si, mas somente 
entre grupos de variedades; isso é o que geralmente acontece quando já se dispõe de um programa de melhoramento em andamento e/ou grupos heteróticos já definidos, ou ainda quando "à priori" o material disponivel é dividido em dois ou mais grupos tais como: dentado $x$ flint, alto $\times$ baixo, precoce $x$ tardio, adaptado $x$ exótico, etc, no presente caso foram identificados dois grupos: variedades provenientes de híbridos comerciais e variedades provenientes de hibridos experimentais. Como nesse caso não houve cruzamentos entre materiais de uma mesma empresa, que podem ter 1 inhagens comuns, esperava-se que a heterose observada fosse maior que nos experimentos anteriores, fato esse que não ocorreu, mostrando que a divergência entre os dois grupos de variedades não é tão grande, o que foi confirmado pela ANAVA (Tabela 35) que não detectou significância para efeito de grupos. O efeito de variedades nesse experimento mostrou significância à 5\% para o grupo I e à $1 \%$ para o grupo II, havendo portanto diferenças entre as variedades, podendo-se concluir que existem diferenças gênicas para o caráter. Quanto à heterose, novamente se detectou significância para heterose média, indicando que a heterose está distribuida entre os cruzamentos, isto é, cada variedade possui um pequeno número de alelos favoráveis em diferentes locos de modo que o cruzamento 2 à 2 entre elas não leva à híbridos muito diferentes entre sí no que diz respeito à produção de grãos. 
Os parâmetros componentes de médias para o caráter produção no local 1 (Tabelas 38, 40 e 41) incluem a capacidade geral de combinação $\left(g_{i}\right)$ das variedades dando uma melhor idéia do valor intrínseco de cada variedade pois ele é calculado com base nos valores de $v_{i}$ (efeito de variedades) e de $h_{i}$ (heterose de variedades) tornando assim mais segura a escolha de determinadas variedades pelo seu valor próprio. CARDOSO (1980) trabalhou com um dialélico de 20 variedades e com base na capacidade geral de combinação escolheu as 10 melhores e seus cruzamentos para a predição de compostos. No presente trabalho, se fosse usado esse indice para se escolher as melhores variedades nesse local, no experimento 1 escolheria-se as variedades $V 4, V 5$ e $V 6$, no experimento 2 as variedades $V 4, V 6$ e $V 9$ e no experimento 3 as variedades $V 1, V 3$ e V4 no grupo I e E3, E4 e E8 no grupo II.

\subsubsection{Produção de Grãos no Local 2}

Nesse local os experimentos foram mais precisos, e houve deteção de significância para todos os componentes dos três modelos usados (Tabelas 30,33 e 36 ) à excessão dos efeitos de heterose de variedades do grupo I e I I no experimento 3 . Isso indica que houve diferenças entre as variedades, que houve heterose e que as variedades diferem entre sí quanto ao seu potencial heterótico dentro do grupo I (experimentos 1 e 2) mas não diferem quanto ao seu 
60.

potencial heterótico quando cada uma delas é cruzada com o grupo II e vice-versa, como demonstrado no experimento 3 (Tabela 36). A significancia do efeito de heterose especifica nos três experimentos significa que em pelo menos alguns cruzamentos o efeito de heterose especifica é importante. Essa heterose especifica é gerada por diferentes niveis de complementação gênica nos híbridos, ou pelo menos em alguns deles. No caso do experimento 2 , onde a heterose especifica não é determinada, essas informações seriam perdidas como já foi discutido.

Quanto à significância dos componentes, os resultados do experimento 1 concordam com os trabalhos de HALLAUER \& SEARS (1968), TROYER \& HALLAUER (1968), EBERHART (1971) e HALLAUER (1972) que detectaram significância para todos os componentes do mode10. Quanto ao experimento 2, trata-se de uma metodologia inédita mas a significância dos componentes do modelo também está de acordo com os trabalhos citados acima. No experimento 3, não se encontrou nenhum trabalho na literatura onde a heterose de variedades não tenha sido significativa ao mesmo tempo que a heterose especifica foi significativa.

A decomposição da soma de quadrados de tratamentos no local 2 mostra que os efeitos de variedades e heterose foram de 33 e $67 \% ; 14$ e $86 \% ; 55$ e $45 \%$ para os experimentos 1,2 e 3 respectivamente, sendo que somente 0 experimento 3 apresentou resultados semelhantes aos obtidos 
por GARDNER (1967) e MIRANDA FILHO (1974), devendo-se isso à menor heterose observada nesse experimento em relação aos outros.

Quanto à capacidade geral de combinação (Tabelas 39,40 e 42) as melhores variedades foram V4, V6 e V8 no experimento $1, \vee 4, \quad \vee 5$ e $\vee 8$ no experimento 2 , e no experimento 3 foram $V 4, V 6$ e $V 8$ no grupo $I$ e $E 4$, E6 e E8 no grupo II.

\subsubsection{Altura de Planta no Local 1}

Todas as ANAVA para esse caractere nesse local (Tabelas 29, 32 e 35) nos três modelos detectaram efeito de variedades e heterose média, sendo que não houve significancia para heterose de variedades e de heterose especifica indicando que existem diferenças entre as variedades para o caráter, bem como heterose no cruzamento entre elas, sendo que essa heterose se distribui uniformemente entre os cruzamentos. No experimento 3 houve significância para efeito de grupos indicando divergência entre eles para o caráter. Resultados semelhantes não foram encontrados na literatura.

A decomposição de soma de quadrados de tratamentos nesse local mostrou que $61 \%$ da variação para esse caráter foi por efeito de variedades e 39\% por efeito de heterose no experimento 1,84 e $16 \%$ no experimento 2 , e 50 e 
50\% no experimento 3 , valores esse que estão em desacordo com a maioria dos trabalhos anteriores, já que se esperava um efeito de heterose menor. Vale aqui a mesma explicação dada com relação ao caráter produção, isto é, a endogamia presente nas variedades diminuiu as médias do caráter e superestimou a heterose. As proporções encontradas no experimento 2 são semelhantes às encontradas por MIRANDA FILHO (1974) no grupo I de variedades estudadas por esse autor.

Com relação à seleção de variedades para um programa de melhoramento, para o caráter altura de planta, haveria a necessidade de se escolher as variedades com menor altura e com menor capacidade de combinação para o caráter, já que normalmente se procura materiais mais baixos, assim no experimento 1 (Tabela 43) selecionar-se-iam as variedades V2, V8 e V10; no experimento 2 (Tabela 44), V2, V5 e V10, e no experimento 3 (Tabela 46), V2, V5 e V8 no grupo I e E1, E5 e E8 no grupo II.

\subsubsection{Altura de Planta no Local 2}

As ANAVA referentes à esse caractere nesse local encontram-se nas Tabelas 30,33 e 36 para os experimentos 1,2 e 3 respectivamente e indicam significância para efeito de variedades nos 3 experimentos havendo portanto diferenças entre elas para esse caráter, os 3 experimentos acusaram significância para heterose média indicando portanto 
sua presença na maioria dos cruzamentos. Para o efeito de heterose de variedades os experimentos 1 e 2 não acusaram significância, implicando num potencial heterótico uniforme entre as variedades, já no experimento 3 , onde um novo grupo de variedades foi incluido, houve efeito significativo desse componente para os dois grupos de variedades, indicando que cada uma delas difere da outra quanto ao seu potencial heterótico quando em cruzamento com as variedades do outro grupo. Com relação à heterose especifica, ela foi significativa nos dois experimentos cujos modelos à levam em consideração (experimentos 1 e 3 ), isso indica que pelo menos alguns cruzamentos entre as variedades exibem um componente de heterose especifica importante.

A decomposição da soma de quadrados de tratamentos para altura de planta para o experimento 1 no local 2 indica que $61 \%$ foi devido ao efeito de variedades e $39 \%$ devido à heterose, no experimento 2 tivemos 93 e $7 \%$, e no experimento 3, 55 e 45\%, sendo que só no caso do experimento 2 os dados se aproximam dos valores encontrados por CASTRO et a 1 (1968) e MIRANDA FILHO (1974).

Com relação às variedades selecionadas com base na capacidade geral de combinação (Tabelas 44, 45 e 47 ) nesse local são $\vee 2, V 7$ e $\vee 9$ no experimento $1 ; \vee 2, \vee 8$ e $\vee 9$ no experimento 2 , e no experimento 3 são $\vee 2$, $\vee 5$ e $\vee 7$ para o grupo I e E2, E4 e E8 para o grupo II. 
64.

\subsubsection{Avaliação dos Materiais Quanto ao seu} Potencial Heterótico

Um programa de obtenção de híbridos de qualquer espécie só tem sucesso se esse híbrido tiver performance nitidamente superior ao pai mais produtivo em um ou mais caracteres importantes economicamente. Assim, num programa de melhoramento é de suma importância a identificação de divergência genética entre os materiais: MOLL et al (1962) e MOLL et al (1965) constataram grande relação entre heterose e divergência genética, isto é, concluiram que quanto maior a heterose em um cruzamento, maior a divergência genética entre os materiais que o constituem. A heterose é, portanto, função das diferenças de frequências gênicas entre as populações nos locos que apresentam algum grau de dominância. CRESS (1966) concluiu que a ausência de heterose não implica necessariamente na falta de divergência genética, pois se os efeitos de dominância não forem unidirecionais em grande parte dos locos, pode ocorrer compensação de efeito entre locos e portanto ausência de heterose.

A presença de heterose indica divergência genética e nesse sentido, os resultados de heterose encontrados nesse trabalho indicam uma grande divergência entre os materiais, o que é um indicativo do grande potencial deles para uso em programas de melhoramento comerciais, visto 
que essa diversidade pode ser usada na sintese de populações base para melhoramento (compostos), populações essas que vão possuir uma grande variabilidade genética, ou 0 aproveitamento direto de informações de cruzamentos especificos em programas de seleção recorrente recíproca.

Como já relatado, no local 1, para produção tivemos heteroses de $-10,7$ à $78,1 \%$ com heterose médias de $27,4,35,7$ e $23,7 \%$ para os experimentos 1,2 e 3 respectivamente. No local 2 a variação foi de $-7,3$ à $78,1 \%$ com heteroses médias de $36,4,34,1$ e $28,3 \%$ para os mesmos experimentos (Tabelas 25 e 26). Essas heteroses médias são superiores às normalmente encontradas na literatura como se verifica nos trabalhos de EBERHART (1971), HALLAUER (1972), MIRANDA FILHO (1974), CARVALHO (1980), SOUZA JR. (1981), DELBONI (1989) entre outros, sendo que todos esses autores usaram em seus estudos variedades de polinização livre. Como já destacado, neste trabaino foram usadas gerações F2 de hibridos comerciais que possuem uma base genética muito mais estreita e portanto com um grande efeito de depressão endogâmica, que reduziu bastante a média dos materiais aumentando assim a heterose dos cruzamentos. Uma indicação do efeito da endogamia sobre a média das variedades pode ser dada pela média das variedades 1,2 e 3 em relação aos hibridos que lhes deram origem isto é G-551, G-85 e G-500 respectivamente que são as testemunhas dos experimentos. Assim verifica-se que na média dos 2 locais (Tabela 12) houve 
uma redução de $28,12 \%$ na produtividade. Essa redução é bastante grande e dá uma idéia do quanto a geração $F 2$ perde em relação à semente comercial; redução da mesma ordem de magnitude foram relatadas por MARTIN \& HALLAUER (1976).

A superestimação da heterose não prejudica no entanto a avaliação da divergência genética entre os materiais em estudo, que foi maior que a esperada uma vez que foram usados nos experimentos 1 e 2 gerações F2 de 10 hibridos comerciais de apenas cinco companhias diferentes, esperando-se que houvessem materiais comuns não somente dentro de híbridos da mesma companhia (linhagens comuns à diferentes hibridos), mas também pouca divergência entre companhias devido ao uso de germoplasma semelhante. No entanto, os niveis de divergência evidenciados pela heterose nos levam a crer que não só essas empresas trabalham com materiais bastante distintos, como também comercializam hibridos de linhagens com diferentes origens entre os hibridos, isso torna os materiais comerciais bastante atrativos como fonte de germoplama pela possibilidade que eles oferecem de se trabalhar com grande variabilidade genética. Deve-se destacar aqui que parte da variabilidade genética aqui detectada deve-se também ao pequeno tamanho efetivo da amostra (poucas 1 inhagens) do germoplasma em cada híbrido, o que pode ter causado efeitos de deriva, aumentando assim a diversidade entre os materiais. No experimento 3 , além das mesmas 10 variedades dos experimentos 1 e 2 que se 
constituem no grupo I de variedades do dialélico parcial, o grupo I I se constituiu também de gerações f2 de híbridos experimentais da EMBRAPA, a heterose média obtida nesse experimento foi em média menor que a dos experimentos anteriores, indicando que existe menos divergência entre os 2 grupos de variedades que dentro do próprio grupo I, fato que também é demonstrado pela falta de significância para o componente "grupos" na ANAVA no local 1 e significância somente à $5 \%$ no local 2. Mesmo assim, as heteroses obtidas nos cruzamentos entre os dois grupos de variedades foram bastante altas, mostrando que existe potencial na sua exploração, havendo chance de se selecionar as melhores variedades dentro de cada grupo com base de seu comportamento em cruzamentos intergrupos dando assim origem à diferentes grupos heteróticos.

Quanto ao caráter altura de planta, as heteroses obtidas variaram de $-4,3$ à $24 \%$ nos 3 experimentos, sendo que as heteroses médias no local 1 foram de 4,$9 ; 4,12$ e 4,4\% e 4,9;2,4 e 5,4\% no local 2 (Tabelas 27 e 28), sendo esses valores médios somente um pouco superiores aos encontrados na literatura, como por exemplo nos trabalhos de PATERNIANI (1970), BARRIGA \& VENKO VSKY (1973), MIRANDA FIL HO (1974), SO UZA JR. (1981), entre outros. Embora aqui também a heterose seja um indicativo de divergência genética, na prática procuram-se materiais que exibam pouca ou nenhuma 
68.

heterose para o caráter, já que os cultivares modernos de milho devem ser preferencialmente de porte baixo.

Com relação à detecção dos híbridos mais heteróticos pelos três experimentos, verificou-se pouca coincidência entre os experimentos 1 e 2 que envolveram os mesmos materiais mas em sistemas de cruzamentos diferentes (dialélico completo para o experimento 1 e "top crosses" para o experimento 2), assim, nos experimentos 1 e 2 conseguiu-se detectar as melhores variedades em cruzamentos gerais (capacidade geral de combinação) como já discutido anteriormente, mas só o experimento 1 pode dar informações confiáveis sobre cruzamentos específicos entre grupos já que o modelo inclui o componente heterose especifica $\left(s_{i j}\right)$. Como já se concluiu que no presente caso a heterose serve mais como indicador de divergência genética, não se dará ênfase à seleção dos materiais com base na heterose apresentada, sendo mais conveniente a seleção de materiais em comparação com testemunhas ou com base nos parâmetros dos modelos empregados.

Com relação aos valores negativos de heterose observados em alguns cruzamentos, todos eles não são significativos o que indica na prática, ausência de heterose, como já era esperado, principalmente quando houve o cruzamento de materiais de uma mesma empresa e que provavelmente tem parentesco (1 inhagens comuns ou mesmo germoplasma de origem), sendo que em alguns deles pode ter 
ocorrido endogamia devido à base genética bastante estreita do material.

Outro aspecto à considerar é o comportamento da heterose nos dois locais onde foram conduzidos os experimentos. No local 1 o caráter produtividade teve maior expressão e o caráter altura menor. No local 2 aconteceu o contrário; as Tabelas 10 à 23 mostram que houve uma tendência a uma maior heterose nos locais menos favoráveis à média do caráter. Esse fato confirma outros trabalhos da literatura como o de SAVELLI GOMES (1991), indicando que a heterose aumenta a estabilidade dos materiais, explicando assim a maior estabilidade dos híbridos em relação aos pais.

\subsubsection{Avaliação do Potencial dos Materiais com Base na Comparação com as Testemunhas}

o comportamento heterótico que aparece em determinados cruzamentos, como já discutido anteriormente, é uma indicação de divergência genética entre os pais. Essa divergência pode ser usada pelo melhorista de duas maneiras distintas, ele pode usá-la para gerar variabilidade por autofecundação do híbrido, ou pode optar por manter os parentais separados e explorar a heterose. Os dois processos não são antagônicos, mas sim complementares, uma vez que quase sempre não se trabalha em um programa de melhoramento somente com dois materiais, mas sim com uma série deles, 
sendo que na prática procura-se a formação de grupos heteróticos, agrupando materiais em dois ou mais grupos dentro dos quais se procura aumentar a variabilidade e a média, e, nos cruzamentos entre grupos heteróticos procura-se aumentar a média através do aumento da heterose.

No entanto, variabilidade e heterose sozinhos nem sempre podem dar uma indicação segura do potencial de um material, sendo que para finalidades comerciais a média do caráter é de grande importancia pois podem existir cruzamentos altamente heteróticos com médias relativamente baixas, o que é bastante comum em milho quando são cruzados materiais não melhorados. Torna-se então de grande conveniência a inclusão de testemunhas nos ensaios de avaliação de produtividade, para que haja um padrão de comportamento conhecido quando existe interesse em materiais a serem incorporados em programas de melhoramento comerciais. Como pode-se verificar pelos resultados dos ensaios, para o caráter produção (Tabelas $11,12,21,31$ e 32) muitos híbridos intervarietais estão no mesmo nível de produtividade das testemunhas em todos os ensaios, esse fato permite afirmar que esses materiais tem um grande potencial para aproveitamento em programas de melhoramento que $v i$ sem produtividade, já que as testemunhas são híbridos de relativo sucesso no mercado com relação à esse caráter. Como o híbrido intervarietal representa o comportamento médio de todos os hibridos simples entre todas as linhagens que possam 
vir a ser extraidas das duas variedades parentais, verificase que pode-se selecionar hibridos simples, triplos ou duplos entre linhagens provenientes dessas variedades com um potencial de produtividade bastante superior aos hibridos intervarietais e consequentemente também às testemunhas.

Quanto ao caráter altura de planta, verificase que os híbridos intervarietais estão no mesmo nivel que as testemunhas (Tabelas 13, 14, 21, 33 e 34), não havendo indicação de que haverá elevação de altura dos híbridos intervarietais em relação às testemunhas, sendo que por seleção pode-se inclusive produzir híbridos de linhagens ou intervarietais mais baixos que essas testemunhas.

Como exemplo, no experimento 1 no local 1 pode-se selecionar os hibridos $H_{2.5}, H_{1.8}, H_{3.8}, H_{4.8}, H_{7.8}$ e $H_{3.10}$; no mesmo experimento no local 2 os hibridos $H_{2.4}, H_{5.4}, H_{5.8}$ e $H_{5.10}$; no experimento 3 no local 1 os híbridos $H_{3.1}, H_{2.2}, H_{3.2}$, $H_{10.3}, H_{1.4}, H_{4.4}, H_{9.4}, H_{1.5}$ e $H_{2.5}$ e no local 2 os híbridos $H_{4.4}, H_{7.8}$ e $H_{10.8}$, todos com uma média de produtividade igual ou superior as testemunhas e altura de planta igual ou inferior as mesmas. 


\section{CONCLUSÕES}

- O sistema em cruzamentos em "top crosses" pode ser usado no lugar de dialélicos quando existe interesse em selecionar variedades pelos componentes do modelo, e/ou pela sua capacidade geral de combinação ou ainda para a determinação de parâmetros que vão ser usados na sintese de compostos onde a capacidade específica de combinação não tem muito efeito. Se o objetivo for identificar alguns cruzamentos específicos dentro de um grupo de variedades, deve-se recorrer aos sistemas tradicionais de cruzamentos dialélicos, principalmente quando se prioriza a produtividade, que é um caráter que possui um componente heterose especifica bastante importante.

- Os hibridos comerciais mostraram-se fontes muito boas de germoplasma para programas de melhoramento comerciais e não devem ser desprezados principalmente quando se possui um programa ainda em sua fase inicial e as fontes de caracteres importantes são escassas no germoplasma disponivel. 


\section{REFERÊNCIAS BIBLIOGRÁFICAS}

ANAND, I.J. \& MURTHY, B.R. Serial analysis of combining ability on diallel and fraccional diallel cross in lineseed. Theorethical and Applied Genetics, Berlin, 39: $88-94,1969$.

BARRIGA, P. \& VENCOVSKY, R. Heterose da produção de grãos e de outros caracteres agronômicos em cruzamentos intervarietais de milho. Ciência e Cultura, São Paulo, 25: $880-5,1973$.

BDLIYA, P.M. \& BURRIS, J.S. Diallel analysis of drying injury in seed corn. Crop Science, Madison, 28: 935-8, 1988 .

BENZANILLA, G.P.B. A eficiência de alguns cultivares de milho (Zea mays L.) na produção de grãos. Piracicaba, 1971. 84p. (Mestrado - Escola Superior de Agricultura "Luiz de Queiroz"/USP). 
BORGES F., O.L. Diallel analysis of maize resistance to sorghum downy mildew. Crop Science, Madison, 27: 178-80, 1987.

BRAY, R.A. Quantitative evaluation of the circulant partial diallel cross. Heredity, London, 27: 189-202, 1971.

BROWN, W.L. Broader germplasm base in corn and sorghum. In: Annual corn and sorghum research conference, 1975. Proceedings, $30: 81-9$.

CALLAWAY, M.B.; SMITH, M.E.; COFFMAN, W.R. Diallel analysis of resistance to anthracnose stalk rot in maize imbreds. Crop Science, Madison, 30: 335-7, 1990.

CARVALHO, H.W.L. Predição de compostos de milho (Zea mays L.) para a microregião homogênea 131 do estado da Bahia. Piracicaba, 1980. 112p. (Mestrado - Escola Superior de Agricultura "Luiz de Queiroz"/USP).

CHAVES, L.J. \& MIRANDA FILHO, J.B. Predicting variety composite means without diallel crossing. XVII Int. Congress of Genetics. Birmingham (U.K.). Abstrats. p. 227 . 
CHAVES, L.J. \& MIRANDA FILHO, J.B. Predicting variety composite means without diallel crossing. 1995 (no prelo).

CRESS, C.E. Heterosis of the hybrid related to gene frequency diffences between two populations. Genetics, New York, 53: 269-74, 1966.

DELBONI, J.S.; SILVA, J.C.; CRUZ, D.C.; SILVA, C.H.O: Análise de cruzamentos dialélicos entre variedades de milho braquítico-2, usando o método de Gardner e Eberhart. Revista Ceres, Viçosa, 36(206): 365-72, 1989.

DUDLEY, J.W.; LAMBERT, R.J.; DE LA ROCHE, I.A. Genetis analysis of crosses among corn strains divergently selected for percent oil and protein. crop science, Madison, 17: 111-7, 1977 .

EBERHART, S.A. Regional maize diallels with U.S. and semi exotic varieties. Crop Science, Madison, 11: 911-4, 1971.

GAITAN, M.A.G.; MENDOZA, H.M.; WATHICA, E.N.; GARDNER, C.O.; GARCIA, M.O.; HALLAUER, A.R.; DARRAH, L.L. Testcross evaluation of Mexican maize populations. Crop Science, Madison, 26: 99-104, 1986. 
GARDNER, C.O. Teoria genética estatistica aplicada a las médias de variedades, sus cruces y poblaciones afines. Fitotecnia Latinoamericana, Caracas, 2: 11-22, 1965.

GARDNER, C.O. Simplified methods for estimating constants and computing sums of squares for diallel cross analysis. Fitotecnia Latinoamericana, Caracas, 4: 1-12, 1967.

GARDNER, C.O. \& PATERNIANI, E. A genetic model used to evaluate the breeding potential of open polinated varieties of corn. Ciência e cultura, São Paulo, 19: 95-101, 1967.

GERALDI, I.D. \& MIRANDA FILHO, J.B. Adapted models for the analysis of combining ability of varieties in parcial diallel crosses. Revista Brasileira de Genética, Ribeirão Preto, 11: 419-30, 1988 .

GERRISH, E.E. Indications from a diallel study for interracial maize hybridization in the corn Belt. crop Science, Madison, 23: 1082-4, 1983.

GONÇALVES, P.S. Esquema circulante de cruzamentos para avaliação de linhagens de milho (Zea mays L.) ao nível interpopulacional. Piracicaba, 1987. 140p. (Doutorado Escola Superior de Agricultura "Luiz de Queiroz"/USP). 
GOODMAN, M.M. Exotic maize germplasm: status, prospects and remedies. Iowa State Journal of Research, Ames, 59: $4497-527,1985$.

GREEN, J.M. Inheritance in combining ability in maize hybrids. Journal of American Soc. Ames, 40: 58-63, 1948.

GRIFFING, J.B. Analysis of quantitative gene action by constant parent regressions and related techniques. Genetics, New York, 35: 303-21, 1950.

GRIFFING, B. A generalized treatment of the use of diallel crosses in quant itative inheritance. Heredity, Edinburgh, 10: 31-50, 1956a.

GRIFFING, B. Concept of general and specific combining ability in relation to diallel crossing systems. Australian Journal of Biological Sciences, 9: 463-93, $1956 b$.

HALLAUER, A.R. Breeding methodologies for temperate maize. In: BRANDOLINI, A. \& SALAMINI, F., ed. Breeding strategies for maize production improvement in the tropics. 1985. $457 p$. 
HALLAUER, A.R. Compendium of recurrent selection methods and their application. CRC Critical Review in Plant Sciences, $3(1): 1-33,1089$.

HALLAUER, A.R. \& EBERHART, S.A. Evaluation of synthetic varieties of maize for yield. Crop Science, Madison, 6: 423-7, 1966.

HALLAUER, A.R. \& MIRANDA FILHO, J.B. Quantitative genetics in maize breeding. 2.ed. Ames, Iowa State University Press, 1988. 468p.

HALLAUER, A.R. \& SEARS, J.H. Mass selection for yield in two varieties of maize. Crop Science Madison, 9: 47-50, 1969 .

HAMMOND, J.J. \& GARDNER, C.O. Modification of the variety cross diallel model for evaluating cycles of selection. Crop Science, Madison, 14: 6-8, 1974.

HAYMAN, B.I. The analysis of variance of diallel tables. Biometrics, Tallahasee, 10: 235-44, 1954 a.

HAYMAN, B.I. The theory and analysis of diallel crosses. Genetics, New York, 39: 788-809, 1954b. 
HULL, F.H. Recurrent selection for specific combining ability in corn. Agronomy Journal, Madison, 37: 134-45, 1945.

JINKS, J.L. The analysis of continuous variation in a cross of Nicotiana rustica varieties. Genetics, New York, 39: $767-88,1954$

JINKS, J.L. A survey of genetics basis of heterosis in a variety diallel crosses. Heredity, Edinburgh, 9: 223-38, 1955

JINKS, J.L. \& HAYMAN, B.I. The analysis of diallel crosses. Maize Genetic Cooperation Newsletter, 27: 48-54, 1953.

KEMPTHORNE, O. \& CURNOW, R.N. The partial diallel cross. Biometrics, Tallahasee, 17: 229-50, 1961.

MARTIN, J.M. \& HALLAUER, A.R. Relation between heterozygosis and yield for four types of maize imbred lines. Egyptian Journal of Genetics and Cytology, Alexandria, 5: 119-35, 1976 
MIRANDA FILHO, J.B. Cruzamentos dialélicos e síntese de compostos de milho (Zea mays L.) com ênfase na produtividade e no tipo de planta. Piracicaba, 1974. 116p. (Doutorado - Escola Superior de Agricultura "Luiz de Queiroz"/USP).

MIRANDA FILHO, J.B. \& GERALDI, I.O. An adapted model for the analysis of partial diallel crosses. Revista Brasileira de Genética, Ribeirão preto, VII, 4: 677-688, 1984.

MIRANDA FILHO, J.B. \& RISSI, R. Interação de efeitos genéticos com anos em um cruzamento dialélico intervarietal em milho. Relatório Cientifico do Instituto de Genética, Piracicaba, 9: 102-14, 1975.

MIRANDA FILHO, J.B. \& VENCOVSKY, R. Analysis of diallel crosses among open polinated varieties of maize (Zea mays, L.). Maydica, Bergamo, 217-234, 1984.

MiRANDA FILHO, J.B. \& VENCOVSKy, R. The parcial diallel cross at the interpopulation level theorethical and applied genetics, Berlin, 1995. (enviado para publicação).

MIRANDA FILHO, J.B. \& VENCOVSKY, R. Analysis of variance with interaction of effects. Revista Brasileira de Genética, Ribeirão Preto. (enviado para publicação). 
81.

MiseVIC, D.; MARIC, A.; AleXANDER, D.E.; DUMANOVIC, J.; RATHOVIC, S. Population cross among high oil populations of maize. Crop Science, Madison, 29: 613-7, 1989.

MOLL, R.H.; SALHUANA, W.S.; ROBINSON, H.F. Heterosis and genetic diversity in variety crosses of maize. crop Scince, Madison, 2: 197-8, 1962.

MOLL, R.H.; LONNQUIST, J.V.; FORTUNO, J.V.; JOHNSON, E.C. The relationship of heterosis and genetic divergence in maize. Genetics, New York, 52: 139-44, 1965.

MORAIS, A.R.; OLIVEIRA, A.C.; GAMA, E.E.G.; SOUZA JR., C.L. A method for combined analysis of the diallel crosses repeated in several environments. Pesquisa Agropecuária Brasileira, Brasilia, 26(3): 371-81, 1991.

MUNGONA, C.G. \& POLLACK, L.M. Heterotic patterns among ten corn belt and exotic maize populations. Crop science, Madison, 28: 500-4, 1988 .

MURTHY, B.R.; ARUNACHALAM, V.; ANAND, I.J. Diallel and partial diallel analysis of some yield factors in Linus usitatissimun. Heredity, London, 22: 35-41, 1967. 
NEVADO, N.E. \& CROSS, H.Z. Diallel analysis of relative growth rates in maize synthetics. Crop Science, Madison, $30: 549-52,1990$.

PATERNIANI, E. Cruzamentos intervarietais em milho. Relatório Cientifico do Instituto de Genética, Piracicaba, 1: $49-50,1967$.

PATERNIANI, E. Heterose em cruzamentos intervarietais de milho. Relatório Cientifico do Instituto de Genética, Piracicaba, 4: 95-100, 1970.

PATERNIANI, E. Maize breeding in the tropics. Critical Review in Plant Sciences, 9(2): 125-54, 1990.

ROOD, S.B. \& MAYOR, D.J. Diallel analysis of the photoperiodic response of maize. Crop Science, Madison, $15: 1-4,1975$

RUSSEL, W.A. Melhoramento de populações de milho como fonte de linhagens. Editora Fundação Cargill, 1975. 53p.

SAVELLI GOMES, L. Interação genótipos x épocas de plantio em milho (Zea mays, L.) em dois locais do oeste do Paraná. Piracicaba, 1990. 148p. (Mestrado - Escola Superior de Agricultura "Luiz de Queiroz"/USP). 
SILVA, J.C. Estimativas dos efeitos gênicos epistáticos em cruzamentos intervarietais de milho (Zea mays, L.) e suas gerações avançadas. Viçosa, 1969. 61p. (Mestrado Universidade Federal de Viçosa).

SMITH, J.S.C. Diversity of United States hybrid maize germplasm. Isozymic and chromathographic evidence. $\underline{\text { crop }}$ Science, Madison, 28: 63-9, 1988 .

SOUZA JR., C.L. Análise de cruzamentos dialélicos e predição de médias de compostos de milho (Zea mays, L.) braquitico. Piracicaba, 1981. 102p. (Mestrado - Escola Superior de Agricultura "Luiz de Queiroz"/USP).

SPRAGUE, G.F. Genetic vulnerability to disease and insects in corn and sorghum. Annual Corn and Sorghum Res. Conf. Proc., 26: 96-104, 1971 .

SPRAGUE, G.F. \& TATUM, L.A. General vs specific combining ability in single crosses of corn. Journal of American Society of Agronomy, Madison, 34: 923-32, 1942.

STEEL, R.G.D. \& TORRIE, J.H. Principles and procedures of statistics. New York, Mac Graw-Hill Book Company, 1960. $481 \mathrm{p}$ 
THOMPSON, D.L.; BERQUIST, R.R.; PAYNE, G.A.; BOWMAN, D.T.; GOODMAN, M.M. Inheritance of resistance to gray leaf spot in maize. Crop Science, Madison, 27: 243-6, 1987.

TROYER, A.F. \& HALlAUER, A.R. Analysis of a set of early flint varieties of maize. Crop Science, Madison, 8: $581-4,1968$.

ULRICH, J.F.; HAWK, J.A.; CARROL, R.B. Diallel analysis of maize imbreds for resistance to gray leaf spot. crop Science, Madison, 30: 1198-200, 1990.

VENCOVSKY, R. Alguns aspectos teóricos e aplicados relativos à cruzamentos dialélicos entre variedades. Piracicaba, 1970. 110p. (Livre Docência - Escola superior de Agricultura "Luiz de Queiroz"/USP).

YATES, F. Analysis of data from all possible reciprocal crosses between a set of parental lines. Heredity, Edinburgh, 1: 287-301, 1947 . 
85.

Apêndices 
Tabela 1 - Valores e significância dos quadrados médios obtidos das ANAVA preliminares para produção (t/ha) e altura de planta ( $\mathrm{cm}$ ) no experimento 1 local 1.

\begin{tabular}{lrcc}
\hline & & \multicolumn{2}{c}{ Q.M. } \\
\cline { 2 - 4 } F.V. & G.L. & PRODUÇÃo & ALT. DE PLANTA \\
\hline Repetições & 2 & $6,8454 * *$ & $544,9715^{\text {ns }}$ \\
Tratamentos & 57 & $2,2682^{* *}$ & $520,9644^{*}$ \\
$\quad$ Variedades & 9 & $0,7500^{\text {ns }}$ & $408,2407^{\text {ns }}$ \\
Hibridos & 44 & $1,6893^{\text {ns }}$ & $429,7306 *$ \\
$\quad$ Testemunhas & 2 & $2,3410^{\text {ns }}$ & $2158,3333^{* *}$ \\
Grupos & 2 & $21,7640 * *$ & $1397,9950 * *$ \\
Erro & 114 & 1,2127 & 290,0480 \\
\hline C.V.(\%) & & 19,37 & 7,66 \\
\hline
\end{tabular}

* Significativo ao nível de $5 \%$ de probabilidade pelo teste $F$ ** Significativo ao nível de $1 \%$ de probabilidade pelo teste $F$ 
Tabela 2 - Valores e significância dos quadrados médios obtidos das ANAVA preliminares para produção (t/ha) e altura de planta ( $\mathrm{cm}$ ) no experimento 1 local 2 .

\begin{tabular}{lrcc}
\hline & & \multicolumn{2}{c}{ Q.M. } \\
\cline { 2 - 4 } F.V. & G.L. & PRODUÇÃo & ALT. DE PLANTA \\
\hline Repetições & 2 & $1,3659 * *$ & $35,4885^{\text {ns }}$ \\
Tratamentos & 57 & $1,3614^{* *}$ & $661,9480 * *$ \\
$\quad$ Variedades & 9 & $0,4992 *$ & $791,2037 * *$ \\
Hibridos & 44 & $1,0574 * *$ & $582,0455^{* *}$ \\
$\quad$ Testemunhas & 2 & $0,7991^{\text {ns }}$ & $936,1112 * *$ \\
Grupos & 2 & $12,4910 * *$ & $1563,9885 * *$ \\
Erro & 114 & 0,2128 & 96,0148 \\
\hline C.V.(\%) & & 12,84 & 4,17 \\
\hline
\end{tabular}

* Significativo ao nivel de $5 \%$ de probabilidade pelo teste $F$

** Significativo ao nível de $1 \%$ de probabilidade pelo teste $F$ 
Tabela 3 - Valores e significância dos quadrados médios obtidos das ANAVA preliminares conjuntas para produção ( $t / h a)$ e para altura de planta $(\mathrm{cm})$ no experimento 1 - 2 locais com 3 repetiçōes por local.

\begin{tabular}{|c|c|c|c|}
\hline \multirow[b]{2}{*}{$F . V}$. & \multirow[b]{2}{*}{ G.L. } & \multicolumn{2}{|c|}{ Q.M. } \\
\hline & & PRODUÇÃO & ALT. DE PLANTA \\
\hline Locais & 1 & $379,2873 * *$ & $14354,0920 * *$ \\
\hline Repet i ções/Local & 4 & $4,1057 * *$ & $290,2300^{n s}$ \\
\hline Tratamentos & 57 & $2,7213 * *$ & $1016,3906 * *$ \\
\hline Variedades & 9 & $0,5766^{n s}$ & $1120,5556 * *$ \\
\hline Hibridos & 44 & $1,9077 * *$ & $819,9411 * *$ \\
\hline Test emunhas & 2 & $0,3900^{\text {ns }}$ & $2926,3889 * *$ \\
\hline Grupos & 2 & $32,6035 * *$ & $2959,5400 * *$ \\
\hline Tratamento $x$ Local & 57 & $0,9082^{n s}$ & $166,5218^{n s}$ \\
\hline Variedades $x$ Local & 9 & $0,6930^{n s}$ & $78,8889^{n s}$ \\
\hline Hibridos $x$ Local & 44 & $0,8432^{n s}$ & $191,8350 *$ \\
\hline Testemunha $x$ Local & 2 & $2,7492 *$ & $168,0555^{\mathrm{ns}}$ \\
\hline Grupos $x$ Local & 2 & $1,6514^{\mathrm{ns}}$ & $2,4440^{\text {ns }}$ \\
\hline Erro & 228 & 0,7127 & 133,0661 \\
\hline$C . V .(\%)$ & & 18,2 & 5,04 \\
\hline
\end{tabular}

* Significativo ao nivel de $5 \%$ de probabilidade pelo teste $F$

** Significativo ao nivel de $1 \%$ de probabilidade pelo teste $F$ 
Tabela 4 - Valores e significância dos quadrados médios obtidos das ANAVA preliminares para produção de grãos (t/ha) e altura de planta (cm) no experimento 2 - local 1 .

\begin{tabular}{lrcc}
\hline & & \multicolumn{2}{c}{ Q.M. } \\
\cline { 3 - 4 } F.V. & G.L. & PRODUÇÃO & ALT. DE PLANTA \\
\hline Repetições & 5 & $3,0318 * *$ & $3117,8260 * *$ \\
Tratamentos & 22 & $5,3260 * *$ & $902,4539 * *$ \\
$\quad$ Variedades & 9 & $0,9394^{\text {ns }}$ & $1374,8148 * *$ \\
$\quad$ "Top crosses" & 9 & $1,4336 *$ & $324,2593 * *$ \\
$\quad$ Testemunhas & 2 & $1,5255^{\text {ns }}$ & $704,1667 * *$ \\
$\quad$ Grupos & 2 & $46,3821 * *$ & $1576,9930 * *$ \\
Erro & 110 & 0,7215 & 116,3867 \\
\hline C.V. $(\%)$ & & 15,03 & 4,88 \\
\hline
\end{tabular}

* Significativo ao nivel de $5 \%$ de probabilidade pelo teste $F$ ** Significativo ao nivel de $1 \%$ de probabilidade pelo teste $F$ 
Tabela 5 - Valores e significância dos quadrados médios obtidos da ANAVA preliminar para produção de grãos (t/ha) e altura de planta (cm) no experimento 2 - local 2 .

\begin{tabular}{lrcc}
\hline & & \multicolumn{2}{c}{ Q.M. } \\
\cline { 3 - 4 } F.V. & G.L. & PRODUÇÃO & ALT. DE PLANTA \\
\hline Repetições & 5 & $0,1824^{\text {ns }}$ & $1082,3550 * *$ \\
Tratamentos & 22 & $2,3544^{* *}$ & $1044,2852 * *$ \\
$\quad$ Variedades & 9 & $1,0544^{* *}$ & $1487,7778 * *$ \\
$\quad$ "Top crosses" & 9 & $0,8264 * *$ & $489,8148 * *$ \\
$\quad$ Testemunhas & 2 & $0,1620^{\text {ns }}$ & $1926,3889 * *$ \\
$\quad$ Grupos & 2 & $17,2726 * *$ & $661,5820 * *$ \\
Erro & 110 & 0,2231 & 71,5975 \\
\hline C.V. $(\%)$ & & 13,04 & 3,66 \\
\hline
\end{tabular}

* Significativo ao nivel de $5 \%$ de probabilidade pelo teste $F$ ** Significativo ao nível de $1 \%$ de probabilidade pelo teste $F$ 
Tabela 6 - Valores e significancia dos quadrados médios obtidos das ANAVA conjuntas preliminares para produção de grãos ( $t / h a)$ e altura de planta $(\mathrm{cm})$ no experimento 2 - 2 locais com 6 repetições por local.

\begin{tabular}{|c|c|c|c|}
\hline \multirow[b]{2}{*}{$F . V}$. & \multirow[b]{2}{*}{ G.L. } & \multicolumn{2}{|c|}{ Q.M. } \\
\hline & & PRODUÇÃO & ALT. DE PLANTA \\
\hline Locais & 1 & $283,1315 * *$ & $6950,0870 * *$ \\
\hline Repet ições/Local & 10 & $1,6072 * *$ & $2100,0905 * *$ \\
\hline Trat amentos & 22 & $6,7530 * *$ & $1866,5380 * *$ \\
\hline Variedades & 9 & $1,1927 *$ & $2777,3150 * *$ \\
\hline "Top crosses" & 9 & $1,6647 * *$ & $759,8148 * *$ \\
\hline Testemunhas & 2 & $1,2970^{n s}$ & $2479,8613 * *$ \\
\hline Grupos & 2 & $60,1244 * *$ & $2134,9400 * *$ \\
\hline Tratamento $\times$ Local & 22 & $0,9277 * *$ & $80,2045^{n s}$ \\
\hline Variedades $\times$ Local & 9 & $0,8012^{\text {ns }}$ & $85,2778^{\text {ns }}$ \\
\hline "Top crosses" $x$ Local & 9 & $0,5955^{n s}$ & $54,2593^{n s}$ \\
\hline Testemunha $x$ Local & 2 & $0,3906^{n s}$ & $150,6940^{n s}$ \\
\hline Grupos $x$ Local & 2 & $3,5249 * *$ & $103,63652^{n s}$ \\
\hline Erro & 220 & 0,4723 & \\
\hline$C . V .(\%)$ & & 14,82 & 4,29 \\
\hline
\end{tabular}

* Significativo ao nível de $5 \%$ de probabilidade pelo teste $F$ ** Significativo ao nível de $1 \%$ de probabilidade pelo teste $F$ 
Tabela 7 - Valores e significância dos quadrados médios obtidos das ANAVA preliminares para produção de grãos (t/ha) e altura de planta ( $\mathrm{cm}$ ) no experimento 3 - local 1 .

\begin{tabular}{lrrr}
\hline & & & Q.M. \\
\cline { 3 - 4 } F.V. & G.L. & PRODUÇÃo & ALT. DE PLANTA \\
\hline Repetições & 2 & $14,9698 * *$ & $1562,2500 * *$ \\
Tratamentos & 99 & $1,9949 * *$ & $353,1785 * *$ \\
$\quad$ Variedades & 17 & $1,2931^{\text {ns }}$ & $353,8126 * *$ \\
Híbridos & 79 & $1,8249 * *$ & $311,9396 * *$ \\
Testemunhas & 1 & $0,6547^{\text {ns }}$ & $704,1666 *$ \\
Grupos & 2 & $15,2041 * *$ & $1801,2281 * *$ \\
Erro & 198 & 1,0487 & 144,4891 \\
\hline C.V.(\%) & & 17,06 & 5,41 \\
\hline
\end{tabular}

* Significativo ao nível de $5 \%$ de probabilidade pelo teste $F$ ** Significativo ao nivel de $1 \%$ de probabilidade pelo teste $F$ 
Tabela 8 - Valores e significância dos quadrados médios obtidos das ANAVA preliminares para produção de grãos (t/ha) e altura de planta (cm) no experimento 3 - local 2 .

\begin{tabular}{lccc}
\hline & & & Q.M. \\
\cline { 3 - 4 } F.V. & G.L. & PRODUÇÃo & ALT. DE PLANTA \\
\hline Repetições & 2 & $0,0867^{\text {ns }}$ & $121,0000^{\text {ns }}$ \\
Tratamentos & 99 & $0,8482 * *$ & $537,7104 * *$ \\
$\quad$ Variedades & 17 & $0,6002 * *$ & $1112,3094 * *$ \\
$\quad$ Hibridos & 79 & $0,5534 * *$ & $352,3998 * *$ \\
$\quad$ Testemunhas & 1 & $0,3587^{n s}$ & $66,6666^{\text {ns }}$ \\
Grupos & 2 & $14,8461 * *$ & $3208,9117^{* *}$ \\
Erro & 198 & 0,2285 & 116,7913 \\
& & 13,70 & 4,60 \\
C.V.(\%) & & & \\
\hline
\end{tabular}

** Significativo ao nível de $1 \%$ de probabilidade pelo teste $F$ 
Tabela 9 - Valores e significância dos quadrados médios obtidos das ANAVA conjuntas preliminares para produção de grãos ( $t / h a)$ e altura de planta (cm) no experimento 3 - 2 locais com 3 repetições por local.

\begin{tabular}{|c|c|c|c|}
\hline \multirow[b]{2}{*}{$F, V$. } & \multirow[b]{2}{*}{ G.L. } & \multicolumn{2}{|c|}{$Q . M}$. \\
\hline & & PRODUÇÃO & ALT. DE PLANTA \\
\hline Locais & 1 & $948,5222 * *$ & $24576,0000 * *$ \\
\hline Repet ições/Local & 4 & $7,5282 * *$ & $841,6250 * *$ \\
\hline Tratamentos & 99 & $1,9302 * *$ & $713,1212 * *$ \\
\hline Variedades & 17 & $1,1870 *$ & $1126,4161 * *$ \\
\hline Hibridos & 79 & $1,0645 * *$ & $520,2103 * *$ \\
\hline Test emunhas & 1 & $0,0221^{n s}$ & $301,0417^{n s}$ \\
\hline Grupos & 2 & $43,3988 * *$ & $9751,2286 * *$ \\
\hline Tratamento $\times$ Local & 99 & $0,9129 * *$ & $177,7677 * *$ \\
\hline Variedades $x$ Local & 17 & $0,7063^{\text {ns }}$ & $339,7059 * *$ \\
\hline Híbridos $x$ Local & 79 & $0,9376 * *$ & $144,1291^{n s}$ \\
\hline Testemunhas $x$ Local & 1 & $0,4956^{\text {ns }}$ & $84,3750^{\text {ns }}$ \\
\hline Grupos $x$ Local & 2 & $1,6514^{n s}$ & $269,0510^{n s}$ \\
\hline Erro & 396 & 0,6386 & 130,6402 \\
\hline$C . V .(\%)$ & & 16,84 & 5,00 \\
\hline
\end{tabular}

* Significativo ao nivel de $5 \%$ de probabilidade pelo teste $F$ ** Significativo ao nivel de $1 \%$ de probabilidade pelo teste $F$ 
Tabela 10 - Médias de produção de grãos ( $t / h a$ ) das variedades (diagonal), dos híbridos intervarietais (acima da diagonal) e das testemunhas do experimento 1 local 1 - média de 3 repetições.

\begin{tabular}{|c|c|c|c|c|c|c|c|c|c|c|c|c|}
\hline & $v_{1}$ & 12 & V3 & $V_{4}$ & V5 & 16 & 17 & 18 & vg & V10 & $\gamma_{v}$. & $Y_{H .}$. \\
\hline$v 1$ & \multirow[t]{10}{*}{4,820} & 5,236 & 4,082 & 6,906 & 5,691 & 7,223 & 5,470 & 6,296 & 5,679 & 5,423 & 56,826 & 52,006 \\
\hline$\sqrt{2}$ & & $4,945$. & 5,060 & 5,821 & 6,683 & 6,690 & 6,344 & 5,939 & 5,097 & 4,770 & 56,585 & 51,640 \\
\hline V3 & & & 4,323 & 6,730 & 6,166 & 6,090 & 5,275 & 6,399 & 5,877 & 6,245 & 56,247 & 51,324 \\
\hline 14 & & & & 4,781 & 6,339 & 5,912 & 6,435 & 6,363 & 4,777 & 5,102 & 59,166 & 54,385 \\
\hline V5 & & & & & $\underline{3,593}$ & 5,599 & 6,723 & 6,396 & 7,054 & 5,454 & 59,698 & 56,105 \\
\hline V6 & & & & & & 3,991 & 5,719 & 5,668 & 7,170 & 5,674 & 59,736 & 55,745 \\
\hline V7 & & & & & & & 5,200 & 6,623 & 5,457 & 4,744 & 57,990 & 52,790 \\
\hline v8 & & & & & & & & 4,919 & 5,950 & 4,204 & 58,757 & 53,838 \\
\hline vg & & & & & & & & & 4,953 & 5,593 & 57,607 & 52,654 \\
\hline V10 & & & & & & & & & & $4,568$. & 51,777 & 47,209 \\
\hline \multicolumn{2}{|c|}{$\bar{v}=4,609$} & \multicolumn{2}{|c|}{$\bar{H}=5,870$} & \multicolumn{2}{|c|}{$\bar{T}=6,233$} & \multicolumn{2}{|c|}{$\bar{T}_{1}=5,458$} & \multicolumn{2}{|c|}{$\overline{T_{2}}=6,018$} & \multicolumn{2}{|c|}{$\overline{T_{3}}=7,224$} & \\
\hline
\end{tabular}


Tabela 11 - Médias de produção de grãos ( $t / h a$ ) das variedades (diagonal), dos híbridos intervarietais (acima da diagonal) e das testemunhas do experimento 1 local 2 - média de 3 repetições.

\begin{tabular}{|c|c|c|c|c|c|c|c|c|c|c|c|c|}
\hline & $v_{1}$ & 12 & V3 & V4 & V5 & 16 & V7 & 18 & vg & V10 & $y_{v}$. & $Y_{M .}$ \\
\hline$V_{1}$ & \multirow[t]{10}{*}{2,685} & 2.583 & 2,419 & 4,025 & 3,179 & 3,920 & 3,617 & 3,606 & 3,222 & 3,396 & 32,652 & 29,967 \\
\hline V2 & & 2,399 & 3,027 & 4,528 & 4,550 & 4,396 & 3,031 & 3,558 & 3,196 & 4,069 & 35,337 & 32,938 \\
\hline 13 & & & 2,144 & 3,546 & 3,278 & 3,952 & 3,259 & 3,962 & 3,436 & 3,584 & 32,607 & 30,463 \\
\hline V4 & & & & 3,170 & 3,995 & 3,861 & 4,814 & 4,265 & 4,482 & 4,300 & 40,986 & 37,816 \\
\hline 15 & & & & & 3,163 & 4,131 & 3,739 & 4,530 & 3,830 & 4,608 & 39,003 & 35,840 \\
\hline V6 & & & & & & 3,051 & 4,519 & 4,476 & 4,420 & 4,321 & 41,047 & 37,996 \\
\hline 17 & & & & & & & 3,108 & 4,054 & 3,046 & 2,734 & 35,921 & 32,813 \\
\hline 18 & & & & & & & & 2,752 & 3,826 & 3,621 & 38,650 & 35,898 \\
\hline vg & & & & & & & & & 3,076 & 3,210 & 35,744 & 32,668 \\
\hline 110 & & & & & & & & & & 2.171 & 36,014 & 33,843 \\
\hline \multicolumn{2}{|c|}{$\bar{V}=2,772$} & \multicolumn{2}{|c|}{$\bar{H}=3,780$} & \multicolumn{2}{|c|}{$\overline{\mathrm{T}}=3,533$} & \multicolumn{2}{|c|}{$\bar{i}_{1}=4,129$} & \multicolumn{2}{|c|}{$\bar{i} 2=3,228$} & \multicolumn{2}{|c|}{$\bar{\tau} 3=3,242$} & \\
\hline
\end{tabular}


Tabela 12 - Médias de produção de grãos ( $t / h a$ ) das variedades (diagonal), dos híbridos intervarietais (acima da diagonal) e das testemunhas do experimento 1 - 2 locais - média de 6 repetições.

\begin{tabular}{|c|c|c|c|c|c|c|c|c|c|c|c|c|}
\hline & $v_{1}$ & V2 & V3 & V4 & V5 & v6 & V7 & v8 & vg & V10 & $Y_{V}$. & $Y_{H}$. \\
\hline V1 & \multirow[t]{10}{*}{3.753} & 3,910 & 3,251 & 5,466 & 4,434 & 5,572 & 4,544 & 4,951 & 4,451 & 4,410 & 44,738 & 40,985 \\
\hline V2 & & 3,672 & 4,044 & 5,175 & 5,617 & 5,543 & 4,688 & 4,749 & 4,147 & 4,420 & 45,961 & 42,289 \\
\hline V3 & & & 3,224 & 5,138 & 4,722 & 5,021 & 4,266 & 5,181 & 4,612 & 4,915 & 44,371 & $41,147$. \\
\hline V4 & & & & 3,976 & 5,167 & 4,887 & 5,625 & 5,314 & 4,630 & 4,701 & 50,076 & 46,101 \\
\hline 15 & & & & & 3,378 . & 4,865 & 5,231 & 5,463 & 5,442 & 5,031 & 49,349 & 45,971 \\
\hline V6 & & & & & & 3,521 & 5,119 & 5,072 & 5,795 & 4,998 & 50,392 & 46,871 \\
\hline V7 & & & & & & & 4,154 & 5,339 & 4,252 & 3,739 & 46,954 & 42,800 \\
\hline 18 & & & & & & & & $\underline{3,836}$ & 4,888 & 3,913 & 48,704 & 44,868 \\
\hline Vg & & & & & & & & & 4,015 & 4,402 & 46,631 & 42,616 \\
\hline V10 & & & & & & & & & & 3,370 & 43,896 & 40,526 \\
\hline \multicolumn{2}{|c|}{$\bar{v}=3,690$} & \multicolumn{2}{|c|}{$\bar{H}=4,825$} & \multicolumn{2}{|c|}{$\bar{T}=4,833$} & \multicolumn{2}{|c|}{$\overline{T_{i}}=4,793$} & \multicolumn{2}{|c|}{$\overline{T_{2}}=4,790$} & \multicolumn{2}{|c|}{$\overline{T_{3}}=5,233$} & \\
\hline
\end{tabular}


98.

Tabela 13 - Médias de produção ( $t / h a$ ) das variedades, dos híbridos "top crosses" e testemunhas do experimento 2 - locais 1 e 2 (média de 6 repetições) e de 2 locais (média de 12 repetições).

\begin{tabular}{|c|c|c|c|}
\hline & LOCAL 1 & LOCAL 2 & 2 LOCAIS \\
\hline$V_{1}$ & 4,955 & 2,888 & 3,922 \\
\hline V2 & 4,472 & 2,376 & 3,424 \\
\hline v3 & 5,101 & 2,630 & 3,865 \\
\hline V 4 & 5,271 & 3,292 & 4,281 \\
\hline$\vee 5$ & 4,652 & 3,815 & 4,233 \\
\hline V6 & 4,271 & 3,061 & 3,666 \\
\hline$\vee 7$ & 5,316 & 3,386 & 4,350 \\
\hline V8 & 4,396 & 3,047 & 3,722 \\
\hline v9 & 4,525 & 3,347 & 3,936 \\
\hline V10 & 4,344 & 2,765 & 3,554 \\
\hline $\bar{v}$ & 4,730 & 3,061 & 3,895 \\
\hline $\mathrm{TC} 1$ & 6,040 & 3,907 & 4,973 \\
\hline TC2 & 5,348 & 3,295 & 4,321 \\
\hline TC 3 & 5,581 & 3,972 & 4,976 \\
\hline TC4 & 6,891 & 4,312 & 5,601 \\
\hline TC5 & 6,179 & 4,542 & 5,360 \\
\hline TC6 & 7,116 & 4,088 & 5,602 \\
\hline TC7 & 6,393 & 3,883 & 5,138 \\
\hline TC8 & 6,096 & 4,307 & 5,201 \\
\hline TC9 & 6,298 & 3,548 & 4,923 \\
\hline TC10 & 6,162 & 4,149 & 5,156 \\
\hline $\overrightarrow{\mathrm{TC}}$ & 6,250 & 4,000 & 5,125 \\
\hline $\mathrm{T} 1$ & 7,296 & 4,422 & 5,859 \\
\hline T2 & 6,427 & 4,095 & 5,261 \\
\hline T3 & 6,419 & 4,228 & 5,323 \\
\hline$\overline{\mathrm{T}}$ & 6,714 & 4,248 & 5,481 \\
\hline
\end{tabular}


Tabela 14 - Médias de produção ( $t / h a)$ das variedades, dos hibridos intervarietais e das testemunhas do experimento 3 - Tocal 1 - média de 3 repetições.

\begin{tabular}{|c|c|c|c|c|c|c|c|c|c|c|}
\hline 1 & 11 & E2 & E3 & E4 & E 5 & E6 & E7 & $\mathrm{E8}$ & $Y_{i i}$ & $Y_{i}$. \\
\hline V1 & 6,074 & 6,468 & 7,144 & 7,073 & 6,959 & 6,233 & 6,016 & 6,339 & $\underline{5,547}$ & 52,306 \\
\hline V2 & 6,789 & 7,153 & 6,774 & 6,145 & 7,155 & 5,066 & 4,923 & 6,165 & 6,210 & 50,170 \\
\hline V3 & 7,285 & 7,299 & 6,939 & 7,487 & 6,355 & 5,896 & 5,945 & 6,746 & 4,809 & 53,952 \\
\hline V4 & 6,718 & 6,732 & 7,648 & 7,144 & 6,465 & 4,915 & 5,850 & 6,264 & $\underline{5,543}$ & 51,736 \\
\hline V5 & 5,966 & 6,889 & 5,914 & 6,081 & 5,215 & 6,476 & 5,902 & 6,340 & $\underline{5,522}$ & 48,783 \\
\hline V6 & 6,588 & 5,906 & 6,291 & 6,728 & 5,179 & 5,792 & 4,823 & 6,536 & $\underline{5,126}$ & 47,843 \\
\hline v7 & 5,907 & 5,272 & 5,519 & 6,628 & 5,586 & 5,204 & 5,652 & 6,515 & $\underline{5,295}$ & 46,283 \\
\hline v8 & 5,831 & 5,184 & 5,672 & 6,843 & 5,490 & 6,778 & 5,690 & 5,091 & 4,418 & 46,579 \\
\hline v9 & 5,672 & 6,021 & 6,353 & 7,016 & 5,561 & 6,409 & 6,614 & 6,423 & $\underline{5,840}$ & 50,069 \\
\hline V10 & 4,964 & 5,682 & 7,373 & 6,826 & 6,364 & 6,206 & 5,118 & 6,280 & $\underline{5,283}$ & 48,813 \\
\hline$Y_{j j}$ & $\underline{5,372}$ & $\underline{4,653}$ & 4,324 & $\underline{5,699}$ & $\underline{4,523}$ & 3,811 & $\underline{4,029}$ & $\underline{4,987}$ & & \\
\hline$Y . j$ & 61,794 & 62,606 & 65,627 & 67,971 & 60,329 & 58,975 & 56,533 & 62,699 & & \\
\hline $\bar{v}(1$ & $=5,359$ & & $\overline{\mathbf{v}}(\|)=$ & 4,675 & & $\bar{v}=5,0$ & & $\bar{H}=6,207$ & & \\
\hline $\bar{T}_{1}$ & $=6,303$ & & $\overline{\mathrm{T}} 2=6$, & 363 & & $\bar{T}=6,6$ & & & & \\
\hline
\end{tabular}


Tabela 15 - Médias de produção ( $t / h a)$ das variedades, dos híbridos intervarietais e das testemunhas do experimento 3 - local 2 - média de 3 repetições.

\begin{tabular}{|c|c|c|c|c|c|c|c|c|c|c|}
\hline 1 & E1 & E2 & E3 & E4 & E5 & E6 & E7 & E8 & $Y_{i i}$ & $Y_{i}$. \\
\hline v1 & 3,468 & 3,328 & 2,654 & 3,756 & 3,438 & 3,046 & 3,192 & 4,159 & 2,623 & 27,04 \\
\hline v2 & 3,920 & 3,559 & 4,069 & 3,246 & 3,543 & 3,409 & 3,814 & 3,730 & 2,832 & 29,29 \\
\hline v3 & 3,893 & 3,589 & 3,213 & 3,225 & 3,369 & 3,555 & 2,705 & 3,947 & $\underline{2,126}$ & 27,49 \\
\hline V4 & 3,844 & 3,069 & 3,330 & 4,463 & 3,859 & 3,456 & 3,679 & 4,416 & 3,428 & 30,11 \\
\hline V5 & 3,604 & 3,698 & 3,150 & 3,619 & 3,558 & 3,202 & 3,188 & 4,127 & $\underline{3,449}$ & 28,14 \\
\hline v6 & 3,785 & 3,483 & 3,709 & 3,679 & 4,595 & 4,159 & 3,411 & 4,063 & 3,382 & 30,884 \\
\hline v7 & 3,132 & 2,755 & 3,421 & 4,024 & 3,723 & 3,843 & 4,145 & 4,332 & $\underline{3,298}$ & 29,375 \\
\hline v8 & 3,575 & 3,665 & 3,815 & 4,187 & 4,215 & 4,067 & 3,588 & 2,742 & 3,412 & 29,85 \\
\hline v9 & 2,822 & 3,498 & 2,981 & 3,586 & 4,112 & 3,888 & 3,544 & 3,570 & $\underline{2,943}$ & 28,00 \\
\hline V10 & 3,351 & 3,136 & 3,221 & 3,528 & 4,161 & 3,379 & 3,664 & 4,362 & $\underline{2,967}$ & 28,80 \\
\hline$Y_{j j}$ & $\underline{2,786}$ & 2,200 & $\underline{2,682}$ & $\underline{2,423}$ & 3,263 & $\underline{2,503}$ & $\underline{2,453}$ & 2,387 & & \\
\hline Y.j & 35,394 & 33,780 & 33,563 & 37,313 & 38,573 & 36,004 & 34,930 & 39,448 & & \\
\hline $\bar{v}(1)$ & $=3,046$ & & $\bar{v}(11)=$ & 2,587 & & $\bar{v}=2,8$ & & $\bar{H}=3,613$ & & \\
\hline $\bar{\tau}_{1}=$ & $=4,531$ & & $\overline{\mathrm{T}} 2=4$, & 42 & & $\overline{\mathrm{T}}=4,2$ & & & & \\
\hline
\end{tabular}


Tabela 16 - Médias de produção ( $t / h a)$ das variedades, dos hibridos intervarietais e das testemunhas do experimento 3 - 2 locais - média de 6 repetições.

\begin{tabular}{|c|c|c|c|c|c|c|c|c|c|c|}
\hline 1 & E1 & E2 & E3 & E4 & E5 & E 6 & E7 & E8 & $Y_{i i}$ & $Y_{i}$. \\
\hline V1 & 4,771 & 4,898 & 4,899 & 5,414 & 5,199 & 4,639 & 4,604 & 5,249 & 4,085 & 39,673 \\
\hline V2 & 5,355 & 5,356 & 5,421 & 4,696 & 5,349 & 4,238 & 4,369 & 4,947 & 4,521 & 39,731 \\
\hline V3 & 5,589 & 5,444 & 5,076 & 5,356 & 4,862 & 4,725 & 4,325 & 5,346 & 3,468 & 40,723 \\
\hline V4 & 5,281 & 4,901 & 5,489 & 5,804 & 5,162 & 4,186 & 4,764 & 5,340 & 4,486 & 40,927 \\
\hline V5 & 4,785 & 5,294 & 4,532 & 4,850 & 4,386 & 4,839 & 4,545 & 5,234 & 4,486 & 38,465 \\
\hline v6 & 5,187 & 4,694 & 5,000 & 5,203 & 4,887 & 4,976 & 4,117 & 5,300 & 4,254 & 39,364 \\
\hline v7 & 4,520 & 4,013 & 4,470 & 5,236 & 4,654 & 4,524 & 4,898 & 5,423 & 4,297 & 37,828 \\
\hline V8 & 4,703 & 4,424 & 4,743 & 5,515 & 4,853 & 5,423 & 4,639 & 3,916 & 3,915 & 38,216 \\
\hline v9 & 4,247 & 4,759 & 4,667 & 5,301 & 4,836 & 5,148 & 5,079 & 4,996 & 4,406 & 39,033 \\
\hline V10 & 4,157 & 4,409 & 5,297 & 5,177 & 5,262 & 4,792 & 4,391 & 5,231 & 4,125 & 38,806 \\
\hline$Y_{j j}$ & $\underline{4,079}$ & $\underline{3,427}$ & $\underline{3,503}$ & $\underline{4,061}$ & 3,893 & 3,157 & $3,241$. & $\underline{3,687}$ & & \\
\hline$Y_{. j}$ & 48,595 & 48,192 & 49,594 & 52,642 & 49,450 & 47,490 & 45,731 & 51,072 & & \\
\hline $\bar{v}(1)$ & $=4,204$ & & $\bar{v}(\|)=$ & 3,631 & & $\bar{v}=3, s$ & & $\bar{H}=4,91$ & & \\
\hline $\bar{T}_{1}=$ & 5,417 & & $\overline{\mathrm{T}} 2=5$, & & & $\overline{\mathrm{T}}=5$, & & & & \\
\hline
\end{tabular}


Tabela 17 - Médias de altura de planta ( $\mathrm{cm}$ ) das variedades (diagonal), dos híbridos intervarietais (acima da diagonal) e das testemunhas do experimento 1 local 1 - média de 3 repetições.

\begin{tabular}{|c|c|c|c|c|c|c|c|c|c|c|c|c|}
\hline & $V_{1}$ & V2 & V3 & $V 4$ & 15 & V6 & V7 & 18 & $\forall 9$ & V10 & $\gamma_{v}$. & $Y_{H}$. \\
\hline V1 & \multirow[t]{10}{*}{220,00} & 210,00 & 220,00 & 245,00 & 221,67 & 243,33 & 226,67 & 228,33 & 228,33 & 218,33 & 2261,67 & 2041,67 \\
\hline V2 & & 195,00 & 218,33 & 213,33 & 223,33 & 231,67 & 206,67 & 205,00 & 200,00 & 206,67 & 2110,00 & 9915,00 \\
\hline V3 & & & 213,33 & 240,00 & 233,33 & 235,00 & 215,67 & 228,33 & 231,67 & 206,67 & 2263,33 & 2050,00 \\
\hline 14 & & & & 228,33 & 231,67 & 231,67 & 241,67 & 220,00 & 226,67 & 231,67 & 2310,00 & 2081,67 \\
\hline V5 & & & & & 206,67 & 225,00 & 231,67 & 233,33 & 231,67 & 205,00 & 2243,33 & 2036,67 \\
\hline V6 & & & & & & 231,67 & 228,33 & 218,33 & 243,33 & 243,33 & 2331,67 & 2100,00 \\
\hline V7 & & & & & & & 203,33 & 210,00 & 226,67 & 213,33 & 2205,00 & 2001,67 \\
\hline y8 & & & & & & & & 206,67 & 203,33 & 213,33 & 2166,67 & 1960,00 \\
\hline V9 & & & & & & & & & $208,33$. & 213,33 & 2213,33 & 2005,00 \\
\hline V10 & & & & & & & & & & $\underline{221,67}$. & 2193,33 & 1972,67 \\
\hline \multicolumn{2}{|c|}{$\bar{V}=213,50$} & \multicolumn{2}{|c|}{$\bar{H}=223,57$} & \multicolumn{2}{|c|}{$\bar{T}=225,00$} & \multicolumn{2}{|c|}{$\overline{T_{1}}=228,33$} & \multicolumn{2}{|c|}{$\overline{T_{2}}=196,67$} & \multicolumn{2}{|c|}{$\overline{T_{3}}=250,00$} & \\
\hline
\end{tabular}


Tabela 18 - Médias de altura de planta ( $\mathrm{cm}$ ) das variedades (diagonal), dos hibridos intervarietais (acima da diagonal) e das testemunhas do experimento 1 local 2 - média de 3 repetições.

\begin{tabular}{|c|c|c|c|c|c|c|c|c|c|c|c|c|}
\hline & 11 & V2 & 13 & V4 & 15 & V6 & V7 & 18 & Vg & V10 & $Y_{v}$. & $Y_{H}$. \\
\hline vi & \multirow[t]{10}{*}{$\underline{223,33}$} & 215,00 & 218,33 & 248,33 & 230,00 & 256,67 & 238,33 & 241,67 & 238,33 & 241,67 & 2351,67 & 2128,33 \\
\hline Y? & & 198.33 & 221,67 & 235,00 & 225,00 & 243,33 & 198,33 & 233,33 & 211,67 & 221,67 & 2203,33 & 2005,00 \\
\hline 13 & & & $\underline{231,67}$. & 261,67 & 246,67 & 246,67 & 236,67 & 231,67 & 231,67 & 231,67 & 2358,34 & 2126,67 \\
\hline 14 & & & & 245,00 & 231,67 & 265,00 & 246,67 & 240,00 & 263,33 & 251,67 & 2488,33 & 2243,33 \\
\hline 15 & & & & & 210,00 & 238,33 & 255,00 & 231,67 & 225,00 & 235,00 & 2328,33 & 2118,33 \\
\hline 16 & & & & & & 253,33 & 240,00 & 243,33 & 251,67 & 251,67 & 2490,00 & 2236,67 \\
\hline VT & & & & & & & 213,33 & 221,67 & 223,33 & 235,00 & 2308,33 & 2095,00 \\
\hline 18 & & & & & & & & $\underline{223,33}$ & 238,33 & 245,00 & 2350,00 & 2126,66 \\
\hline 19 & & & & & & & & & 228,33 & 226,67 & 2338,33 & 2110,00 \\
\hline V10 & & & & & & & & & & $\underline{231,67}$ & 2371,67 & 2140,00 \\
\hline & 83 & $\bar{H}=2$ & & $\overline{\mathrm{T}}=$ & & $\overline{\mathrm{T}}_{1}=$ & & $\overline{\mathrm{T}} 2=$ &, 67 & $\overline{13}=$ & & \\
\hline
\end{tabular}


Tabela 19 - Médias de altura de planta ( $\mathrm{cm}$ ) das variedades (diagonal), dos hibridos intervarietais (acima da diagonal) e das testemunhas do experimento $1-2$ locais - média de 6 repetições.

\begin{tabular}{|c|c|c|c|c|c|c|c|c|c|c|c|c|}
\hline & V1 & V2 & 13 & V4 & V5 & V6 & V7 & v8 & vg & $V 10$ & yv. & $\gamma_{H .}$ \\
\hline$V_{1}$ & 221.67 & 212,50 & 219,17 & 246,67 & 225,86 & 250,00 & 232,50 & 235,00 & 233,33 & 230,00 & 2306,67 & 2085,00 \\
\hline$V_{2}$ & & 196.67 & 220,00 & $224: 17$ & 224,17 & 237,50 & 202,50 & 219,17 & 205,83 & 214,87 & 2156,68 & 1960,01 \\
\hline 13 & & & $\underline{222,50}$ & 250,83 & 240,00 & 240,83 & 226,67 & 230,00 & 231,67 & 229,17 & 2310,84 & 2088,34 \\
\hline$V_{4}$ & & & & 236,07 & 231,67 & 248,33 & 244,17 & 230,00 & 245,00 & 241,67 & 2399,18 & 2162,51 \\
\hline$\sqrt{5}$ & & & & & 208,33 & 231,67 & 243,33 & 232,50 & 228,33 & 220,00 & 2285,83 & 2077,50 \\
\hline V6 & & & & & & 242,50 & 234,17 & 230,83 & 247,50 & 247,50 & 2410,83 & 2168,33 \\
\hline V7 & & & & & & & 208,33 & 215,83 & 225,00 & 224,17 & 2256,67 & 2048,34 \\
\hline v8 & & & & & & & & 215,00 & 220,83 & 229,17 & 2258,33 & 2043,33 \\
\hline vg & & & & & & & & & $218,33$. & 220,00 & 2275,82 & 2057,49 \\
\hline V10 & & & & & & & & & & 226,67 & 2282,52 & 2055,85 \\
\hline
\end{tabular}

$\bar{V}=219,67 \quad \bar{H}=230,51 \quad \bar{T}=231,39 \quad \bar{T} 1=231,67 \quad \bar{T} 2=209,17 \quad \overline{T_{3}}=253,33$ 
Tabela 20 - Médias de altura de planta ( $\mathrm{cm}$ ) das variedades, dos hibridos "top crosses" e testemunhas do experimento 2 - locais 1 e 2 (médias de 6 repetições por local) e de 2 locais (média de 12 repetições).

\begin{tabular}{|c|c|c|c|}
\hline & LOCAL 1 & LOCAL 2 & 2 LOCAIS \\
\hline$\vee 1$ & 225,00 & 233,33 & 239,17 \\
\hline V2 & 190,00 & 195,00 & 192,50 \\
\hline V3 & 230,00 & 242,50 & 236,25 \\
\hline$\vee 4$ & 239,17 & 245,83 & 242,50 \\
\hline V5 & 215,83 & 222,50 & 219,17 \\
\hline V6 & 230,00 & 248,33 & 239,17 \\
\hline$\vee 7$ & 210,00 & 221,67 & 215,83 \\
\hline V8 & 207,50 & 225,00 & 216,25 \\
\hline V9 & 206,67 & 220,00 & 213,33 \\
\hline V10 & 202,50 & 222,50 & 212,50 \\
\hline $\bar{v}$ & 215,67 & 227,67 & 221,67 \\
\hline TC 1 & 225,00 & 236,67 & 230,83 \\
\hline TC2 & 206,67 & 214,17 & 210,42 \\
\hline TC 3 & 225,00 & 235,00 & 230,00 \\
\hline TC4 & 233,33 & 244,17 & 238,75 \\
\hline TC5 & 220,83 & 236,67 & 228,25 \\
\hline TC 6 & 232,50 & 244,17 & 238,33 \\
\hline TC7 & 225,83 & 231,67 & 228,75 \\
\hline TC8 & 225,00 & 228,33 & 226,67 \\
\hline TC9 & 223,33 & 225,00 & 224,17 \\
\hline TC10 & 220,83 & 229,17 & 225,00 \\
\hline$\overline{T C}$ & 223,83 & 232,50 & 228,17 \\
\hline$T 1$ & 228,33 & 236,67 & 232,50 \\
\hline $\mathrm{T} 2$ & 217,50 & 218,33 & 217,92 \\
\hline T3 & 239,17 & 254,17 & 246,67 \\
\hline $\bar{T}$ & 228,33 & 236,39 & 232,36 \\
\hline
\end{tabular}


Tabela 21 - Médias de altura de planta $(\mathrm{cm})$ das variedades, dos hibridos intervarietais e das testemunhas do experimento 3 - local 1 - média de 3 repetições.

\begin{tabular}{|c|c|c|c|c|c|c|c|c|c|c|}
\hline 1 & E1 & E2 & E3 & E4 & E5 & E6 & E7 & E8 & $r_{i i}$ & $Y_{i}$. \\
\hline v1 & 223,3 & 230,0 & 240,0 & 221,7 & 221,7 & 215,0 & 238,3 & 215,0 & 218,3 & 1805,0 \\
\hline v2 & 220,0 & 225,0 & 225,0 & 206,7 & 218,3 & 221,7 & 206,7 & 211,7 & $\underline{208,3}$ & 1735,1 \\
\hline v3 & 226,7 & 228,3 & 226,7 & 230,0 & 233,3 & 233,3 & 223,3 & 231,7 & $\underline{231,7}$ & 1833,3 \\
\hline V4 & 223,3 & 226,7 & 251,7 & 223,3 & 233,3 & 220,0 & 241,7 & 233,3 & $\underline{235,0}$ & 1853,3 \\
\hline V5 & 220,0 & 216,7 & 225,0 & 211,7 & 211,7 & 223,3 & 223,3 & 213,3 & $\underline{215,0}$ & 1745,0 \\
\hline v6 & 230,0 & 245,0 & 238,3 & 241,7 & 221,7 & 230,0 & 225,0 & 236,7 & $\underline{231,7}$ & 1868,4 \\
\hline v7 & 218,3 & 216,7 & 245,0 & 226,7 & 215,0 & 226,7 & 211,7 & 223,3 & 213,3 & 1783,4 \\
\hline v8 & 220,0 & 201,7 & 220,0 & 225,0 & 206,7 & 213,3 & 206,7 & 206,7 & $\underline{213,3}$ & 1700,1 \\
\hline v9 & 215,0 & 226,7 & 238,3 & 223,3 & 228,3 & 226,7 & 235,0 & 218,3 & $\underline{215,0}$ & 1811,6 \\
\hline V10 & 211,7 & 220,0 & 226,7 & 235,0 & 231,7 & 221,7 & 213,3 & 210,0 & $\underline{206,7}$ & 1770,1 \\
\hline $\mathrm{v}_{i j}$ & 218,3 & 203,3 & 228,3 & 203,0 & 196,7 & $\underline{211,7}$ & 205,0 & $\underline{211,7}$ & & \\
\hline Y.j & 2208,3 & 2236,8 & 2336,7 & 2245,1 & 2221,7 & 2231,7 & 2225,0 & 2200,0 & & \\
\hline $\begin{array}{l}V(1) \\
\bar{T}_{1}=\end{array}$ & $\begin{array}{l}=218,83 \\
=233,3\end{array}$ & & $\begin{array}{l}\bar{v}(11)= \\
\bar{T} 2=21\end{array}$ & $\begin{array}{l}209,75 \\
1,7\end{array}$ & & $\begin{array}{l}\bar{v}=214 \\
\bar{T}=222\end{array}$ & & $\bar{H}=$ & & \\
\hline
\end{tabular}


Tabela 22 - Médias de altura de planta (cm) das variedades, dos hibridos intervarietais e das testemunhas do experimento 3 - local 2 - média de 3 repetições.

\begin{tabular}{|c|c|c|c|c|c|c|c|c|c|c|}
\hline 1 & E1 & E2 & E3 & E4 & E5 & E6 & E7 & E8 & $Y_{i i}$ & $Y_{i}$. \\
\hline V1 & 245,0 & 246,7 & 245,0 & 225,0 & 230,0 & 226,7 & 236,7 & 240,0 & 243,3 & 1895,1 \\
\hline V2 & 225,0 & 228,3 & 246,7 & 206,7 & 233,3 & 240,0 & 238,3 & 236,7 & 171,7 & 1855,0 \\
\hline V3 & 233,3 & 231,7 & 253,3 & 223,3 & 248,3 & 246,7 & 245,0 & 231,7 & $\underline{236,7}$ & 1913,3 \\
\hline V4 & 238,3 & 246,6 & 253,3 & 226,7 & 246,7 & 248,3 & 265,0 & 240,0 & 253,3 & 1964,9 \\
\hline V5 & 236,7 & 226,7 & 250,0 & 210,0 & 223,3 & 238,3 & 241,7 & 240,0 & $\underline{226,7}$ & 1866,7 \\
\hline V6 & 246,7 & 248,3 & 263,3 & 236,7 & 246,7 & 251,7 & 243,3 & 246,7 & $\underline{258,3}$ & 1983,4 \\
\hline V7 & 226,7 & 225,0 & 253,3 & 221,7 & 235,0 & 245,0 & 231,7 & 228,3 & 216,7 & 1866,7 \\
\hline v8 & 245,0 & 231,7 & 245,0 & 233,3 & 241,7 & 225,0 & 231,7 & 216,7 & $\underline{216,7}$ & 1870,1 \\
\hline v9 & 238,3 & 238,3 & 241,7 & 216,7 & 243,3 & 236,7 & 238,3 & 235,0 & $\underline{218,3}$ & 1888,3 \\
\hline V10 & 228,3 & 225,0 & 245,0 & 231,7 & 245,0 & 240,0 & 235,0 & 230,0 & $\underline{226,7}$ & 1880,0 \\
\hline$V_{j j}$ & 233,3 & 220,0 & 231,7 & 208,3 & 221,7 & 241,7 & 218,3 & 213,3 & & \\
\hline Y.j & 2363,3 & 2348,3 & 2496,6 & 2231,8 & 2393,3 & 2398,4 & 2406,7 & 2345,1 & & \\
\hline $\bar{v}(1)$ & $=226,84$ & & $\bar{v}(11)=$ & 223,54 & & $\bar{v}=22$ & & $\bar{H}=23$ & & \\
\hline $\bar{T}_{1}=$ & 233,33 & & $\overline{\mathrm{T}}_{2}=22$ & 0,67 & & $\overline{\mathrm{T}}=230$ & 00 & & & \\
\hline
\end{tabular}


Tabela 23 - Médias de altura de planta ( $\mathrm{cm}$ ) das variedades, dos hibridos intervarietais e das testemunhas do experimento 3 - 2 locais - média de 6 repetições.

\begin{tabular}{|c|c|c|c|c|c|c|c|c|c|c|}
\hline 1 & E1 & E2 & E3 & E4 & E5 & E 6 & E 7 & E8 & $Y_{i i}$ & $Y_{i}$. \\
\hline V1 & 234,2 & 238,4 & 242,5 & 223,4 & 225,9 & 220,9 & 237,5 & 227,5 & 230,8 & 1850,1 \\
\hline v2 & 222,5 & 226,7 & 235,9 & 206,7 & 225,8 & 230,9 & 222,5 & 224,2 & 190,0 & 1795,1 \\
\hline v3 & 230,0 & 230,0 & 240,0 & 226,7 & 240,8 & 240,0 & 234,15 & 231,7 & 234,2 & 1873,3 \\
\hline V4 & 230,8 & 236,7 & 252,5 & 225,0 & 240,0 & 234,2 & 253,4 & 236,7 & 244,2 & 1909,2 \\
\hline V5 & 228,4 & 221,7 & 237,5 & 210,9 & 217,5 & 230,8 & 232,5 & 226,7 & $\underline{220,9}$ & 1805,9 \\
\hline v6 & 238,4 & 246,7 & 250,8 & 239,2 & 234,2 & 240,9 & 234,2 & 241,7 & 245,0 & 1925,9 \\
\hline v7 & 222,5 & 220,9 & 249,2 & 224,2 & 225,0 & 235,9 & 221,7 & 225,8 & 215,0 & 1825,1 \\
\hline v8 & 232,5 & 216,7 & 232,5 & 229,2 & 224,2 & 219,2 & 219,2 & 211,7 & 215,0 & 1785,1 \\
\hline v9 & 226,7 & 232,5 & 240,0 & 220,0 & 235,8 & 231,7 & 236,7 & 226,7 & 216,7 & 1850,0 \\
\hline V10 & 220,0 & 222,5 & 235,9 & 233,4 & 238,4 & 230,9 & 224,2 & 220,0 & 216,7 & 1825,1 \\
\hline$Y_{j j}$ & 225,8 & $\underline{211,7}$ & $\underline{230,0}$ & $\underline{205,7}$ & 209,2 & 226,7 & 211,7 & $\underline{212,2}$ & & \\
\hline Y.j & 2285,8 & 2292,6 & 2416,7 & 2238,5 & 2307,5 & 2315,1 & 2315,9 & 2272,6 & & \\
\hline $\bar{v}(1)$ & $=222,84$ & & $\bar{v}(11)=$ & 216,65 & & $\bar{v}=219$, & & $\bar{H}=230,56$ & & \\
\hline $\bar{\tau}_{1}=$ & 233,33 & & $\bar{T}_{2}=21$ &, 19 & & $\overline{\mathrm{T}}=226$, & 25 & & & \\
\hline
\end{tabular}


Tabela 24 - Intervalos de confiança para as médias de variedades e híbridos intervarietais e "Top crosses" para os 3 experimentos nos 2 locais e na média dos dois locais, para produção ( $t / h a)$ e altura de planta ( $\mathrm{cm}$ ) ao nivel de $95 \%$ de probabilidade.

\begin{tabular}{|c|c|c|c|c|c|c|c|c|}
\hline & \multicolumn{4}{|c|}{ PRODUÇÃO ( $t / h a)$} & \multicolumn{4}{|c|}{ LT. DE PLANTA $(\mathrm{cm})$} \\
\hline & \multicolumn{4}{|c|}{$Y_{j j^{\prime}} \pm$} & \multicolumn{4}{|c|}{$Y_{j j} \pm$} \\
\hline & L1 & L2 & 2 & LOCAIS & L1 & L2 & 2 & LOCAIS \\
\hline$E \times p$ & 1,259 & 0,527 & & 0,676 & 19,47 & 11,20 & & 9,23 \\
\hline$E \times p \cdot 2$ & 0,687 & 0,382 & & 0,389 & 8,72 & 6,84 & & 7,76 \\
\hline$E \times p \cdot 3$ & 1,159 & 0,541 & & 0,639 & 13,60 & 12,23 & & 9,15 \\
\hline
\end{tabular}


Tabela 25 - Heteroses (\%) observadas no experimento 1 (acima da diagonal) e preditas* no experimento 2 (abaixo da diagonal) para o caráter produção de grãos no local 1 e no local 2 .

\begin{tabular}{|c|c|c|c|c|c|c|c|c|c|c|}
\hline \multicolumn{11}{|c|}{ LOCAL 1} \\
\hline & $v_{1}$ & v2 & V3 & V 4 & V5 & V6 & v7 & V8 & v9 & V10 \\
\hline$v_{1}$ & $\longrightarrow$ & 7,2 & $(-10,7)$ & 43,9 & 35,3 & 64,0 & 9,2 & 29,3 & 16,2 & 15,5 \\
\hline V2 & 6,8 & $=$ & 9,2 & 19,7 & 56,5 & 49,7 & 25,1 & 20,4 & 3,0 & 0,3 \\
\hline V3 & 15,9 & 3,6 & $\longrightarrow$ & 47,8 & 55,8 & 46,5 & 10,8 & 38,5 & 26,7 & 40,5 \\
\hline V4 & 36,2 & 25,1 & 32,8 & - & 51,4 & 34,8 & 28,9 & 31,2 & $(-1,9)$ & 9,1 \\
\hline V5 & 26,4 & 14,1 & 23,0 & 43,8 & $\longrightarrow$ & 47,7 & 52,9 & 50,3 & 65,1 & 33,7 \\
\hline v6 & 57,1 & 45,8 & 52,9 & 74,0 & 66,1 & $\longrightarrow$ & 24,4 & 27,2 & 60,3 & 32,6 \\
\hline V7 & 23,5 & 11,9 & 19,6 & 39,9 & 30,7 & 60,3 & $\longrightarrow$ & 30,9 & 17,2 & $(-2,9)$ \\
\hline v8 & 27,7 & 15,0 & 24,1 & 45,4 & 35,7 & 68,8 & 32,1 & $\longrightarrow$ & 20,5 & $(-11,4)$ \\
\hline v9 & 31,2 & 18,9 & 27,6 & 48,6 & 36,7 & 71,9 & 35,4 & 40,9 & $\longrightarrow$ & 17,5 \\
\hline V10 & 30,2 & 17,6 & 26,5 & 47,9 & 38,3 & 71,6 & 34,4 & 40,1 & 39,8 & - \\
\hline \multicolumn{11}{|c|}{ LOCAL 2} \\
\hline & $v_{1}$ & V2 & V3 & V4 & V 5 & v6 & v7 & v8 & v9 & V10 \\
\hline$v_{1}$ & - & 1,6 & 0,2 & 37,5 & 8,7 & 36,7 & 24,9 & 32,6 & 11,9 & 39,9 \\
\hline v2 & 17,9 & - & 33,4 & 62,6 & 63,6 & 61,3 & 10,1 & 38,1 & 16,7 & 78,1 \\
\hline V3 & 43,1 & 26,8 & - & 33,5 & 23,5 & 52,1 & 24,1 & 61,8 & 31,6 & 66,1 \\
\hline V4 & 41,4 & 27,2 & 50,3 & $\longrightarrow$ & 26,2 & 24,1 & 53,4 & 44,0 & 43,5 & 61,0 \\
\hline V5 & 39,1 & 25,5 & 47,2 & 45,3 & $\longrightarrow$ & 33,0 & $19 ; 2$ & 53,2 & 22,8 & 72,8 \\
\hline v6 & 37,7 & 22,4 & 46,7 & 44,7 & 42,2 & - & 46,7 & 54,3 & 44,3 & 65,5 \\
\hline v7 & 22,3 & 6,6 & 30,3 & 29,9 & 28,6 & 26,1 & - & 38,4 & $(-1,5)$ & 3,6 \\
\hline v8 & 47,2 & 32,8 & 56,7 & 53,6 & 50,4 & 50,4 & 34,8 & $\longrightarrow$ & 31,3 & 47,1 \\
\hline v9 & 9,6 & $(-7,3)$ & 17,1 & 18,1 & 17,6 & 13,7 & 0,6 & 22,5 & $\longrightarrow$ & 22,4 \\
\hline V10 & 47,4 & 32,3 & 57,5 & 54,2 & 50,8 & 50,8 & 34,5 & 60,6 & 21,6 & $\longrightarrow$ \\
\hline
\end{tabular}

* $h_{j j^{\prime}}^{*}=\bar{h}+h_{j}+h_{j^{\prime}}$ 
Tabela 26 - Heteroses (\%) observadas no experimento 3 para o caráter produção de grãos nos locais 1 e 2 .

\begin{tabular}{|c|c|c|c|c|c|c|c|c|}
\hline \multicolumn{9}{|c|}{ LOCAL 1} \\
\hline & E1 & E2 & E3 & E4 & E5 & E6 & E7 & E8 \\
\hline$V_{1}$ & 11,3 & 26,8 & 44,7 & 25,8 & 38,2 & 33,2 & 25,6 & 20,4 \\
\hline$\vee 2$ & 17,2 & 31,7 & 28,6 & 3,2 & 33,3 & 1,1 & $(-3,8)$ & 10,1 \\
\hline$\vee 3$ & 43,1 & 54,3 & 52,0 & 42,5 & 36,2 & 36,8 & 34,5 & 37,7 \\
\hline$\vee 4$ & 23,1 & 32,1 & 55,0 & 27,1 & 28,5 & 5,1 & 22,2 & 19,0 \\
\hline V5 & 9,5 & 35,4 & 20,1 & 8,4 & 3,8 & 38,8 & 23,6 & 20,7 \\
\hline V6 & 25,5 & 20,8 & 33,1 & 24,3 & 7,3 & 29,6 & 5,4 & 29,3 \\
\hline$\vee 7$ & 10,8 & 6,0 & 14,8 & 20,6 & 13,8 & 14,3 & 21,2 & 26,7 \\
\hline V8 & 19,1 & 14,3 & 29,8 & 35,3 & 22,8 & 64,7 & 34,7 & 8,3 \\
\hline V9 & 1,2 & 14,8 & 25,5 & 21,6 & 7,3 & 32,8 & 34,0 & 18,6 \\
\hline V10 & $(-6,8)$ & 14,4 & 53,5 & 24,3 & 29,0 & 36,5 & 9,9 & 22,3 \\
\hline \multicolumn{9}{|c|}{ LOCAL 2} \\
\hline & E1 & E2 & E3 & E4 & E5 & E6 & E7 & E8 \\
\hline$\vee 1$ & 27,5 & 37,2 & $(-0,5)$ & 48,0 & 16,8 & 18,8 & 25,8 & 66,0 \\
\hline V2 & 39,6 & 41,5 & 47,6 & 23,5 & 16,3 & 27,8 & 44,3 & 42,9 \\
\hline$\vee 3$ & 58,5 & 65,9 & 33,7 & 41,8 & 25,0 & 53,6 & 18,1 & 74,9 \\
\hline$\vee 4$ & 23,7 & 9,1 & 9,0 & 52,6 & 15,3 & 16,5 & 25,1 & 51,9 \\
\hline$\vee 5$ & 15,6 & 30,9 & 2,8 & 23,3 & 6,0 & 7,6 & 8,0 & 41,4 \\
\hline V6 & 22,7 & 24,8 & 22,3 & 26,8 & 58,3 & 41,3 & 16,9 & 40,9 \\
\hline$\vee 7$ & 3,0 & 0,2 & 14,4 & 40,7 & 13,5 & 32,5 & 44,1 & 52,4 \\
\hline$\vee 8$ & 15,4 & 30,6 & 25,2 & 43,5 & 26,3 & 37,5 & 22,4 & $(-5,4)$ \\
\hline$\vee 9$ & $(-1,5)$ & 36,0 & 6,0 & 33,7 & 32,5 & 42,8 & 31,4 & 34,0 \\
\hline V10 & $i 6,5$ & $2 i, 4$ & 14,0 & 30,9 & 33,6 & 23,5 & 35,2 & 62,9 \\
\hline
\end{tabular}


Tabela 27 - Heteroses (\%) observadas no experimento 1 (acima da diagonal) e preditas* no experimento 2 (abaixo da diagonal) para o caráter altura de planta nos locais 1 e 2 .

\begin{tabular}{|c|c|c|c|c|c|c|c|c|c|c|}
\hline \multicolumn{11}{|c|}{ LOCAL 1} \\
\hline & V1 & v2 & v3 & V 4 & V5 & v6 & v7 & v8 & v9 & V10 \\
\hline$v_{1}$ & - & 1,2 & 1,5 & 9,3 & 3,9 & 7,7 & 7,1 & 7,0 & 6,6 & $(-1,1)$ \\
\hline V2 & $(-1,4)$ & $\longrightarrow$ & 6,9 & 0,8 & 11,2 & 8,6 & 3,8 & 2,1 & $(-0,8)$ & $(-0,8)$ \\
\hline V3 & 0,0 & $(-2,5)$ & - & 8,7 & 11,1 & 5,6 & 4,0 & 8,7 & 9,9 & 4,2 \\
\hline V4 & 2,5 & 0,2 & 1,5 & - & 6,5 & 0,7 & 12,0 & 1,1 & 3,8 & 3,0 \\
\hline V5 & 0,9 & $(-1,7)$ & 0,2 & 2,3 & - & 2,7 & 13,0 & 12,9 & 11,6 & $(-4,3)$ \\
\hline v6 & 4,2 & 1,9 & 3,0 & 5,5 & 4,0 & $=$ & 5,0 & $(-0,4)$ & 10,6 & 7,3 \\
\hline v7 & 5,1 & 2,9 & 3,9 & 6,4 & 4,9 & 8,2 & - & 2,4 & 10,1 & 0,4 \\
\hline v8 & 5,2 & 3,0 & 4,0 & 6,6 & 5,1 & 8,3 & 9,5 & - & $(-2,0)$ & $(-0,3)$ \\
\hline v9 & 4,8 & 2,5 & 3,6 & 6,1 & 4,6 & 7,9 & 9,0 & 9,2 & $\longrightarrow$ & $(-0,8)$ \\
\hline V10 & 4,0 & 1,6 & 2,8 & 5,4 & 3,8 & 7,2 & 8,3 & 8,5 & 8,0 & - \\
\hline \multicolumn{11}{|c|}{ LOCAL 2} \\
\hline & V1 & v2 & v3 & V 4 & V5 & v6 & v7 & v8 & v9 & V10 \\
\hline$v_{1}$ & - & 2,0 & $(-4,0)$ & 6,1 & 6,2 & 7,7 & 9,2 & 8,2 & 5,5 & 6,2 \\
\hline v2 & 0,5 & - & 3,1 & 6,0 & 10,2 & 7,7 & $(-3,6)$ & 10,7 & $(-0,8)$ & 3,1 \\
\hline v3 & 1,4 & $(-2,5)$ & - & 9,8 & 11,7 & 1,7 & 6,4 & 1,8 & 0,7 & 0,0 \\
\hline V4 & 5,6 & 2,0 & 2,7 & - & 1,8 & 6,4 & 7,6 & 2,5 & 11,3 & 5,6 \\
\hline V5 & 6,8 & 2,1 & 3,8 & 8,0 & - & 2,9 & 20,5 & 6,9 & 2,7 & 6,4 \\
\hline v6 & 5,0 & 3,0 & 2,2 & 6,2 & 7,4 & - & 2,9 & 2,1 & 4,5 & 3,8 \\
\hline v7 & 4,3 & 0,3 & 1,3 & 5,5 & 6,8 & 4,9 & - & 1,5 & 1,1 & 5,6 \\
\hline v8 & 1,7 & $(-2,4)$ & $(-1,2)$ & 3,0 & 4,1 & 2,4 & 1,5 & - & 5,5 & 7,8 \\
\hline v9 & 1,0 & $(-3,3)$ & $(-1,9)$ & 2,3 & 3,4 & 1,7 & 0,8 & $(-1,8)$ & $\longrightarrow$ & 0,7 \\
\hline V10 & 2,7 & $(-1,4)$ & $(-0,2)$ & 4,0 & 5,2 & 3,4 & 2,6 & $(-0,1)$ & $(-0,8)$ & - \\
\hline
\end{tabular}

$* \hat{h}=\left(\hat{\bar{h}}+\hat{h}_{j}+\hat{h}_{j^{\prime}}\right)$ 
Tabela 28 - Heteroses (\%) observadas no experimento 3 para o caráter altura de planta nos locais 1 e 2 .

\begin{tabular}{|c|c|c|c|c|c|c|c|c|}
\hline \multicolumn{9}{|c|}{ LOCAL 1} \\
\hline & E1 & E2 & E3 & E4 & E5 & E6 & E7 & E8 \\
\hline V1 & 2,3 & 9,1 & 7,5 & 5,2 & 6,8 & 0,0 & 12,6 & 0,0 \\
\hline V2 & 3,1 & 9,3 & 3,1 & 0,5 & 7,8 & 5,6 & 0,0 & 0,7 \\
\hline V3 & 0,8 & 5,0 & $(-1,4)$ & 5,8 & 8,9 & 5,2 & 2,3 & 4,5 \\
\hline V4 & $(-1,5)$ & 3,4 & 8,7 & 2,0 & 8,1 & $(-1,5)$ & 9,9 & 4,5 \\
\hline V5 & 1,5 & 3,6 & 1,5 & 1,3 & 2,8 & 4,7 & 6,3 & 0,0 \\
\hline V6 & 2,2 & 12,6 & 3,6 & 11,2 & 3,5 & 3,7 & 3,0 & 6,8 \\
\hline$\vee 7$ & 1,2 & 4,0 & 11,0 & 8,9 & 2,4 & 6,7 & 1,2 & 5,1 \\
\hline V8 & 1,9 & $(-3,2)$ & $(-0,4)$ & 8,1 & 0,8 & 0,4 & $(-1,2)$ & $(-3,1)$ \\
\hline v9 & $(-0,8)$ & 8,4 & 7,5 & 6,8 & 10,9 & 6,3 & 11,9 & 2,3 \\
\hline V10 & $(-0,4)$ & 7,3 & 4,2 & 14,7 & 14,9 & 6,0 & 3,6 & 0,4 \\
\hline \multicolumn{9}{|c|}{ LOCAL 2} \\
\hline & E1 & E2 & E3 & E4 & E5 & E6 & E7 & E8 \\
\hline$V_{1}$ & 2,8 & 6,5 & 3,2 & $(-0,4)$ & $(-1,1)$ & $(-6,5)$ & 2,6 & 5,1 \\
\hline v2 & 11,2 & 16,6 & 22,4 & 8,8 & 18,6 & 16,1 & 22,2 & 23,0 \\
\hline V3 & $(-0,7)$ & 1,5 & 8,2 & 0,4 & 8,3 & 3,1 & 7,7 & 3,0 \\
\hline V4 & $(-2,1)$ & 4,2 & 4,5 & $(-1,8)$ & 3,9 & 0,3 & 12,4 & 2,9 \\
\hline V5 & 2,9 & 1,5 & 9,1 & $(-3,4)$ & $(-0,4)$ & 1,8 & 8,6 & 9,1 \\
\hline V6 & 0,4 & 3,8 & 7,5 & 1,5 & 2,8 & 0,7 & 2,1 & 4,6 \\
\hline$\vee 7$ & 0,8 & 3,0 & 13,0 & 4,3 & 7,2 & 6,9 & 6,5 & 6,2 \\
\hline v8 & 8,9 & 6,1 & 9,3 & 9,8 & 10,2 & $(-1,8)$ & 6,5 & 0,8 \\
\hline V9 & 5,5 & 8,7 & 7,4 & 1,6 & 10,6 & 2,9 & 9,2 & 8,9 \\
\hline V10 & $(-0,7)$ & 0,7 & 6,9 & 6,5 & 9,3 & 2,5 & 5,6 & 4,5 \\
\hline
\end{tabular}


Tabela 29 - Valores e significância dos quadrados médios obtidos das análises da variância das tabelas dialélicas para os caracteres produção de grãos (t/ha) e altura de planta (cm) - experimento 1 local 1 .

\begin{tabular}{lrcc}
\hline & & & Q.M. \\
\cline { 3 - 4 } F.V. & G.L. & PRODUçÃo & ALT. DE PLANTA \\
\hline Tratamentos & 54 & $0,7393^{*}$ & $156,2206 * *$ \\
$\quad$ Variedades & 9 & $0,4382^{\text {ns }}$ & $486,8789 * *$ \\
Het. média & 1 & $13,0030 * *$ & $908,4130 * *$ \\
Het. de variedade & 9 & $0,6061^{\text {ns }}$ & $55,2805^{\text {ns }}$ \\
Het. específica & 35 & $0,5005^{\text {ns }}$ & $75,6590^{\text {ns }}$ \\
Erro médio & 114 & 0,4042 & 96,6827 \\
\hline
\end{tabular}

* Significativo ao nível de $5 \%$ de probabilidade pelo teste $F$ ** Significativo ao nível de $1 \%$ de probabilidade pelo teste $F$ 
Tabela 30 - Valores e significância dos quadrados médios obtidos das análises da variância das tabelas dialélicas para os carecteres produção de grãos (t/ha) e altura de planta (cm) - experimento 1 local 2 .

\begin{tabular}{lrrr}
\hline & & \multicolumn{2}{c}{ Q.M. } \\
\cline { 3 - 4 } F.V. & G.L. & PRODUçÃo & ALT. DE PLANTA \\
\hline Tratamentos & 54 & $0,4682 * *$ & $220,9369 * *$ \\
$\quad$ Variedades & 9 & $0,9158 * *$ & $813,0098 * *$ \\
Het. média & 1 & $8,3226 * *$ & $1020,2570 * *$ \\
Het. de variedade & 9 & $0,2314 * *$ & $29,1099^{\text {ns }}$ \\
Het. especifica & 35 & $0,1895 * *$ & $95,1788 * *$ \\
Erro médio & 114 & 0,0709 & 32,0049 \\
\hline
\end{tabular}

** Significativo ao nível de $1 \%$ de probabilidade pelo teste $\mathrm{F}$ 
Tabela 31 - Valores e significância dos quadrados médios obtidos da análise da variância das tabelas dialélicas para os caracteres produção de grãos (t/ha) e altura de planta ( $\mathrm{cm}$ ) no experimento 1 - 2 locais.

\begin{tabular}{|c|c|c|c|}
\hline \multirow[b]{2}{*}{$F . V}$. & \multirow[b]{2}{*}{ G.L. } & \multicolumn{2}{|c|}{ Q.M. } \\
\hline & & PRODUÇÃO & ALT. DE PLANTA \\
\hline Tratamentos & 54 & $0,4698 * *$ & $160,3198 * *$ \\
\hline Variedades & 9 & $0,5240 * *$ & $606,6131 * *$ \\
\hline Het. média & 1 & $10,5317 * *$ & $963,5200 * *$ \\
\hline Het. de variedade & 9 & $0,2603 *$ & $28,2411^{n s}$ \\
\hline Het. especifica & 35 & $0,2223 * *$ & $56,5732 * *$ \\
\hline Tratamento $x$ Locais & 54 & $0,1339^{n s}$ & $28,2589^{n s}$ \\
\hline Variedades $x$ Locais & 9 & $0,1530^{\text {ns }}$ & $43,3339 *$ \\
\hline Het. média x Locais & 1 & $0,1311^{\text {ns }}$ & $0,8165^{n s}$ \\
\hline Het. de var. x Locais & 9 & $0,1585^{n s}$ & $13,9541^{n s}$ \\
\hline Het. esp. x Locais & 35 & $0,1227^{\text {ns }}$ & $1,3007^{\text {ns }}$ \\
\hline Erro médio & 228 & 0,1188 & 22,1777 \\
\hline
\end{tabular}

* Significativo ao nível de $5 \%$ de probabilidade pelo teste $F$ ** Significativo ao nivel de $1 \%$ de probabilidade pelo teste $F$ 
Tabela 32 - Valores e significância dos quadrados médios obtidos das análi ses da variância dos cruzamentos "top crosses" para os caracteres produção ( $t / h a$ ) e altura de planta $(\mathrm{cm})$ - experimento 2 local 1 .

\begin{tabular}{lccc}
\hline & & & Q.M. \\
\cline { 3 - 4 } F.V. & G.L. & PRODUÇÃo & ALT. DE PLANTA \\
\hline Tratamentos & 19 & $0,7972 * *$ & $151,8796 * *$ \\
$\quad$ Variedades & 9 & $0,1908^{\text {ns }}$ & $268,2327^{* *}$ \\
Het. média & 1 & $11,5535 * *$ & $333,4178 * *$ \\
Het. de variedades & 9 & $0,2047^{\text {ns }}$ & $14,9128^{\text {ns }}$ \\
Erro médio & 110 & 0,1203 & 19,4000 \\
\hline
\end{tabular}

** Significativo ao nível de $1 \%$ de probabilidade pelo teste $F$ 
Tabela 33 - Valores e significância dos quadrados médios obtidos das análises da variância dos cruzamentos "top crosses" para os carecteres produção (t/ha) e altura de planta (cm) - experimento 2 local 2 .

\begin{tabular}{lrcc}
\hline & & & Q.M. \\
\cline { 3 - 4 } F.V. & G.L. & PRODUÇÃO & ALT. DE PLANTA \\
\hline Tratamentos & 19 & $0,3808 * *$ & $161,7256 * *$ \\
$\quad$ Variedades & 9 & $0,2372 * *$ & $318,3232 * *$ \\
Het. média & 1 & $4,4142 * *$ & $118,5381 * *$ \\
Het. de variedades & 9 & $0,0764 *$ & $9,9269^{n s}$ \\
Erro médio & 110 & 0,0372 & 11,9329 \\
\hline
\end{tabular}

* Significativo ao nivel de $5 \%$ de probabilidade pelo teste $F$ ** Significativo ao nível de $1 \%$ de probabilidade pelo teste $F$ 
Tabela 34 - Valores e significância dos quadrados médios obtidos das análi ses da variância dos cruzamentos "top crosses" para os caracteres produção ( $t / h a$ ) e altura de planta $(\mathrm{cm})$ - experimento 2 2 locais.

\begin{tabular}{lrrr}
\hline & & \multicolumn{2}{c}{ Q.M. } \\
\cline { 3 - 4 } F.V. & G.L. & PRODUÇÃo & ALT. DE PLANTA \\
\hline Tratamentos & 19 & $0,5105^{* *}$ & $151,3189 * *$ \\
$\quad$ Variedades & 9 & $0,1523^{* *}$ & $290,0451^{* *}$ \\
Het. média & 1 & $7,5620 * *$ & $213,8580^{* *}$ \\
Het. de variedades & 9 & $0,0853^{*}$ & $5,6355^{\text {ns }}$ \\
Tratamento x Locais & 19 & $0,0785^{*}$ & $5,4877^{\text {ns }}$ \\
$\quad$ Variedades x Locais & 9 & $0,0617^{\text {ns }}$ & $3,2328^{\text {ns }}$ \\
Het. média x Locais & 1 & $0,4218 * *$ & $14,1255^{\text {ns }}$ \\
Het.de var. x Locais & 9 & $0,0552^{\text {ns }}$ & $6,7843^{\text {ns }}$ \\
Erro médio & 220 & 0,0394 & 7,8368 \\
\hline
\end{tabular}

* Significativo ao nível de $5 \%$ de probabilidade pelo teste $F$ ** Significativo ao nível de $1 \%$ de probabilidade pelo teste $F$ 
Tabela 35 - Valores e significância dos quadrados médios obtidos das análises da variância das tabelas dialélicas para os caracteres produção ( $t / h a) e$ altura de planta $(\mathrm{cm})$ - experimento 3 - local 1 .

\begin{tabular}{lrcc}
\hline & & \multicolumn{2}{c}{ Q.M. } \\
\cline { 3 - 4 } F.V. & G.L. & PRODUÇAO & ALT. DE PLANTA \\
\hline Tratamentos & 97 & $0,6657^{* *}$ & $117,6045 * *$ \\
$\quad$ Variedades (1) & 9 & $0,6990^{*}$ & $427,2445^{* *}$ \\
$\quad$ Variedades (2) & 7 & $1,5151^{* *}$ & $227,6790 * *$ \\
Grupos & 1 & $0,9844^{\text {ns }}$ & $242,4150 *$ \\
Het. média & 1 & $20,5857^{* *}$ & $1319,9918 * *$ \\
Het. de var. (1) & 9 & $0,3325^{\text {ns }}$ & $42,3389^{\text {ns }}$ \\
Het. de var. (2) & 7 & $0,2124^{\text {ns }}$ & $52,9239^{\text {ns }}$ \\
Het. especifica & 63 & $0,3432^{\text {ns }}$ & $1,2044^{\text {ns }}$ \\
Erro médio & 198 & 0,3496 & 48,1630 \\
\hline
\end{tabular}

* Significativo ao nível de $5 \%$ de probabilidade pelo teste $\mathrm{F}$ ** Significativo ao nível de $1 \%$ de probabilidade pelo teste $\mathrm{F}$ 
Tabela 36 - Valores e significância dos quadrados médios obtidos das análises da variância das tabelas dialélicas para os carecteres produção ( $t / h a)$ e altura de planta (cm) - experimento 3 - local 2.

\begin{tabular}{|c|c|c|c|}
\hline \multirow[b]{2}{*}{$F . V}$. & \multirow[b]{2}{*}{ G.L. } & \multicolumn{2}{|c|}{$Q . M}$. \\
\hline & & PRODUÇÃO & ALT. DE PLANTA \\
\hline Tratamentos & 97 & $0,2751 * *$ & $182,0185 * *$ \\
\hline Variedades (1) & 9 & $0,3140 * *$ & $638,9557 * *$ \\
\hline Variedades (2) & 7 & $0,4226 * *$ & $582,8915 * *$ \\
\hline Grupos & 1 & $0,4427 *$ & $5,4484^{n s}$ \\
\hline Het. média & 1 & $9,2162 * *$ & $2131,3604 * *$ \\
\hline Het, de var. (1) & 9 & $0,0634^{n s}$ & $194,8120 * *$ \\
\hline Het. de var. (2) & 7 & $0,1483^{\text {ns }}$ & $97,2669 *$ \\
\hline Het. especifica & 63 & $0,1530 * *$ & $51,6503 *$ \\
\hline Erro médio & 198 & 0,0762 & 38,9304 \\
\hline
\end{tabular}

* Significativo ao nível de 5\% de probabilidade pelo teste $F$ ** Significativo ao nível de $1 \%$ de probabilidade pelo teste $F$ 
Tabela 37 - Valores e significância dos quadrados médios obtidos das análises da variância das tabelas dialélicas para os caracteres produção de grãos (t/ha) e altura de planta ( $\mathrm{cm}$ ) no experimento 3 - 2 locais.

\begin{tabular}{|c|c|c|c|}
\hline \multirow[b]{2}{*}{$F, V}$. & \multirow[b]{2}{*}{ G.L. } & \multicolumn{2}{|c|}{ Q.M. } \\
\hline & & PRODUÇÃO & ALT. DE PLANTA \\
\hline Tratamentos & 97 & $0,3172 * *$ & $120,0538 * *$ \\
\hline Variedades (1) & 9 & $0,1010^{\text {ns }}$ & $494,6831 * *$ \\
\hline Variedades (2) & 7 & $0,5121 * *$ & $308,7343 * *$ \\
\hline Grupos & 1 & $0,6933 *$ & $81,4312^{n s}$ \\
\hline Het. média & 1 & $14,3115 * *$ & $1707,5960 * *$ \\
\hline Het. de variedades (1) & 9 & $0,1352^{\text {ns }}$ & $50,7517 *$ \\
\hline Het. de variedades (2) & 7 & $0,0700^{\text {ns }}$ & $45,3357 *$ \\
\hline Het. específica & 63 & $0,1517 *$ & $39,1871 * *$ \\
\hline Tratamento $\times$ Local & 97 & $0,1533 * *$ & $29,7577 * *$ \\
\hline Variedades $(1) \times$ Local & 9 & $0,4055 * *$ & $38,4170^{\text {ns }}$ \\
\hline Variedades (2) x Local & 7 & $0,4568 * *$ & $96,5509 * *$ \\
\hline Grupos $\times$ Local & 1 & $0,0203^{n s}$ & $42,5005^{n s}$ \\
\hline Het. média $\times$ Local & 1 & $0,5895 *$ & $18,0801^{\text {ns }}$ \\
\hline Het.de var. (1) x Local & 9 & $0,0628^{n s}$ & $67,8237 * *$ \\
\hline Het.de var. (2) x Local & 7 & $0,1104^{\text {ns }}$ & $29,7597^{\text {ns }}$ \\
\hline Het. esp. x Local & 63 & $0,0964^{n s}$ & $15,6441^{n s}$ \\
\hline Erro médio & 396 & 0,1064 & 21,7734 \\
\hline
\end{tabular}

* Significativo ao nível de $5 \%$ de probabilidade pelo teste $F$ ** Significativo ao nível de $1 \%$ de probabilidade pelo teste $F$ 
Tabela 38 - Parâmetros componentes de médias do modelo de GARDNER \& EBERHART (1966) aplicado ao estudo de cruzamentos dialélicos, suas respectivas variâncias $(t / h a)^{2}$, e capacidade geral de combinação $\left(\hat{g}_{\mathbf{j}}\right)$ das variedades para o caráter produção (t/ha) no experimento 1 - local 1.

\begin{tabular}{|c|c|c|c|c|c|c|c|c|c|}
\hline \multicolumn{10}{|c|}{$s_{j j^{\prime}}$} \\
\hline & V2 & V3 & V4 & V5 & V6 & V7 & V8 & V9 & V10 \\
\hline V1 & $-0,382$ & $-1,572$ & 0,888 & $-0,485$ & 1,092 & $-0,292$ & 0,403 & $-0,066$ & 0,359 \\
\hline V2 & $\longrightarrow$ & $-0,548$ & $-0,095$ & 0,552 & 0,604 & 0,628 & 0,092 & $-0,602$ & $-0,249$ \\
\hline V3 & & $\longrightarrow$ & 0,779 & 0,000 & $-0,031$ & $-0,477$ & 0,516 & 0,142 & 1,191 \\
\hline V4 & & & - & $-0,135$ & $-0,517$ & 0,376 & 0,173 & $-1,265$ & $-0,260$ \\
\hline V5 & & & & $\longrightarrow$ & $-1,045$ & 0,449 & $-0,009$ & 0,800 & $-0,123$ \\
\hline V6 & & & & & $\longrightarrow$ & $-0,510$ & $-0,692$ & 0,958 & 0,142 \\
\hline V7 & & & & & & - & 0,632 & $-0,386$ & $-0,418$ \\
\hline V8 & & & & & & & - & $-0,024$ & $-1,145$ \\
\hline v9 & & & & & & & & - & 0,448 \\
\hline \multicolumn{10}{|c|}{$\operatorname{vâr}\left(s_{j j^{\prime}}\right)=0,314$} \\
\hline & & & $\hat{v}_{j}$ & \multicolumn{3}{|c|}{$\hat{h}_{\mathrm{j}}$} & \multicolumn{3}{|c|}{$\hat{\mathrm{g}}_{\mathrm{j}}$} \\
\hline$V_{1}$ & & & 0,211 & \multicolumn{3}{|c|}{$-0,208$} & \multicolumn{3}{|c|}{$-0,103$} \\
\hline v2 & & & 0,336 & \multicolumn{3}{|c|}{$-0,317$} & \multicolumn{3}{|c|}{$-0,149$} \\
\hline V3 & & & $-0,286$ & \multicolumn{3}{|c|}{0,030} & \multicolumn{3}{|c|}{$-0,113$} \\
\hline V4 & & & 0,172 & \multicolumn{3}{|c|}{0,109} & \multicolumn{3}{|c|}{0,194} \\
\hline V5 & & & $-1,016$ & \multicolumn{3}{|c|}{0,918} & \multicolumn{3}{|c|}{0,409} \\
\hline V6 & & & $-0,618$ & \multicolumn{3}{|c|}{0,674} & \multicolumn{3}{|c|}{0,364} \\
\hline V7 & & & 0,591 & \multicolumn{3}{|c|}{$-0,300$} & \multicolumn{3}{|c|}{0,005} \\
\hline v8 & & & 0,310 & \multicolumn{3}{|c|}{$-0,029$} & \multicolumn{3}{|c|}{0,126} \\
\hline v9 & & & 0,344 & \multicolumn{3}{|c|}{$-0,194$} & \multicolumn{3}{|c|}{$-0,022$} \\
\hline V10 & & & $-0,041$ & \multicolumn{3}{|c|}{$-0,682$} & \multicolumn{3}{|c|}{$-0,703$} \\
\hline vâr & & & 0,364 & \multicolumn{3}{|c|}{0,136} & & & \\
\hline$\hat{\mu}=$ &, 609 & $\operatorname{vâr}(\hat{A})$ & $=0,040$ & $\hat{\bar{h}}=1$ & $61 \quad 27$ & , 35\%) & vâr ( $\hat{\bar{h}}$ & )$=0,049$ & \\
\hline
\end{tabular}


Tabela 39 - Parâmetros componentes de médias do modelo de GARDNER \& EBERHART (1966) aplicado ao estudo de cruzamentos dialélicos, suas respectivas variâncias $(t / h a)^{2}$, e capacidade geral de combinação $\left(\hat{g}_{j}\right)$ das variedades para o caráter produção (t/ha) no experimento 1 - local 2 .

\begin{tabular}{|c|c|c|c|c|c|c|c|c|c|}
\hline \multicolumn{10}{|c|}{$s_{j j^{\prime}}$} \\
\hline & V2 & V3 & V4 & V5 & V6 & V7 & V8 & V9 & V10 \\
\hline$V_{1}$ & $-0,555$ & $-0,410$ & 0,278 & $-0,321$ & 0,150 & 0,495 & 0,099 & 0,118 & 0,145 \\
\hline V2 & 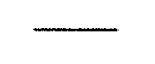 & $-0,173$ & 0,409 & 0,678 & 0,255 & $-0,462$ & $-0,321$ & $-0,279$ & 0,447 \\
\hline V3 & & $\longrightarrow$ & $-0,263$ & $-0,284$ & 0,120 & 0,075 & 0,393 & 0,270 & 0,271 \\
\hline V4 & & & - & $-0,486$ & $-0,890$ & 0,711 & $-0,224$ & 0,397 & 0,068 \\
\hline V5 & & & & - & $-0,373$ & $-0,117$ & 0,288 & $-0,008$ & 0,623 \\
\hline V6 & & & & & - & 0,394 & $-0,035$ & 0,313 & 0,067 \\
\hline V7 & & & & & & - & 0,191 & $-0,414$ & $-0,872$ \\
\hline V8 & & & & & & & - & $-0,019$ & $-0,371$ \\
\hline V9 & & & & & & & & $\longrightarrow$ & $-0,378$ \\
\hline \multicolumn{10}{|c|}{$\operatorname{var}\left(s_{j j^{\prime}}\right)=0,055$} \\
\hline & & & $\hat{\nabla}_{j}$ & & \multicolumn{2}{|c|}{$\hat{n}_{j}$} & \multicolumn{3}{|c|}{$\hat{g}_{j}$} \\
\hline$V_{1}$ & & & $-0,087$ & & \multicolumn{2}{|c|}{$-0,464$} & \multicolumn{3}{|c|}{$-0,507$} \\
\hline V2 & & & $-0,373$ & & \multicolumn{2}{|c|}{0,051} & \multicolumn{3}{|c|}{$-0,136$} \\
\hline V3 & & & $-0,628$ & & \multicolumn{2}{|c|}{$-0,131$} & \multicolumn{3}{|c|}{$-0,445$} \\
\hline V4 & & & $-0,398$ & & \multicolumn{2}{|c|}{0,275} & \multicolumn{3}{|c|}{0,474} \\
\hline V5 & & & 0,391 & & \multicolumn{2}{|c|}{0,031} & \multicolumn{3}{|c|}{0,227} \\
\hline V6 & & & 0,279 & & \multicolumn{2}{|c|}{0,357} & \multicolumn{3}{|c|}{0,496} \\
\hline V7 & & & 0,336 & & \multicolumn{2}{|c|}{$-0,319$} & \multicolumn{3}{|c|}{$-0,151$} \\
\hline V8 & & & $-0,020$ & & \multicolumn{2}{|c|}{0,244} & \multicolumn{3}{|c|}{0,234} \\
\hline v9 & & & 0,304 & & \multicolumn{2}{|c|}{$-0,322$} & \multicolumn{3}{|c|}{$-0,170$} \\
\hline V10 & & & $-0,601$ & & \multicolumn{2}{|c|}{0,278} & \multicolumn{3}{|c|}{$-0,023$} \\
\hline vâr & & & 0,064 & & \multicolumn{2}{|c|}{0,024} & & & \\
\hline
\end{tabular}

$\hat{\mu}=2,772 \quad \operatorname{vâr}(\hat{\mu})=0,007 \quad \hat{\bar{h}}=1,009(36,39 \%) \quad \operatorname{vâr}(\hat{\bar{h}})=0,009$ 
Tabela 40 - Parâmetros componentes de médias do modelo III de GARDNER (1967) aplicado ao estudo de cruzamentos "top crosses", e capacidade geral de combinação $\left(\hat{g}_{j}\right)$ das variedades para o caráter produção ( $t / h a)$ no experimento 2 - local 1 e local 2.

LOCAL 1

\begin{tabular}{|c|c|c|c|}
\hline & $\widehat{v}_{j}$ & $\hat{h}_{j}$ & $\hat{g}_{j}$ \\
\hline V1 & 0,225 & $-0,375$ & $-0,263$ \\
\hline V2 & $-0,258$ & $-0,998$ & $-1,128$ \\
\hline V3 & 0,371 & $-0,522$ & $-0,336$ \\
\hline V4 & 0,541 & $-0,531$ & 0,801 \\
\hline V5 & $-0,078$ & $-0,050$ & $-0,128$ \\
\hline V6 & $-0,460$ & 1,312 & 1,083 \\
\hline V7 & 0,585 & $-0,114$ & 0,179 \\
\hline V8 & $-0,334$ & $-0,025$ & $-0,193$ \\
\hline V9 & $-0,205$ & 0,163 & 0,060 \\
\hline V10 & $-0,386$ & 0,083 & $-0,110$ \\
\hline vâr & 0,108 & 0,211 & \\
\hline \multirow[t]{3}{*}{$\hat{\mu}=4,730$} & $\operatorname{vâr}(\hat{\mu})=0,020$ & $\hat{\bar{h}}=1,689(35,71 \%)$ & $\operatorname{vâr}(\hat{\bar{h}})=0,030$ \\
\hline & \multicolumn{3}{|c|}{ LOCAL 2} \\
\hline & $\hat{\nabla}_{j}$ & $\hat{n}_{j}$ & $g_{j}$ \\
\hline V1 & $-0,173$ & $-0,030$ & $-0,117$ \\
\hline V2 & $-0,685$ & $-0,539$ & $-0,882$ \\
\hline V3 & $-0,431$ & 0,180 & $-0,035$ \\
\hline V4 & 0,231 & 0,274 & 0,390 \\
\hline V5 & 0,754 & 0,300 & 0,677 \\
\hline V6 & 0,000 & 0,110 & 0,110 \\
\hline V7 & 0,325 & $-0,310$ & $-0,147$ \\
\hline V8 & $-0,014$ & 0,390 & 0,383 \\
\hline V9 & 0,286 & 0,710 & $-0,565$ \\
\hline V10 & $-0,296$ & 0,334 & 0,186 \\
\hline vâr & 0,033 & 0,065 & \\
\hline$a=3,601$ & $\operatorname{vâr}(\hat{\Lambda})=0,004$ & $\hat{\bar{h}}=1,044(34,11 \%)$ & $\operatorname{vâr}(\hat{\bar{h}})=0,009$ \\
\hline
\end{tabular}


Tabela 41 - Parâmetros componentes de médias do modelo de GARDNER \& EBERHART (1966) adaptado por MIRANDA FILHO \& GERALDI (1984) aplicado ao estudo de cruzamentos dialélecos parciais, suas respectivas variâncias $(t / h a)^{2}$, e capacidade geral de combinação $\left(\hat{g}_{j}\right)$ das variedades para o caráter produção de grãos (t/ha) no experimento 3 local 1.

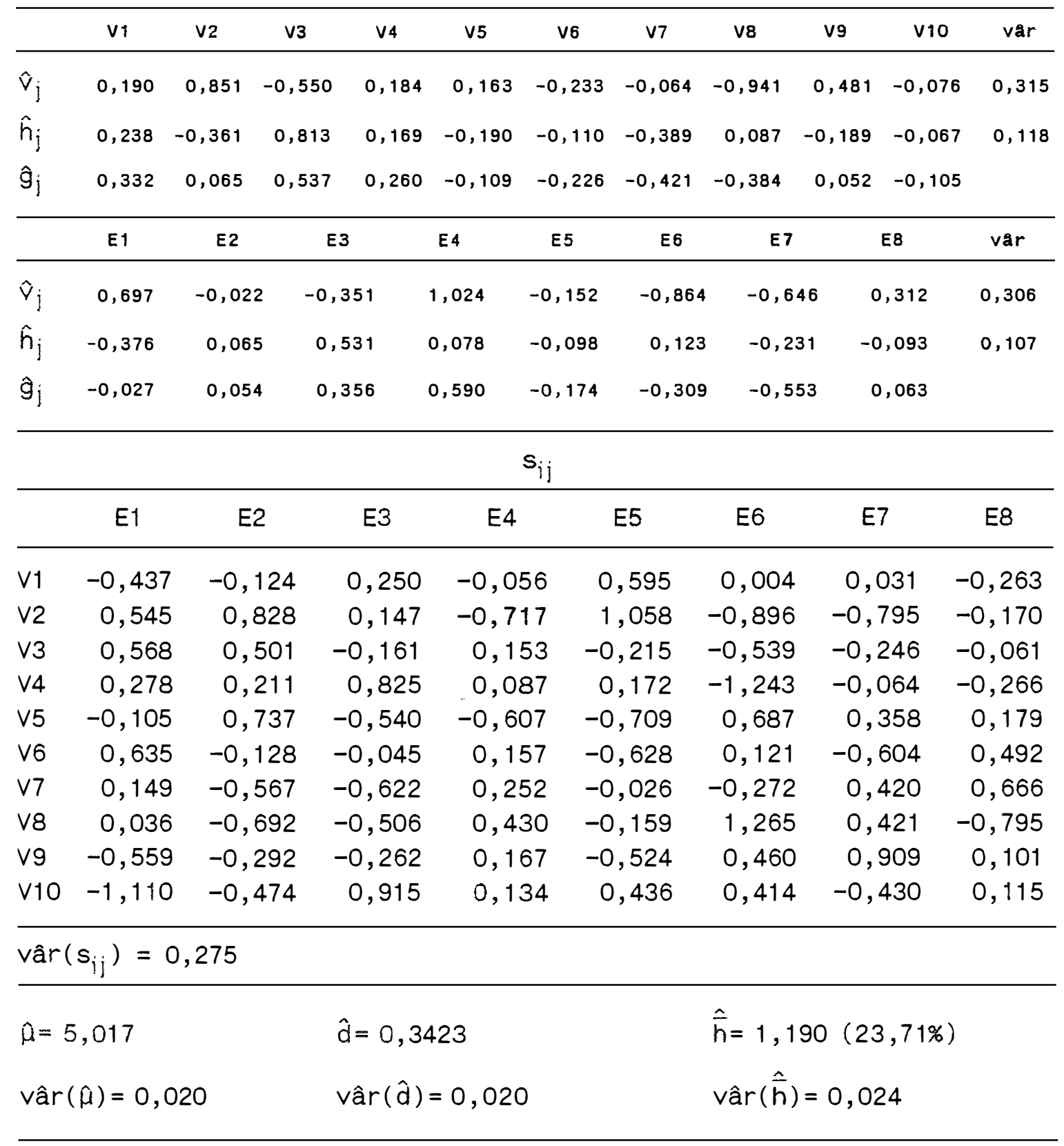


Tabela 42 - Parâmetros componentes de médias do modelo de GARDNER \& EBERHART (1966) adaptado por MIRANDA FILHO \& GERALDI (1984) aplicado ao estudo de cruzamentos dialélecos parciais, suas respectivas variâncias $(t / h a)^{2}$, e capacidade geral de combinação $\left(\hat{g}_{j}\right)$ das variedades para o caráter produção de grãos ( $t / h a$ ) no experimento 3 local 2.

\begin{tabular}{|c|c|c|c|c|c|c|c|c|}
\hline & $v_{1}$ & v2 & $v_{4}$ & V5 & v7 & v8 & $v_{10}$ & var \\
\hline$\hat{v}_{j}$ & $-0,423$ & $-0,214-0,9$ & $920 \quad 0,382$ & $0,403 \quad 0$ & $336 \quad 0,252$ & 0,366 & $-0,103 \quad-0,07$ & $9 \quad 0,069$ \\
\hline$\hat{n}_{j}$ & $-0,021$ & $0,156 \quad 0,2$ & $284-0,039$ & $-0,296 \quad 0$ & $080-0,067$ & $-0,064$ & $-0,061 \quad 0,02$ & $27 \quad 0,026$ \\
\hline$\hat{g}_{j}$ & $-0,214$ & $0,049-0,1$ & $176 \quad 0,152$ & $-0,094 \quad 0$ & $248 \quad 0,059$ & 0,119 & $-0,012$ & \\
\hline & $E 1$ & E2 & E3 & E4 & E6 & E7 & $E 8$ & var \\
\hline$\hat{v}_{j}$ & 0,199 & $-0,387$ & 0,095 & 0,164 & $-0,084$ & $-0,134$ & $-0,200$ & 0,067 \\
\hline$\hat{n}_{j}$ & $-0,173$ & $-0,041$ & $-0,304$ & 0,201 & 0,030 & $-0,05$ & 0,432 & 0,023 \\
\hline$\hat{g}_{j}$ & $-0,073$ & $-0,235$ & $-0,256$ & 0,119 & $-0,012$ & \multicolumn{2}{|c|}{$-0,120 \quad 0,332$} & \\
\hline \multicolumn{9}{|c|}{$s_{i j}$} \\
\hline & E1 & E2 & E3 & E4 & E5 & E6 & E7 & E8 \\
\hline$V_{1}$ & 0,161 & 0,183 & $-0,470$ & 0,257 & $-0,187$ & $-0,322$ & $-0,069$ & 0,447 \\
\hline v2 & 0,332 & 0,132 & 0,664 & $-0,534$ & $-0,363$ & $-0,240$ & 0,272 & $-0,264$ \\
\hline V3 & 0,529 & 0,387 & 0,113 & $-0,331$ & $-0,313$ & 0,130 & $-0,612$ & 0,178 \\
\hline V4 & 0,153 & $-0,461$ & $-0,178$ & 0,580 & $-0,150$ & $-0,296$ & 0,034 & 0,319 \\
\hline V5 & 0,159 & 0,414 & $-0,112$ & $-0,018$ & $-0,205$ & $-0,304$ & $-0,211$ & 0,277 \\
\hline V6 & $-0,002$ & $-0,143$ & 0,105 & $-0,300$ & 0,490 & 0,311 & $-0,330$ & $-0,130$ \\
\hline V7 & $-0,467$ & $-0,682$ & 0,005 & 0,233 & $-0,194$ & 0,183 & 0,593 & 0,328 \\
\hline v8 & $-0,084$ & 0,168 & 0,340 & 0,337 & 0,239 & 0,347 & $-0,024$ & $-1,322$ \\
\hline v9 & $-0,605$ & 0,233 & $-0,263$ & $-0,033$ & 0,367 & 0,400 & 0,164 & $-0,262$ \\
\hline V10 & $-0,176$ & $-0,230$ & $-0,123$ & $-0,191$ & 0,316 & $-0,210$ & 0,183 & 0,430 \\
\hline \multicolumn{9}{|c|}{$\operatorname{vâr}\left(s_{i j}\right)=0,060$} \\
\hline \multicolumn{3}{|c|}{$\hat{\rho}=2,817$} & \multicolumn{3}{|c|}{$\hat{d}=0,230$} & $\hat{\bar{h}}=0,7$ & $97(28,29 \%)$ & \\
\hline vâı & )$=0$, & & vâr ( $\hat{d})$ & $=0,004$ & & $\operatorname{vâr}(\hat{\bar{h}})$ & $=0,005$ & \\
\hline
\end{tabular}


128.

Tabela 43 - Parâmetros componentes de médias do modelo de GARDNER \& EBERHART (1966) aplicado ao estudo de cruzamentos dialélicos, suas respectivas variâncias $(\mathrm{cm})^{2}$, e capacidade geral de combinação $\left(g_{j}\right)$ das variedades para o caráter altura de planta $(\mathrm{cm})$ no experimento 1 - local 1.

\begin{tabular}{|c|c|c|c|c|c|c|c|c|c|}
\hline \multicolumn{10}{|c|}{$s_{i i^{\prime}}$} \\
\hline & V2 & V3 & V4 & V5 & V6 & V7 & V8 & V9 & V10 \\
\hline V1 & $-4,56$ & $-11,43$ & 9,61 & $-8,10$ & 5,65 & 1,28 & 8,15 & 2,52 & $-3,31$ \\
\hline V2 & $\longrightarrow$ & 2,73 & $-6,23$ & 9,40 & 9,82 & $-2,89$ & 0,65 & $-9,98$ & 0,86 \\
\hline V3 & & - & 3,57 & 2,52 & $-3,73$ & $-9,76$ & 7,11 & 4,82 & 3,99 \\
\hline V4 & & & - & $-3,10$ & $-10,83$ & 11,28 & $-5,18$ & $-4,14$ & 5,03 \\
\hline V5 & & & & - & $-12,06$ & 6,90 & 13,77 & 6,49 & $-16,02$ \\
\hline V6 & & & & & - & $-4,35$ & $-9,15$ & 10,23 & 14,40 \\
\hline V7 & & & & & & - & $-5,18$ & 5,86 & $-3,31$ \\
\hline V8 & & & & & & & - & $-12,27$ & 1,90 \\
\hline V9 & & & & & & & & - & $-3,73$ \\
\hline
\end{tabular}

$\operatorname{vâr}\left(s_{i j^{\prime}}\right)=75,20$

\begin{tabular}{lrrr}
\hline & \multicolumn{1}{c}{$\hat{v}_{j}$} & $\hat{h}_{j}$ & $\hat{g}_{j}$ \\
\hline V1 & 6,50 & $-0,06$ & 3,19 \\
V2 & $-18,50$ & $-3,40$ & $-12,65$ \\
V3 & $-0,17$ & 4,31 & 4,23 \\
V4 & 14,83 & 0,77 & 8,19 \\
V5 & $-6,83$ & 5,98 & 2,57 \\
V6 & 18,17 & 1,39 & 10,48 \\
V7 & $-10,17$ & 3,27 & $-1,82$ \\
V8 & $-6,83$ & $-3,61$ & $-7,03$ \\
V9 & $-5,17$ & 1,19 & $-1,40$ \\
V10 & 8,17 & $-9,65$ & $-5,57$ \\
vâr & 87,01 & 32,68 & \\
\hline & & & \\
p=213,50 & $\operatorname{vâr}(\hat{\mu})=9,668$ & $\hat{\bar{h}}=10,52(4,93 \%)$ & $\operatorname{vâr}(\hat{\bar{h}})=11,817$ \\
\hline
\end{tabular}


Tabela 44 - Parâmetros componentes de médias do modelo de GARDNER \& EBERHART (1966) aplicado ao estudo de cruzamentos dialélicos, suas respectivas variâncias $(\mathrm{cm})^{2}$, e capacidade geral de combinação $\left(\hat{g}_{\mathrm{j}}\right)$ das variedades para o caráter altura de planta ( $\mathrm{cm})$ no experimento 1 - local 2 .

\begin{tabular}{|c|c|c|c|c|c|c|c|c|c|}
\hline \multicolumn{10}{|c|}{$s_{j j^{\prime}}$} \\
\hline & V2 & V3 & V4 & V5 & V6 & V7 & V8 & V9 & V10 \\
\hline V1 & $-5,42$ & $-17,30$ & $-1,88$ & $-4,58$ & 7,30 & 6,66 & 6,05 & 4,79 & 4,38 \\
\hline V2 & - & 1,46 & 0,21 & 5,83 & 9,37 & $-17,92$ & 13,12 & $-6,46$ & $-0,21$ \\
\hline V3 & & - & 11,67 & 12,30 & $-2,50$ & 5,21 & $-3,75$ & $-1,66$ & $-5,41$ \\
\hline V4 & & & - & $-17,29$ & 1,25 & 0,63 & $-10,00$ & 15,41 & 0,00 \\
\hline V5 & & & & - & $-9,80$ & 24,58 & $-2,70$ & $-7,29$ & $-1,04$ \\
\hline V6 & & & & & - & $-5,21$ & $-5,84$ & 4,59 & 0,84 \\
\hline V7 & & & & & & $\longrightarrow$ & $-9,79$ & $-6,05$ & 1,88 \\
\hline V8 & & & & & & & - & 5,00 & 7,92 \\
\hline V9 & & & & & & & & - & $-8,33$ \\
\hline \multicolumn{10}{|c|}{$\operatorname{vâr}\left(s_{i j^{\prime}}\right)=24,89$} \\
\hline & & & $\hat{v}_{j}$ & & \multicolumn{2}{|c|}{$\hat{n}_{j}$} & \multicolumn{3}{|c|}{$\mathrm{g}_{\mathrm{j}}$} \\
\hline V1 & & & $-2,50$ & & \multicolumn{2}{|c|}{0,67} & \multicolumn{3}{|c|}{$-0,58$} \\
\hline V2 & & & $-27,50$ & & \multicolumn{2}{|c|}{$-2,25$} & \multicolumn{3}{|c|}{$-16,00$} \\
\hline V3 & & & 5,84 & & \multicolumn{2}{|c|}{$-3,71$} & \multicolumn{3}{|c|}{$-0,79$} \\
\hline V4 & & & 19,17 & & \multicolumn{2}{|c|}{4,21} & \multicolumn{3}{|c|}{13,80} \\
\hline V5 & & & $-15,83$ & & \multicolumn{2}{|c|}{6,08} & \multicolumn{3}{|c|}{$-1,84$} \\
\hline V6 & & & 27,50 & & \multicolumn{2}{|c|}{$-0,79$} & \multicolumn{3}{|c|}{12,96} \\
\hline V7 & & & $-12,50$ & & \multicolumn{2}{|c|}{1,50} & \multicolumn{3}{|c|}{$-4,75$} \\
\hline V8 & & & $-2,50$ & & \multicolumn{2}{|c|}{0,46} & \multicolumn{3}{|c|}{$-0,79$} \\
\hline V9 & & & 2,50 & & \multicolumn{2}{|c|}{$-4,12$} & \multicolumn{3}{|c|}{$-2,87$} \\
\hline V10 & & & 5,84 & & \multicolumn{2}{|c|}{$-2,04$} & \multicolumn{3}{|c|}{0,88} \\
\hline vâr & & & 28,80 & & \multicolumn{2}{|c|}{10,82} & & & \\
\hline
\end{tabular}

$\hat{a}=225,83 \quad \operatorname{vâr}(\hat{\mu})=3,20 \quad \hat{\bar{h}}=11,17(4,95 \%) \quad \operatorname{vâr}(\hat{\hat{h}})=3,91$ 
Tabela 45 - Parâmetros componentes de médias do modelo III de GARDNER (1967) aplicado ao estudo de cruzamentos "top crosses", e capacidade geral de combinação $\left(\hat{g}_{j}\right)$ das variedades para o caráter altura de planta $(\mathrm{cm})$ no experimento 2 - local 1 e local 2 .

\begin{tabular}{|c|c|c|c|}
\hline \multicolumn{4}{|c|}{ LOCAL 1} \\
\hline & $\hat{v}_{j}$ & $\hat{h}_{\mathrm{j}}$ & $\hat{g}_{j}$ \\
\hline V1 & 9,33 & $-3,27$ & 1,40 \\
\hline V2 & $-25,67$ & $-8,68$ & $-21,50$ \\
\hline V3 & 14,33 & $-5,77$ & 1,40 \\
\hline V4 & 23,50 & 0,06 & 11,81 \\
\hline V5 & 0,16 & $-3,89$ & $-3,81$ \\
\hline V6 & 14,33 & 3,61 & 10,78 \\
\hline V7 & $-5,67$ & 5,27 & 2,44 \\
\hline V8 & $-8,17$ & 5,49 & 1,40 \\
\hline V9 & $-9,00$ & 4,44 & $-0,06$ \\
\hline V10 & $-13,17$ & 2,77 & $-3,81$ \\
\hline vâr & 17,46 & 34,10 & \\
\hline$\mu=215,67$ & $\operatorname{vâr}(\mu)=1,94$ & $\hat{\bar{h}}=9,12(4,12 \%)$ & $\operatorname{vâr}(\hat{\bar{h}})=4,79$ \\
\hline \multicolumn{4}{|c|}{ LOCAL 2} \\
\hline & $\hat{v}_{j}$ & $\hat{n}_{j}$ & $\hat{g}_{j}$ \\
\hline$V_{1}$ & 5,70 & 2,36 & 5,21 \\
\hline V2 & $-32,63$ & $-6,60$ & $-22,91$ \\
\hline V3 & 14,87 & $-4,31$ & 3,13 \\
\hline V4 & 17,87 & 5,65 & 14,59 \\
\hline V5 & $-5,13$ & 7,78 & 5,21 \\
\hline V6 & 20,70 & 4,24 & 14,59 \\
\hline V7 & $-5,96$ & 1,94 & $-1,04$ \\
\hline V8 & $-2,63$ & $-3,90$ & $-5,21$ \\
\hline V9 & $-7,63$ & $-5,56$ & $-9,38$ \\
\hline V10 & $-5,13$ & $-1,60$ & $-4,16$ \\
\hline vâr & 10,74 & 20,96 & \\
\hline$\hat{a}=227,67$ & $\operatorname{vâr}(\hat{a})=1,19$ & $\hat{\overline{\mathrm{h}}}=5,37 \quad(2,4 \%)$ & $\operatorname{vâr}(\hat{\bar{h}})=2,95$ \\
\hline
\end{tabular}


Tabela 46 - Parâmetros componentes de médias do modelo de GARDNER \& EBERHART (1966) adaptado por MIRANDA FILHO \& GERALDI (1984) aplicado ao estudo de cruzamentos dialélecos parciais, suas respectivas variâncias $(\mathrm{cm})^{2}$, e capacidade geral de combinação das variedades $\left(\hat{g}_{j}\right)$ para o caráter altura de planta $(\mathrm{cm})$ no experimento 3 - local 1.

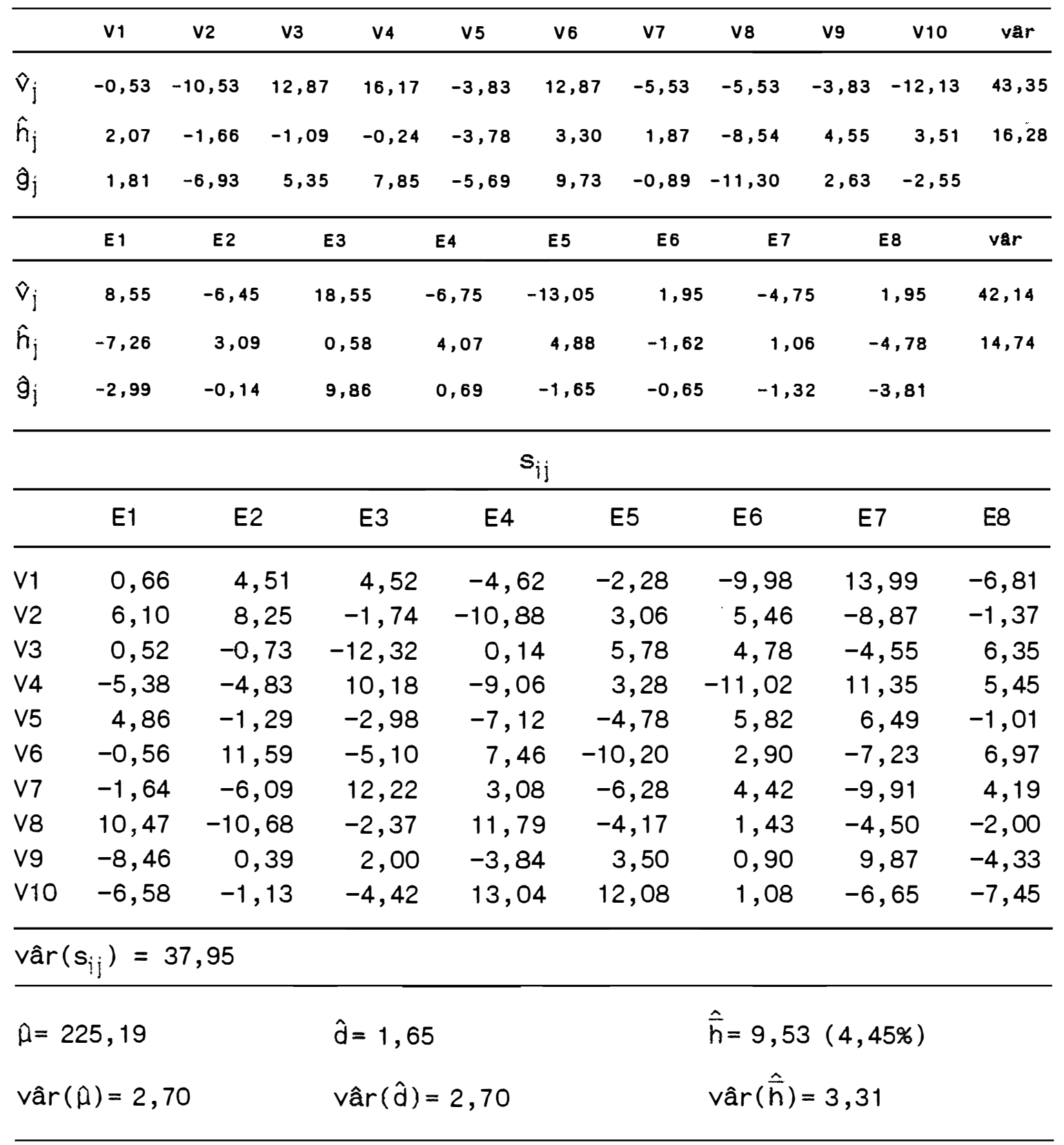


Tabela 47 - Parâmetros componentes de médias do modelo de GARDNER \& EBERHART (1966) adaptado por MIRANDA FILHO \& GERALDI (1984) aplicado ao estudo de cruzamentos dialélecos parciais, suas respectivas variâncias $(\mathrm{cm})^{2}$, e capacidade geral de combinação $\left(\hat{g}_{j}\right)$ para o caráter altura de planta $(\mathrm{cm})$ no experimento 3 - local 2.

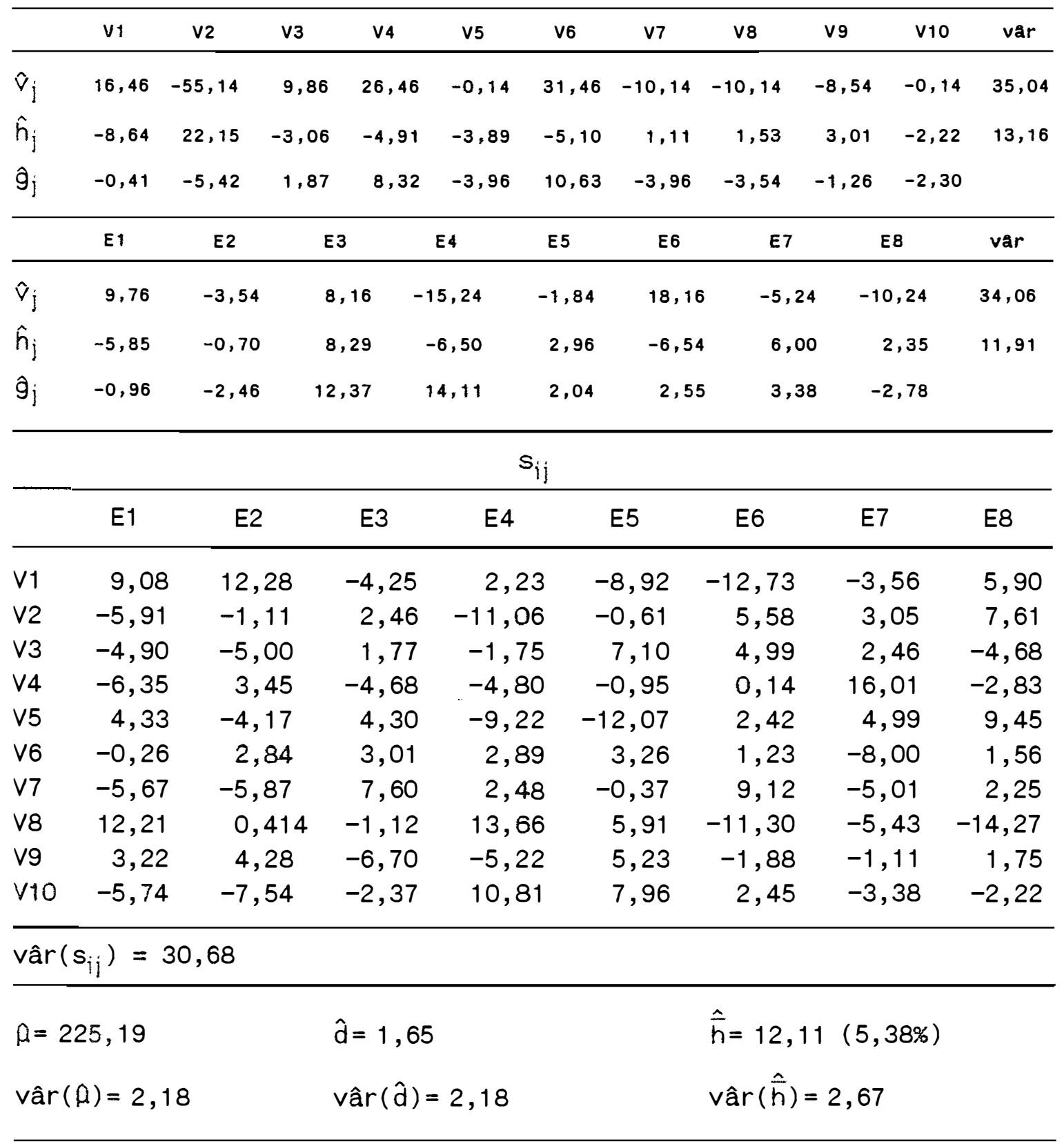


Tabela 48 - Correlação de Spearman entre os parâmetros dos modelos e capacidade geral de combinação no experimento 1 (dialélico) e no experimento 2 ("top crosses") nos 2 locais para producão e altura de planta.

\begin{tabular}{cccccc}
\hline & \multicolumn{2}{c}{ LOCAL 1} & & \multicolumn{2}{c}{ LOCAL 2} \\
\cline { 2 - 3 } \cline { 5 - 6 } Parâmetro & Produção & $\begin{array}{c}\text { Altura } \\
\text { de Planta }\end{array}$ & & Produção & $\begin{array}{c}\text { Altura } \\
\text { de Planta }\end{array}$ \\
\hline$v_{j}$ & 0,26 & 0,89 & & 0,62 & 0,56 \\
$h_{j}$ & 0,39 & 0,55 & & $-0,19$ & 0,85 \\
$g_{j}$ & 0,56 & 0,61 & & 0,72 & 0,72 \\
\hline
\end{tabular}

